\title{
A JOULE-HEATED MELTER TECHNOLOGY FOR THE TREATMENT AND IMMOBILIZATION OF LOW-ACTIVITY WASTE
}

\author{
S. E. Kelly \\ Washington River Protection Solutions \\ Richland, WA 99352 \\ U.S. Department of Energy Contract DE-AC27-08RV14800
EDT/ECN: DRF UC:
Cost Center: 2GH00 Charge Code: 200993
B\&R Code: $\quad$ Total Pages: 68

Key Words: Immobilization, Joule-Heat, Melter, JHCM, Cold Cap, Second LAW,

\begin{abstract}
This report is one of four reports written to provide background information regarding immobilization technologies remaing under consideration for supplemental immobilization of Hanford's low-activity waste. This paper provides the reader a general understanding of joule-heated ceramic lined melters and their application to Hanford's low-activity waste.
\end{abstract}

TRADEMARK DISCLAIMER. Reference herein to any specific commercial product, process, or service by trade name. trademark, manufacturer, or otherwise, does not necessarily constitute or imply its endorsement, recommendation, or' favoring by the United States Government or any agency thereof or its contractors or subcontractors.
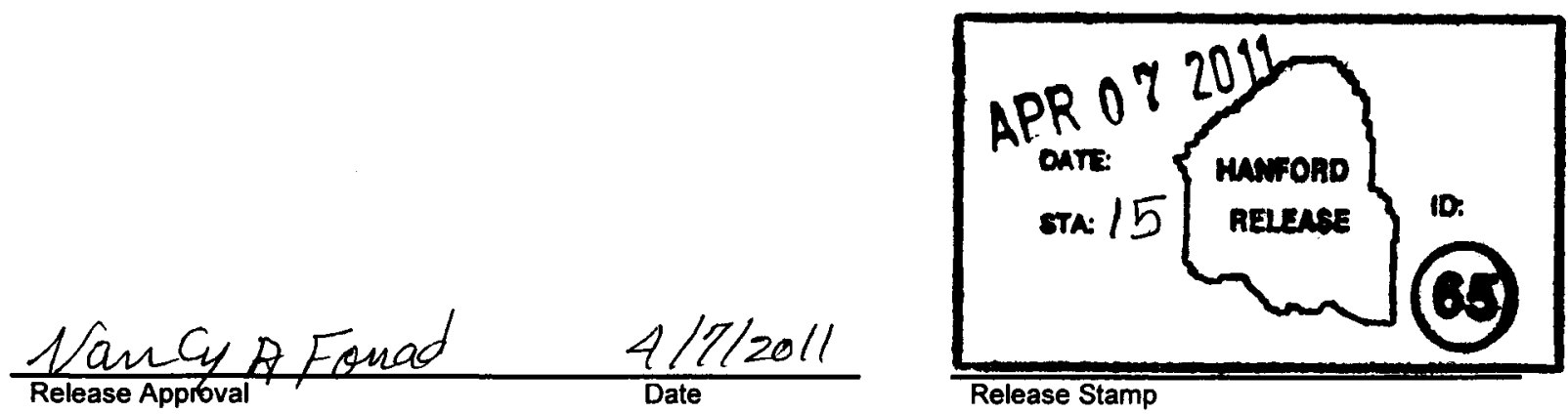


\section{A JOULE-HEATED MELTER TECHNOLOGY FOR THE TREATMENT AND IMMOBILIZATION OF LOW-ACTIVITY WASTE}

\section{Author:}

S. E. Kelly

Washington River Protection Solutions, LLC

Date Published

March 2011

Prepared for the U.S. Department of Energy

Office of River Protection

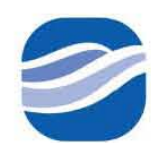

washington river

protectionsolutions

\section{P. O. Box 850 \\ Richland, Washington}

This report was prepared as an account of work sponsored by an agency of the United States Government. Neither the United States Government nor any agency thereof, nor any of their employees, nor any of their contractors, subcontractors or their employees, makes any warranty, express or implied, or assumes any legal liability or responsibility for the accuracy, completeness, or any third party's use or the results of such use of any information, apparatus, product, or process disclosed, or represents that its use would not infringe privately owned rights. Reference herein to any specific commercial product, process, or service by trade name, trademark, manufacturer, or otherwise, does not necessarily constitute or imply its endorsement, recommendation, or favoring by the United States Government or any agency thereof or its contractors or subcontractors. The views and opinions of authors expressed herein do not necessarily state or reflect those of the United States Government or any agency thereof. 


\section{PURPOSE}

The U.S. Department of Energy is building a Waste Treatment and Immobilization Plant to treat the approximately 55 million gallons of wastes from reprocessing spent nuclear fuel stored in 177 underground tanks at the Hanford Site in Washington State. Following treatment to remove key radionuclides to the maximum extent practical, approximately $90 \%$ of the tank waste mass (excluding water) will be immobilized as low-activity waste. The remainder will be immobilized as high-level waste.

The Waste Treatment and Immobilization Plant Low-Activity Waste vitrification plant should be capable of immobilizing approximately one-third of the total low-activity Hanford waste. A supplemental low-activity waste immobilization facility will be required to immobilize the remaining low-activity waste in order to complete the treatment mission on or before 2047 in accordance with the Hanford Federal Facility Agreement and Consent Order, which is also referred to in this report as the Tri-Party Agreement. Based on extensive reviews that started in 2002 by the Department of Energy, the Washington Department of Ecology, the U.S., the Environmental Protection Agency, and the Department of Energy contractors, four-candidate supplemental low-activity waste immobilization technologies remain under consideration.

1. Second Low-Activity Waste Vitrification Plant (RPP-48395, A Joule-Heated Melter Technology for the Treatment and Immobilization of Low-Activity Waste) (same technology as the LAW vitrification plant currently under construction).

2. Bulk Vitrification (RPP-48703, Bulk Vitrification Technology for the Treatment and Immobilization of Low-Activity Waste) (an in-container vitrification technology).

3. Cast Stone (RPP-49062, Cast Stone Technology for the Treatment and Immobilization of Low-Activity Waste) (a grout-based immobilization technology tailored to Hanford low-activity waste).

4. Fluidized Bed Steam Reforming (RPP-48903, Fluidized Bed Steam Reforming for Treating and Immobilizing Low-Activity Waste) (a thermal technology that produces a mineral waste form).

Four reports, as numbered above, have been prepared by Washington River Protection Solutions. Each report is designed to stand-alone or be used in conjunction with the others to provide background information about these technologies. The reports do not attempt to directly or indirectly recommend, compare, or contrast any one technology over the other. Rather, the goal is to present information as a high-level introduction to the four technologies, and assist the reader in further exploration of any given topic. Each of the reports will follow the same basic structure as outlined below.

- Common introduction providing background to the Office of River Protection mission.

- Introduction to the specific technology.

- Current state of knowledge for the technology.

- Current information needs.

- Risks and data needs.

- References. 
Note: The above sections are not numbered as each topic may require less or more sections to delineate the information on the topics.

This report is focused on Second LAW technology.

The information in this report is primarily digested from scientific information published in the literature, vendor information, independent reports, and studies funded by DOE. Information from those sources is presented in this report in a format and style intended to be understandable by non-technical readers yet to also be informative to DOE, regulators, and other technically informed readers.

The intent of the document is to summarize information in an easily assimilated format with references to source documents. The intent is not to compare the merits of Second LAW to other technologies nor promote the use of Second LAW. The selection decision regarding which technology will be used in accordance with applicable DOE Orders, the National Environmental Policy Act, and the Tri-Party.

This report describes known data gaps, technical risks, and other issues to be addressed through waste form qualification test programs or through subsequent maturation tests or engineering studies.

It should be noted that discussions of these technologies are based on pre-conceptual design information. As such the level of design descriptions is intended to be general. Current and accurate cost information specific to each technology is not available. 


\section{EXECUTIVE SUMMARY SECOND LAW VITRIFICATION}

The U.S. Department of Energy is building a Waste Treatment and Immobilization Plant to treat the approximately 55 million gallons of wastes resulting from reprocessing irradiated nuclear fuel as part of the defense program. That waste is currently stored in 177 underground tanks at the Hanford Site in Washington State. Following treatment to remove key radionuclides to the maximum extent practical, approximately $90 \%$ of the tank waste mass (excluding water) will be immobilized as low-activity waste. The Department of Energy plans to immobilize and dispose of the low-activity waste stream on-site.

The remainder of the tank waste, which will contain approximately $95 \%$ of the total tank waste radioactive inventory, will be vitrified as high-level waste. The vitrified high-level waste will be interim-stored on-site until a final disposal solution is identified. A simplified Hanford tank waste cleanup, treatment, and disposal flowsheet is depicted in Figure ES-1.

\section{Figure ES-1. Hanford Nominal Tank Waste Treatment \& Disposition Flowsheet}

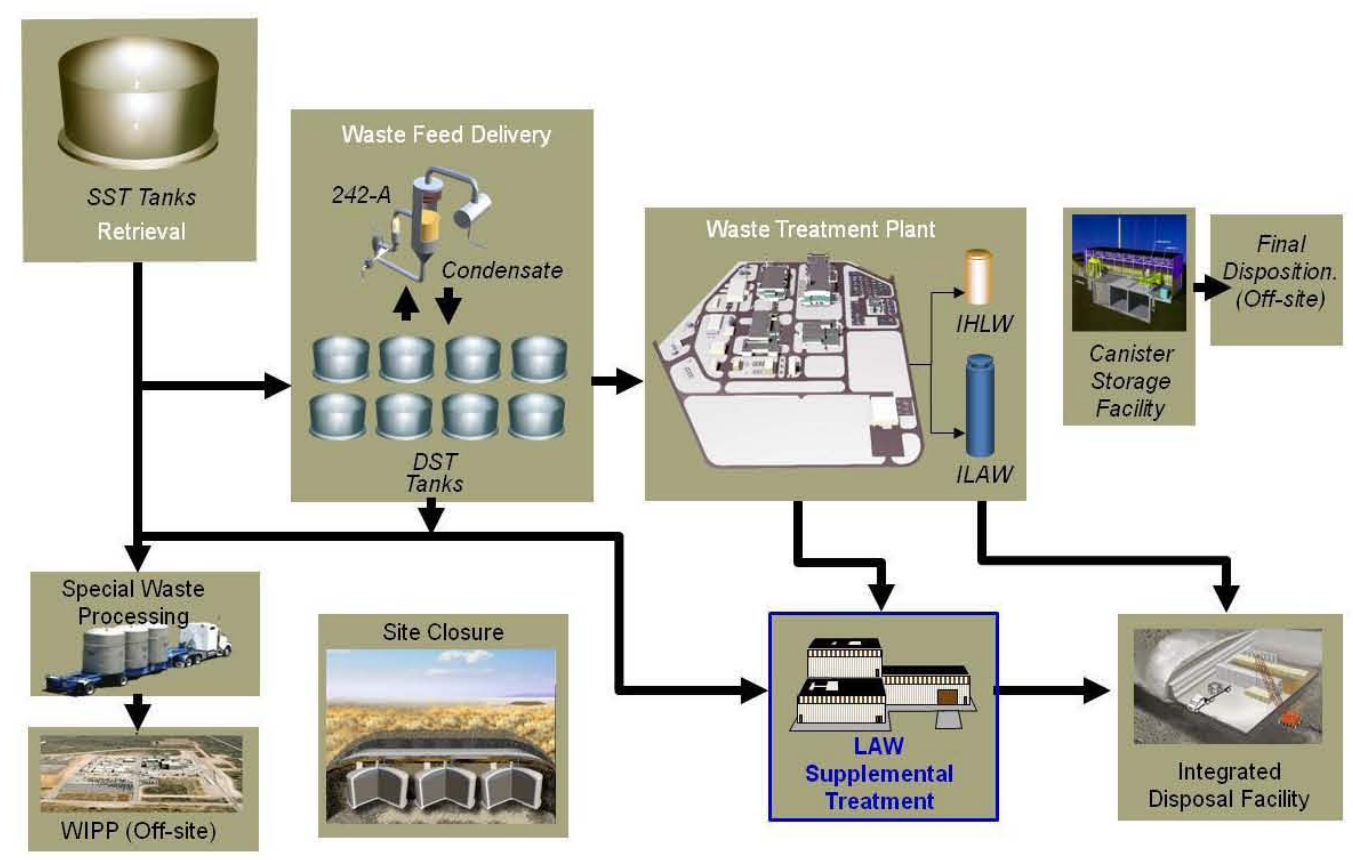

The Waste Treatment and Immobilization Plant low-activity waste vitrification plant should be capable of vitrifying approximately one-third to one-half of the total low-activity waste. Supplemental low-activity waste immobilization will be required to immobilize the remainder. The Hanford Federal Facility Agreement and Consent Order, which is also referred to in this report as the Tri-Party Agreement or TPA, requires all Hanford tank waste treatment and immobilization to be completed by 2047.

Because waste retrieved from the tanks is separated into high-level waste and low-activity waste fractions during pretreatment, unless the low-activity waste can be immobilized at the rate at which it is produced, the pretreatment processing and high-level waste vitrification will operate 


$$
\text { RPP-48935, Rev.0 }
$$

below the nominal production capacity throughput required to complete the mission on or before 2047. Accordingly, the Department of Energy is currently considering ways to supplement the Waste Treatment and Immobilization Plant low-activity waste vitrification plant capacity in a manner that is protective of human health and the environment while also fiscally responsible.

Based on extensive reviews that started in 2002 by the Department of Energy, the Washington Department of Ecology (Ecology), and the U.S. Environmental Protection Agency (EPA), four candidate supplemental low-activity waste immobilization technologies are under consideration.

1. Second Low-Activity Waste Vitrification Plant (same technology as currently in the WTP).

2. Bulk Vitrification (an in-container vitrification technology).

3. Cast Stone (a grout-based immobilization technology tailored to Hanford lowactivity waste).

4. Fluidized Bed Steam Reforming (a thermal technology that produces a mineral waste form).

The decision regarding which of the four candidate technologies will be ultimately deployed will be made in accordance with Department of Energy Orders, the National Environmental Policy Act (NEPA), and the TPA. It is not known as of this writing which of those technologies will be selected.

The implementation of a Second Low-Activity Waste Vitrification Facility is the subject of this report. The vitrification technology employed would be a joule-heated, ceramic lined melter that produces a glass product. Temperature in the glass pool is maintained by joule-heating (electrical resistance heating). The joule heating is accomplished by passing alternating current directly through the molten waste glass. The energy consumed to push the current through the melts is absorbed into the melt as heat.

The vitrification process uses heat to decompose waste into elemental oxides that dissolve into a glass pool. The glass is poured into a container where it cools. As the glass cools, it passes through its glass transition temperature, where the physical characteristics of the material change from a state where some amount of physical change can be imparted on it without fracture to a hard, brittle substance and where large-scale molecular motion is not possible.

Joule-heated ceramic melters that produce a vitrified waste product have been implemented at many DOE sites and countries throughout the world. The technology produces a stable waste form with a high level of waste loading.

Major developments for the technology are focused on increasing processing rates and the retention of waste components in the melt. The implementation of a Second Low-Activity Waste Vitrification Facility would most likely include the use of a melter with greater melt surface-area-to-melter footprint and glass formulations or operating strategies targeting the increased throughput and retention of technetium-99. 
Figure ES-2. Joule-Heated Ceramic Lined Melter

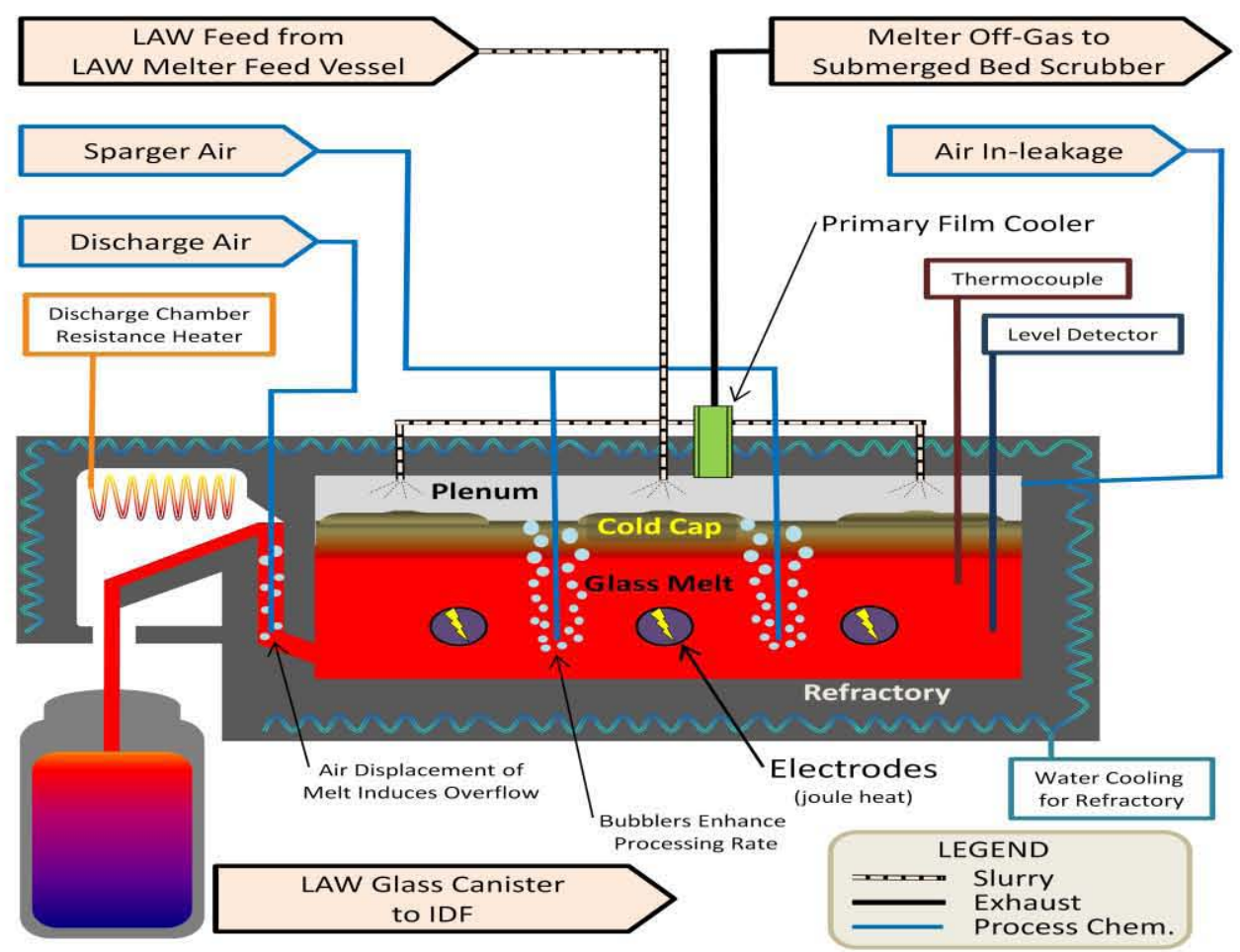

Table ES-2. Table of Technology Attributes

\begin{tabular}{|l|l|}
\hline \multicolumn{1}{|c|}{ Favorable Attributes } & \multicolumn{1}{|c|}{ Unfavorable Attributes } \\
\hline $\begin{array}{l}\text { Product is well studied and meets disposal } \\
\text { requirements }\end{array}$ & $\begin{array}{l}\text { Facility construction costs are assumed to be high } \\
\text { when compared to alternatives }\end{array}$ \\
\hline $\begin{array}{l}\text { Waste form is very compact (high waste loading per } \mathrm{ft}^{3} \\
\text { of product) }\end{array}$ & $\begin{array}{l}\text { Facility operational costs are assumed to be high when } \\
\text { compared to alternatives }\end{array}$ \\
\hline $\begin{array}{l}\text { Product performance tests are developed, understood, } \\
\text { and accepted }\end{array}$ & $\begin{array}{l}\text { Does not incorporate all waste components into the } \\
\text { product (e.g., some Tc will be present in the secondary } \\
\text { waste stream) }\end{array}$ \\
\hline $\begin{array}{l}\text { Although the waste processing method is mature, there } \\
\text { are still advances being made to the technology that } \\
\text { are resulting substantial process improvements }\end{array}$ & $\begin{array}{l}\text { High temperature operating conditions cause } \\
\text { equipment failure }\end{array}$ \\
\hline & $\begin{array}{l}\text { Number of units required will be greatly dependent on } \\
\text { melter specifications (operating temperature and } \\
\text { surface area per footprint) and waste loading } \\
\text { assumptions. }\end{array}$ \\
\hline
\end{tabular}

All production-scale vitrification efforts within the Department of Energy have been implemented with joule-heated melters. Joule-heated melting technology is mature and has been successfully applied in both the commercial glass-making industry and the Department of Energy complex. At the Defense Waste Processing Facility alone, more than 3,000 canisters of immobilized waste have been produced. In addition, a joule-heated ceramic melter process was 
RPP-48935, Rev.0

successfully used at the West Valley site in New York to process over 600,000 gallons of reprocessing wastes producing 275 glass canisters.

For these reasons joule-heated ceramic lined melters are strong candidates for the processing of Hanford's low-activity waste. 


\section{TABLE OF CONTENTS}

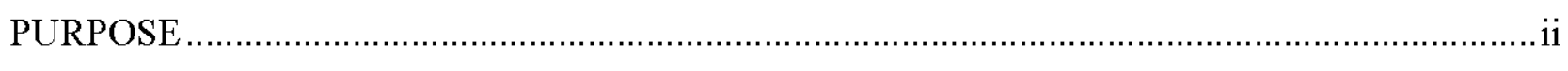

EXECUTIVE SUMMARY SECOND LAW VITRIFICATION .............................................iv

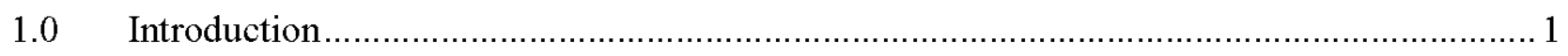

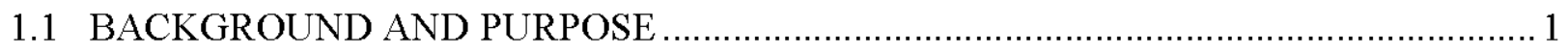

1.2 WHAT IS HANFORD TANK WASTE? ............................................................. 2

1.3 WHAT IS LOW-ACTIVITY WASTE? ........................................................... 3

1.4 WHY IS ADDITIONAL WTP LAW IMMOBILIZATION CAPACITY NECESSARY?..5

1.5 HOW WERE THE CANDIDATE LAW TECHNOLOGIES SELECTED? ..................... 6

1.6 REGULATORY REQUIREMENTS FOR ON-SITE DISPOSAL OF LAW ..................... 7

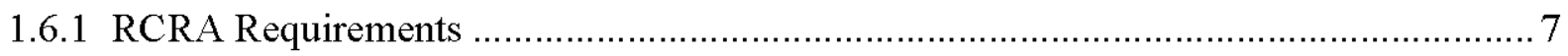

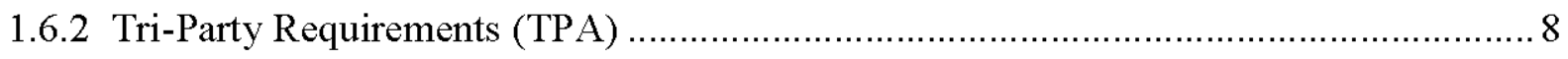

1.6.3 DOE Manual 435.1-1 Waste Incidental to Reprocessing (WIR).............................. 8

1.6.4 DOE Manual 435.1-1 Disposal Authorization.................................................... 9

1.6.5 IDF Waste Acceptance Criteria Requirement..................................................

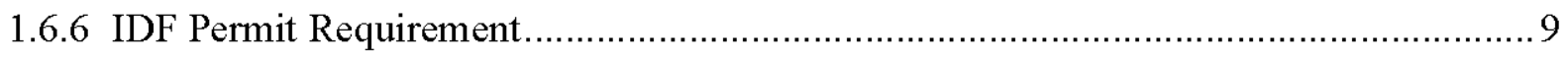

1.7 DETERMINING WASTE FORM PERFORMANCE …............................................. 10

1.7.1 Tests Used to Predict Long-Term Waste Form Performance .................................. 10

1.7.2 Performance Objectives Used to Evaluate Performance Assessment Results.............. 13

1.8 DESIRED ATTRIBUTES OF SELECTED TECHNOLOGIES .................................. 16

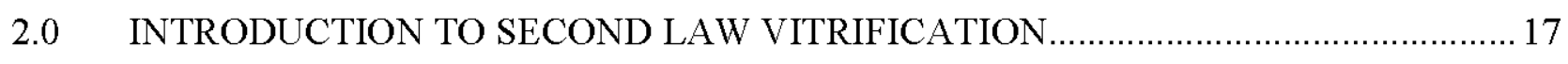

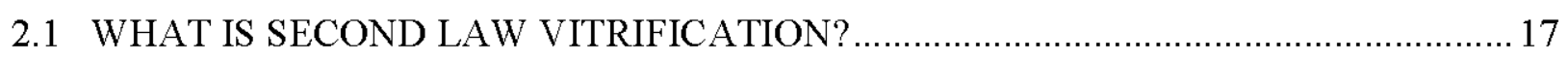

2.2 WHY IS SECOND LAW BEING EVALUATED FOR POSSIBLE USE AT

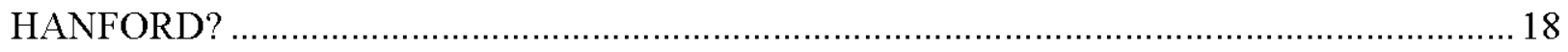

2.3 HOW DOES THE SECOND LAW VITRIFICATION PROCESS WORK? ................... 18

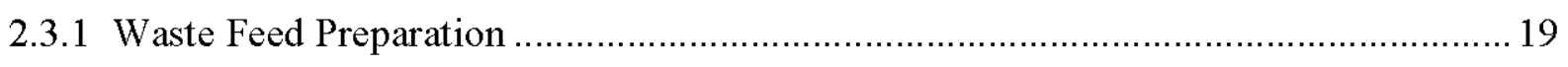

2.3.2 Melter and Product Handling ........................................................................ 27

2.3.3 LAW Primary and Secondary Off-gas Treatment Systems .................................... 32

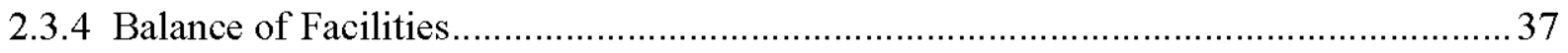

3.0 PREVIOUS RELEVANT TESTS AND DEVELOPMENT HISTORY ........................ 38

3.1 OVERVIEW OF PREVIOUS RELEVANT TESTS AND DEVELOPMENT HISTORY 38

3.1.1 PROCESS ISSUES AND LESSONS LEARNED …......................................... 39

3.2 PREVIOUS USES INSIDE AND OUTSIDE THE DOE COMPLEX ............................... 
4.0 CURRENT STATE OF THE KNOWLEDGE FOR USING VITRIFICATION TECHNOLOGY FOR HANFORD LAW

4.1 HOW SECOND LAW MIGHT FIT INTO THE HANFORD TANK WASTE

TREATMENT FLOW SHEET 41

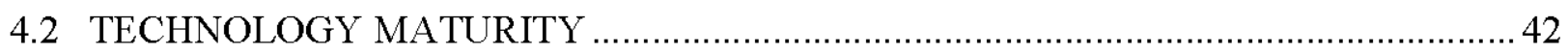

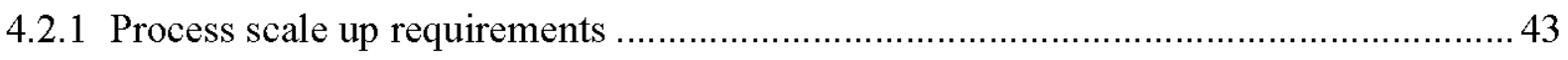

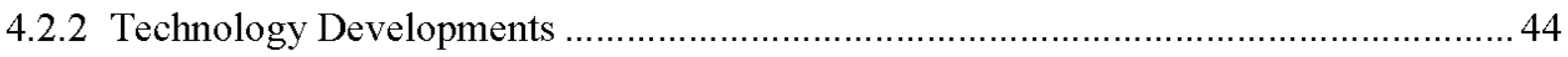

4.3 PROCESS SAFETY CONSIDERATIONS AND CONCERNS …............................... 44

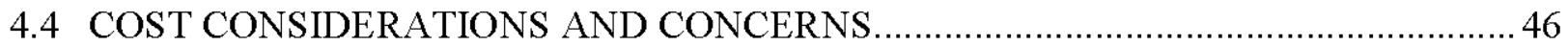

4.5 WASTE FORM CHARACTERISTICS INCLUDING STRENGHS, WEAKNESSES, OR UNCERTANTIES 46

4.6 OFF-GAS TREATMENT AND CONSTITUENTS OF OFF-GAS RELEASED TO THE

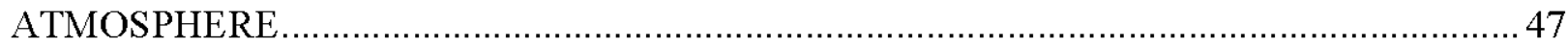

4.7 SECONDARY WASTE STREAMS AND THEIR MANAGEMENT........................... 47

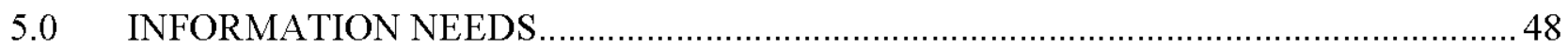

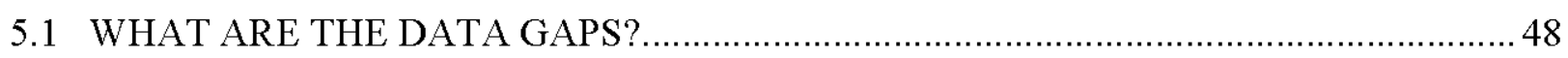

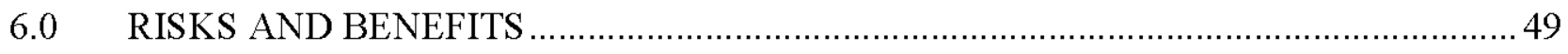

6.1 KEY TECHNICAL AND PROGRAMMATIC RISKS ............................................. 49

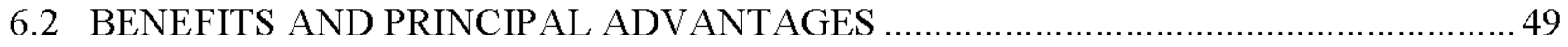

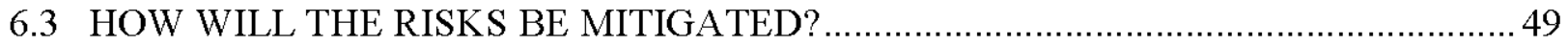

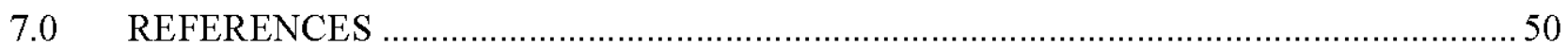

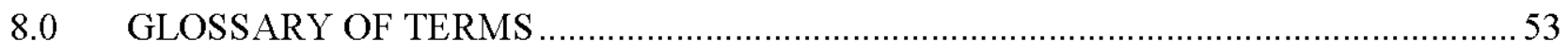




$$
\text { RPP-48935, Rev.0 }
$$

\section{LIST OF FIGURES}

Figure ES-1. Hanford Nominal Tank Waste Treatment \& Disposition Flowsheet .................... iv

Figure ES-2. Joule-Heated Ceramic Lined Melter ............................................................. vi

Figure 1-1. Hanford Nominal Tank Waste Treatment \& Disposition Flowsheet........................ 2

Figure 1-2. Radionuclides Make Up a Small Fraction of Hanford Tank Waste......................... 3

Figure 1-3. Depiction of Basic Pretreatment Processes to Remove Key Radionuclides from Hanford Tank Waste and Produce LAW Feed for Immobilization ........................... 5

Figure 1-4. Eight Steps Assumed in Performance Assessment Groundwater Pathway Models . 14

Figure 2-1. Examples of Crystalline and Glass Matrices. ................................................ 18

Figure 2-2. Melter Feed Preparation....................................................................... 19

Figure 2-3. Graph of Rules for Waste Loading as a Function of SO3 and Na2O ................... 21

Figure 2-4. Glass Former Facility (WTP December 2009) .............................................. 26

Figure 2-5. Glass Former Feed Hopper (WTP LAW facility March 2010) ........................... 27

Figure 2-6. LAW Melter under Construction (prior to installation of ceramic lining)............... 28

Figure 2-7. LAW Melter During Operation.................................................................... 29

Figure 2-8. Canister Turntables beneath LAW Melter Discharge Chambers.......................... 30

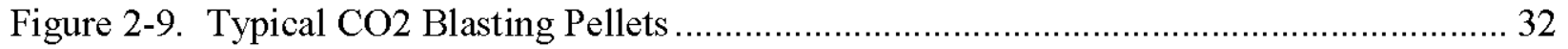

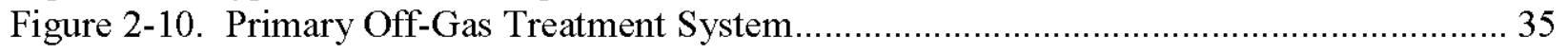

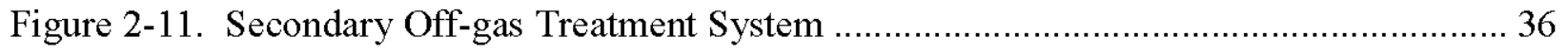

Figure 4-1. LAW Immobilization Facility Interface Diagram............................................ 41

Figure 4-2. DOE Integration of TRL with the Critical Decision Process ................................. 42

\section{LIST OF TABLES}

Table ES-2. Table of Technology Attributes ................................................................... vi

Table 1-2. Principal Waste Form Test Protocals .................................................................. 11

Table 1-2. Key Performance Objectives for Performance Assessment .................................. 15

Table 2-1. Summary of WTP LAW Feed, Melt, and Glass Constraints ................................. 20

Table 2-2. Glass Component Properties .................................................................... 22

Table 4-1. Technology Readiness Level Determination and Associated Rationale (RPP-RPT-

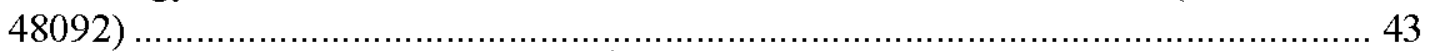

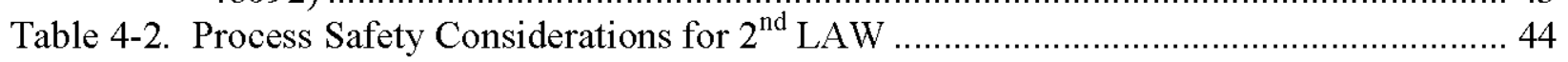

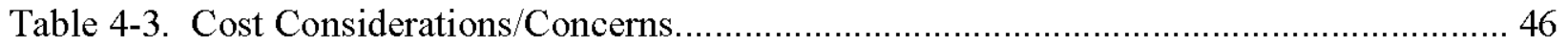


RPP-48935, Rev.0

\section{ABBREVIATIONS AND ACRONYMS}

\begin{tabular}{|c|c|}
\hline Al & aluminum \\
\hline $\mathrm{Al}_{2} \mathrm{O}_{3}$ & aluminum oxide \\
\hline BPP & Bismuth Phosphate Process \\
\hline $\mathrm{B}_{2} \mathrm{O}_{3}$ & boron trioxide \\
\hline $\mathrm{CCC}$ & Centerline Cooling Curve \\
\hline $\mathrm{Cl}$ or $\mathrm{Cl}_{2}$ & chlorine \\
\hline $\mathrm{CO}$ & carbon monoxide \\
\hline $\mathrm{CO}_{2}$ & carbon dioxide \\
\hline CRV & Concentrate Receipt Vessel \\
\hline Cs & cesium \\
\hline DF & Decontamination Factor \\
\hline DOE & Department of Energy \\
\hline DST & Double-Shell Tank \\
\hline DWPF & Defense Waste Processing Facility \\
\hline Ecology & Washington State Department of Ecology \\
\hline EDTA & ethylenediamine tetra-acetic acid \\
\hline EIS & Environmental Impact Statement \\
\hline EPA & Environmental Protection Agency \\
\hline ETF & Effluent Treatment Facility \\
\hline FBSR & Fluidized Bed Steam Reformer \\
\hline $\mathrm{Fe}$ & iron \\
\hline $\mathrm{Fe}_{2} \mathrm{O}_{3}$ & Iron III oxide \\
\hline GFF & Glass Former Facility \\
\hline GFFH & Glass Former Feed Hopper \\
\hline $\mathrm{HCl}$ & hydrochloric acid \\
\hline HEDTA & N-(2-hydroxyethyl)ethylenediamine tri-acetic acid \\
\hline HEPA & High Efficiency Particulate Air \\
\hline $\mathrm{Hg}$ & mercury \\
\hline HLW & High Activity Waste \\
\hline I & iodine \\
\hline IDF & Integrated Disposal Facility \\
\hline ILAW & Immobilized Low Activity Waste \\
\hline INL & Idaho National Laboratory \\
\hline JHCM & Joule-Heated Ceramic Melter \\
\hline $\mathrm{K}_{2} \mathrm{O}$ & potassium oxide \\
\hline $\mathrm{LAW}$ & Low-Activity Waste \\
\hline LDR & Land Disposal Requirements \\
\hline LERF & Liquid Effluent Retention Facility \\
\hline MFH & Melter Feed Hopper \\
\hline MFPV & Melter Feed Preparation Vessel \\
\hline $\mathrm{MFV}$ & Melter Feed Vessel \\
\hline MTGD & Metric Tons Glass per Day \\
\hline $\mathrm{Na}$ & sodium \\
\hline $\mathrm{Na}_{2} \mathrm{O}$ & sodium oxide \\
\hline $\mathrm{NaOH}$ & sodium hydroxide \\
\hline $\mathrm{NH}_{3}$ & ammonia \\
\hline NOx & nitrogen oxide \\
\hline NRC & Nuclear Regulatory Commission \\
\hline ORP & Office of River Protection \\
\hline
\end{tabular}




\begin{tabular}{|c|c|}
\hline PCBs & Polychlorinated Biphenyls \\
\hline PCT & Product Consistency Test \\
\hline PNNL & Pacific Northwest National Laboratory \\
\hline $\mathrm{Pu}$ & plutonium \\
\hline PUF & Pressure Unsaturated Flowthrough \\
\hline PUREX & Plutonium-Uranium Extraction \\
\hline RCRA & Resource Conservation and Recovery Act \\
\hline REDOX & Reduction-Oxidation \\
\hline ROD & Record of Decision \\
\hline RPP & River Protection Project \\
\hline $\mathrm{S}$ & sulfur \\
\hline SBS & Submerged Bed Scrubber \\
\hline SCR & Selective Catalytic Reducer \\
\hline $2^{\text {nd }} \mathrm{LAW}$ & Second LAW Vitrification Facility \\
\hline $\mathrm{SO}_{2}$ & sulfur dioxide \\
\hline $\mathrm{SO}_{3}$ & sulfur trioxide \\
\hline $\mathrm{SOx}$ & sulfur Oxide \\
\hline SPFT & single Pass Flow Through Test \\
\hline $\mathrm{Sr}$ & strontium \\
\hline SRS & Savannah River Site \\
\hline SST & Single-Shell Tank \\
\hline $\mathrm{Tc}$ & technetium \\
\hline $\mathrm{TcO}_{2}$ & technetium Oxide \\
\hline $\mathrm{Tc}_{2} \mathrm{O}_{7}$ & Ditechnetium Heptoxide \\
\hline TCLP & Toxicity Characteristic Leaching Procedure \\
\hline TCO & Thermal Catalytic Oxidizers \\
\hline $\operatorname{Tg}$ & Glass Transition Temperature \\
\hline $\mathrm{TiO}_{2}$ & titanium oxide \\
\hline $\mathrm{T}_{\mathrm{L}}$ & Liquidus Temperature \\
\hline TPA & Tri-Party Agreement (Hanford Federal Facility Agreement and Consent Order) \\
\hline TWINS & Tank Waste Information Network System \\
\hline TWRS & Tank Waste Remediation System \\
\hline VEK & Waste Vitrification Plant in Karlsruhe, Germany \\
\hline VHT & Vapor Hydration Test \\
\hline VOCs & Volatile Organic Carbons \\
\hline VSL & Vitreous State Laboratory \\
\hline WESP & Wet Electrostatic Precipitator \\
\hline WIR & Waste Incidental to Reprocessing \\
\hline WSRC & Washington Savannah River Company \\
\hline WTP & Waste Treatment and Immobilization Plant \\
\hline WVDP & West Valley Demonstration Project \\
\hline $\mathrm{ZnO}$ & zinc oxide \\
\hline $\mathrm{ZrO}_{2}$ & zirconium oxide \\
\hline
\end{tabular}

\section{Units}

ppm

$\mathrm{M}$

$\mu \mathrm{g}$ acfm scfm
Parts per million

Molar

Micro gram (1x10-6 gram)

Actual Cubic Feet per Minute

Standard Cubic Feet per Minute 
RPP-48935, Rev.0

\subsection{INTRODUCTION}

\subsection{BACKGROUND AND PURPOSE}

The United States Department of Energy (U.S. DOE) is currently storing over 55 million gallons of wastes in underground storage tanks at it Hanford Site in Washington State. The DOE plans to separate the wastes into a High-Level Waste (HLW) stream and a Low-Activity Waste (LAW) stream. The HLW stream will be vitrified and ultimately disposed of off-site. Following treatment to remove key radionuclides to the maximum extent practical, the LAW stream will be immobilized for on-site disposal. Because tank wastes include both radioactive and hazardous waste constituents, the LAW will be treated, immobilized, and disposed of in a manner that meets performance objectives comparable to those in the U.S. Nuclear Regulatory Commission (U.S. NRC) regulations ${ }^{1}$ for the disposal of Low-Level Waste (LLW) ${ }^{2}$ and Resource Conservation and Recovery Act (RCRA) Land Disposal Restriction (LDR) requirements.

The DOE is currently building a LAW vitrification plant as part of the Waste Treatment and Immobilization Plant (WTP) that will convert a portion of the projected LAW waste stream into glass. The LAW Vitrification plant does not have the throughput capacity to vitrify all of the LAW. Accordingly, DOE is evaluating several immobilization techniques that could potentially be used to supplement the WTP LAW vitrification plant and convert the LAW into a solid waste form that safely meets applicable disposal requirements. Figure 1-1 depicts a nominal Hanford River Protection Project (RPP) flowsheet and indicates how supplemental LAW immobilization fits into the overall flowsheet regardless of the technology deployed.

The immobilization technologies currently under consideration include:

- $\quad$ Second $\left(2^{\text {nd }}\right)$ LAW Vitrification;

- Cast Stone Technology (grout-based waste form tailored to Hanford LAW);

- Bulk Vitrification (in-container vitrification technology); and

- Fluidized Bed Steam Reforming (FBSR) (thermal process producing a mineral waste form).

The decision regarding which of the four technologies identified above will be ultimately deployed to supplement WTP LAW vitrification will be made in accordance with DOE Orders, NEPA, and the Ecology, EPA, and DOE, 1989, Hanford Federal Facility Agreement and Consent Order (Ecology et al. 1989) also known as the Tri-Party Agreement (TPA). It is not known as of this writing which technology will be selected. Discussions of these technologies are based on pre-conceptual design information. As such the level of design descriptions is general and specific cost information is not available.

\footnotetext{
${ }^{1} \mathrm{DOE}$ is not subject to NRC regulations for LAW waste treatment and disposition activities at Hanford; however, DOE does consult with the NRC on the classification of LAW as low-level waste and certain sections of NRC regulation 10 CFR Part 61 are used in the classification processes.

${ }^{2}$ Note that while LLW and LAW are essentially the same relative to radioactivity, the term LAW only applies to DOE tank waste that has been pretreated to remove key radionuclides.
} 


\section{Figure 1-1. Hanford Nominal Tank Waste Treatment \& Disposition Flowsheet}

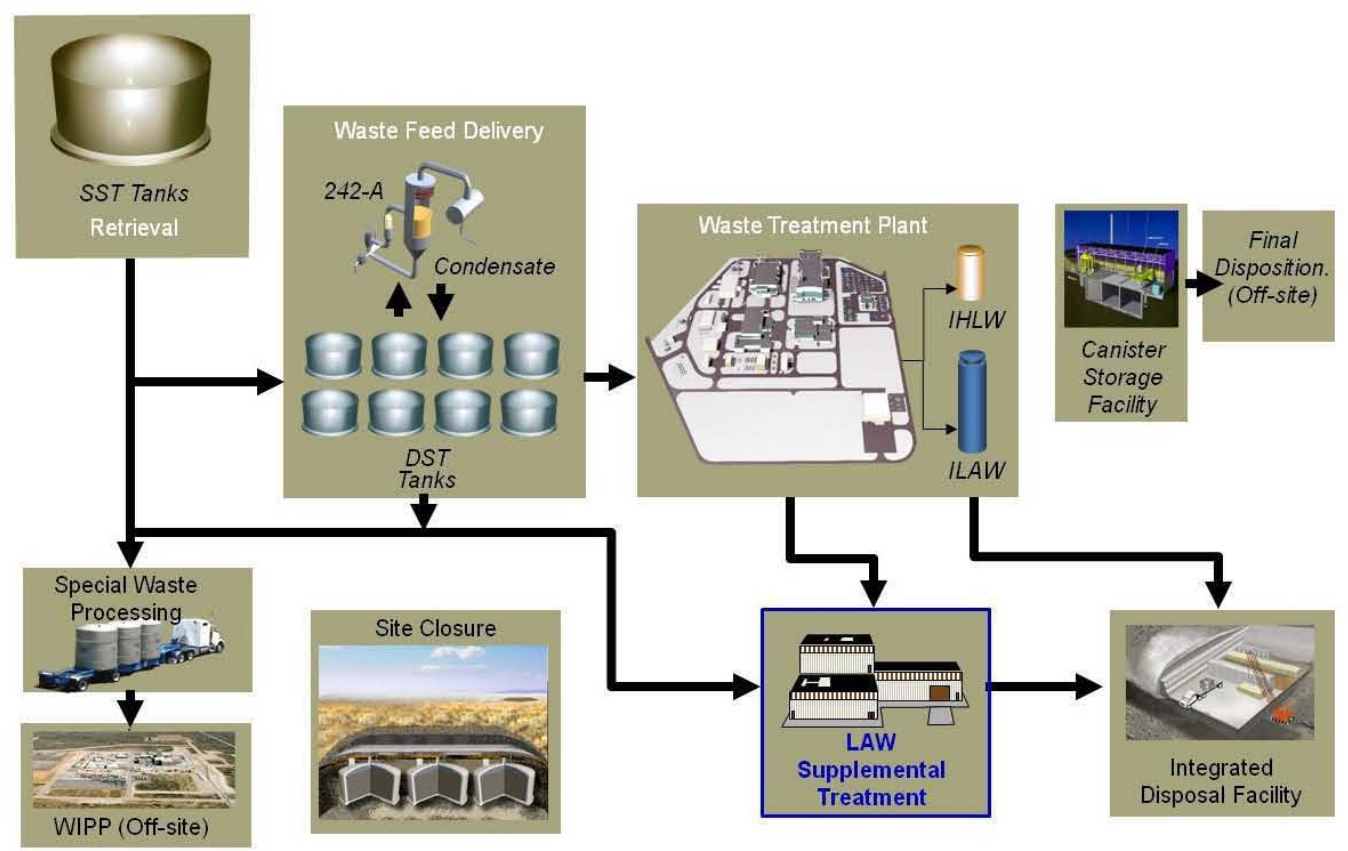

\subsection{WHAT IS HANFORD TANK WASTE?}

The 177 Hanford underground storage tanks managed under the RPP contain over 55 million gallons of liquid (referred to as supernatant), saltcake, and sludge wastes, much of which was generated during the reprocessing of nuclear fuel to produce weapons grade plutonium $(\mathrm{Pu})$ for national defense. A variety of irradiated nuclear fuel reprocessing and chemical separations processes and campaigns were conducted at Hanford between 1945 and 1989, which resulted in highly complex chemical wastes in the Hanford tanks. Moreover, because Hanford started operations during World War II when stainless steel was in high demand, the Hanford tanks were constructed of carbon steel. The use of carbon steel required that the acidic reprocessing wastes be neutralized with sodium hydroxide $(\mathrm{NaOH})$ to prevent acid attack. This greatly added to the mass of chemicals stored in the tanks. In addition, the reprocessing technology used at Hanford for the first ten years was the Bismuth Phosphate Process (BPP). While that process produced very high purity $\mathrm{Pu}$ for the first nuclear weapons ever produced, the BPP created one hundred times more waste per ton of Pu recovered than the PUREX Process, which later became the standard for DOE uranium (U) and Pu as well as for commercial spent nuclear fuel reprocessing.

The result is that the Hanford tank wastes are far more chemically complex and heterogeneous than tank wastes at other DOE production sites. The Hanford tank wastes also tend to have substantially lower average radionuclide concentrations than other DOE tank wastes because of the inefficient recovery processes initially used (BPP), and the more than one hundred million curies of radionuclides [particularly cesium- $137\left({ }^{137} \mathrm{Cs}\right)$ and strontium- $\left.90\left({ }^{90} \mathrm{Sr}\right)\right]$ that were removed from the Hanford tanks forty years ago.

It is generally understood that the highly radioactive materials resulting from the reprocessing of spent nuclear fuel are HLW (NWPA 1983, Nuclear Waste Policy Act of 1983, Public Law 97- 
425; 96 Stat. 2201). Given the high cost and limited availability of potentially suitable deep geologic disposal sites for HLW, DOE recognizes that the high chemical content of the Hanford tank waste was unsuitable for total immobilization as vitrified HLW. Figure 1-2, which was derived from data in the Hanford Tank Waste Information Network System (TWINS) database, illustrates the relationships between the mass of radionuclides and the mass of chemicals that make up the Hanford tank wastes.

The pretreatment processes that will be carried out in the WTP pretreatment plant accomplish two key activities. First they separate the chemical wastes from the radioactive materials to the maximum extent practical to minimize the mass of wastes that will require vitrification as HLW. Second, by removing key radionuclides from the chemical waste fraction to the maximum extent technically and economically practical, the pretreatment processes should satisfy the first Waste Incidental to Reprocessing (WIR) criterion in DOE Manual 435.1-1,

Figure 1-2. Radionuclides Make Up a Small Fraction of Hanford Tank Waste.

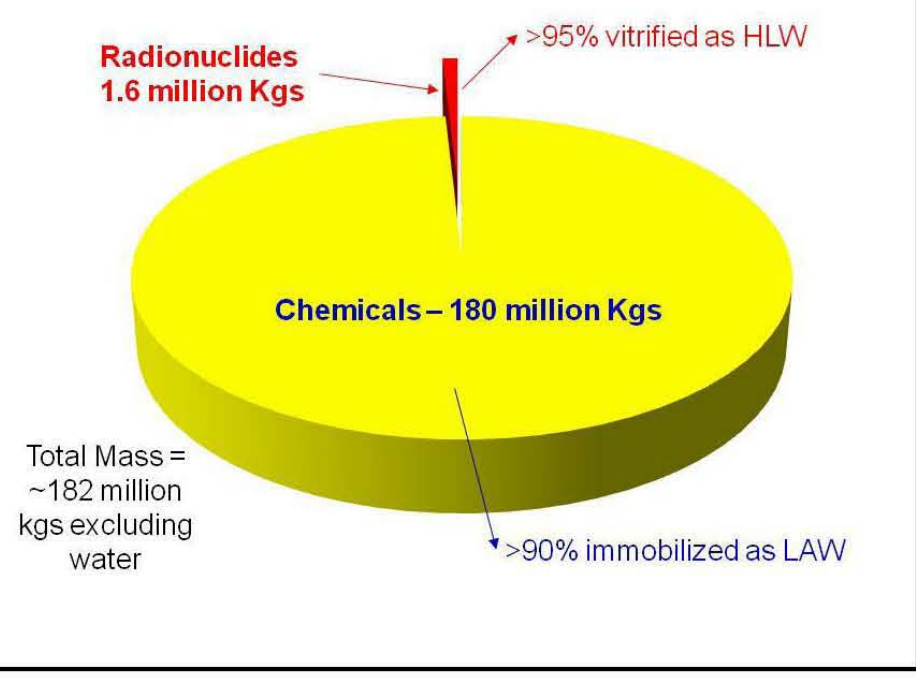

Radioactive Waste Management. The second factor is a critical element to classifying the LAW as non-HLW suitable for disposal on-site at Hanford. In addition to the chemicals in the tanks, substantial quantities of process sodium $(\mathrm{Na})$ will be added during the pretreatment of the tank wastes. The Hanford tanks contain approximately 48,000 metric tons (MT) of Na, essentially all of which will require immobilization as LAW. Additional process $\mathrm{Na}$ will be added during the waste pretreatment in the WTP.

The largest contributor to pretreatment $\mathrm{Na}$ additions will result from $\mathrm{NaOH}$ added to remove $\mathrm{Al}$ from HLW sludge waste during hot sludge leaching and the additional $\mathrm{NaOH}$ added to keep the aluminum (Al) in solution as the leachate is cooled from $80^{\circ}-90^{\circ}$ Celsius (leach temperature) to $25^{\circ}-45^{\circ}$ Celsius for processing through the cesium (Cs) ion exchange system. Because the LAW storage and treatment systems in the WTP pretreatment plant are not designed to handle solids (solids are separated and sent to the HLW storage and treatment systems), it is important that solids do not precipitate in those systems. For purposes of this report it is estimated that the total mass of $\mathrm{Na}$ that will require immobilization will be in the range of 65,000 to 70,000 MT.

\subsection{WHAT IS LOW-ACTIVITY WASTE?}

Low Activity Waste is the fraction of the tank wastes that is mostly chemicals and from which key radionuclides have been removed to the maximum extent technically and economically practical to render the waste not highly radioactive. The DOE will use a formal process to establish that the LAW waste produced through its planned pretreatment and immobilization processes is not HLW and is suitable for disposal on-site. The criteria used to make a 


$$
\text { RPP-48935, Rev.0 }
$$

determination $^{3}$ that the LAW is not HLW were developed in concert with the NRC (Bernero 1993) and the NRC will consult with DOE on its analyses showing that those criteria are met. The criteria are contained in DOE Manual 435.1-1, "Waste Incidental to Reprocessing (WIR) Requirements". The process by which the waste determination is made is called the WIR evaluation process. That process requires that DOE demonstrate that:

1. Waste is processed to remove key radionuclides ${ }^{4}$ to the maximum extent technically and economically practical,

2. If the treated and immobilized waste is disposed of by land disposal, that performance objectives comparable to those set forth in 10 CFR 61, Subpart C will be met, and

3. Waste is converted into a solid material with radionuclide concentrations that do not exceed 10 CFR 61.55 Class C concentration limits.

The resulting waste would be radioactively equivalent to LLW (i.e., no longer highly radioactive) and proven to be safe for disposal on-site. Given the derivation of the waste from tank wastes, DOE applies the term LAW to avoid confusion with wastes that are LLW at the point of generation. Because the Hanford tank wastes are regulated under the RCRA, LAW wastes are mixed LLW.

A two-step treatment approach removes the key radionuclides to the maximum extent technically and economically practical. The first step conducts solid and liquid separations on the liquid waste (supernatant) from the tanks to remove insoluble radionuclides such as transuranic isotopes and ${ }^{90} \mathrm{Sr}$. The second step performs $\mathrm{Cs}$ ion exchange on those wastes to remove ${ }^{137} \mathrm{Cs}$. The Hanford WTP implements this key radionuclide removal approach in the pretreatment plant. The plant produces the LAW liquid feed that will be converted to glass in the LAW melters. Figure 1-3 depicts the basic pretreatment concept to produce Hanford LAW feed from tank waste.

\footnotetext{
${ }^{3}$ The same criteria and process will also be applied to other tank waste related waste streams such as residuals remaining following the retrieval of wastes from tanks in accordance with TPA retrieval requirements.

${ }^{4}$ Key radionuclides generally refers to those radionuclides that if not removed would result in the most significant impacts to human health.
} 
Figure 1-3. Depiction of Basic Pretreatm ent Processes to Remove Key Radionuclides from Hanford Tank Waste and Produce LAW Feed for Immobilization

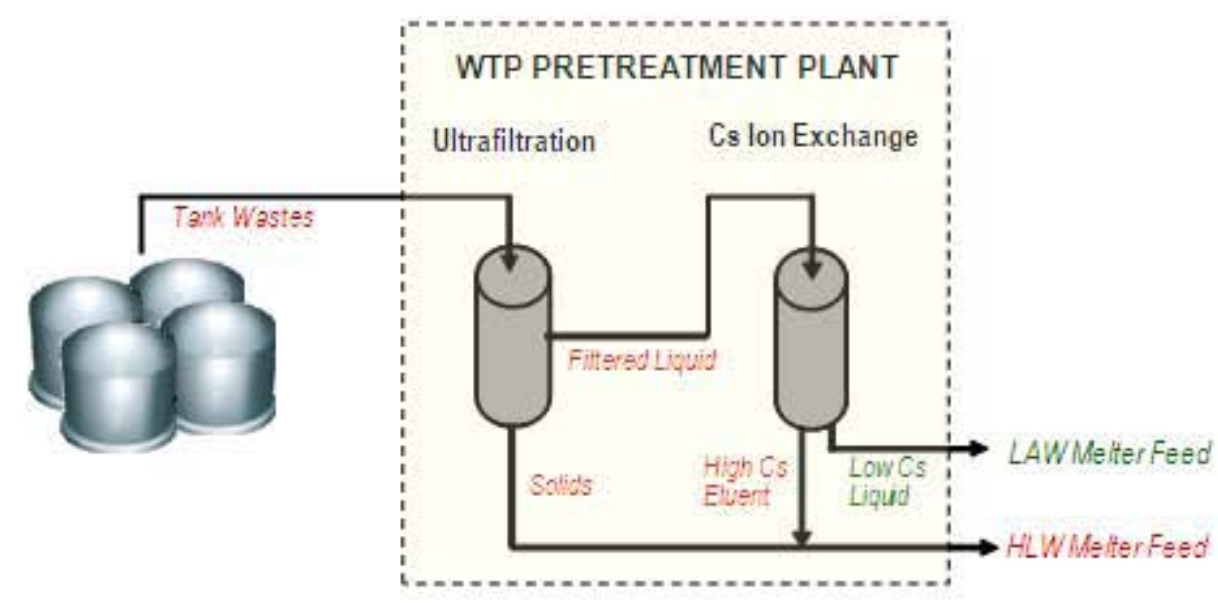

While Figure 1-3 illustrates the WTP pretreatment processes currently under construction, DOE is also considering supplemental pretreatment approaches that would provide filtration and ion exchange pretreatment of LAW feed in the tank farms. This latter apprach could potentially decrease the treatment mission duration by enabling the WTP pretreatment plant to primarily focus on the sludge pretreatment processes.

\subsection{WHY IS ADDITIONAL WTP LAW IMMOBILIZATION CAPACITY NECESSARY?}

The Hanford WTP Project was established in the 1990's. It was under a privatization concept wherein a private contractor would design, build, and operate the WTP using its own funding sources, i.e., no upfront federal funding. The contractor was to be paid on a unit basis as waste was successfully treated and immobilized.

Given project uncertainties and the high cost of building treatment facilities, a phased implementation approach was planned. The first phase would include a pretreatment facility, a HLW vitrification facility, and a LAW vitrification facility. The initial WTP would treat at least $10 \%$ of the tank waste mass containing at least $25 \%$ of the tank waste radioactivity during Phase I. Based on lessons learned during Phase I, the WTP would be upgraded to complete treatment and immobilization of the rem aining tank wastes during Phase II.

The pretreatment plant was to be designed to process all of the tank waste over both mission phases, but would operate at a relatively low throughput capacity during Phase I. The HLW vitrification plant was designed to accommodate two melters, each processing 3 metric tons of glass per day (MTGD), however, only one $1.5 \mathrm{MTGD}$ melter was to be initially installed and used for Phase I operations. The LAW vitrification plant was initially planned for three LAW melters, but the design was finalized for two LAW melters having a total net throughput capacity of net $30 \mathrm{MTGD}$, which was sufficient to handle all LAW generated during Phase I. The LAW immobilization throughput would need to be increased for Phase $I$ to several times the throughput that could be provided by the first LAW plant. While economies of scale made it practical to design the Pretreatment and $H L$ W vitrification facilities to accommodate the 


$$
\text { RPP-48935, Rev.0 }
$$

higher throughput required for Phase II, the same was not true for the LAW vitrification plant for two reasons.

The first was uncertainty regarding how much LAW immobilization capacity would actually be required to complete the overall treatment mission. One of the principal objectives of the WTP is to transfer as much non-radioactive waste mass as reasonable from the HLW fraction to the LAW fraction in order to minimize the amount of geologic repository space and disposal cost required to accommodate the HLW. DOE was conducting studies to determine how much Al and other non-radioactive wastes could be leached from the HLW sludge from the tanks, as well as to determine how much non-waste, sodium hydroxide $(\mathrm{NaOH})$ would need to be added during pretreatment to reach its objectives. Whatever waste was leached from the HLW sludge and whatever $\mathrm{Na}$ needed to be added to the process to effect that removal was to be immobilized as LAW. Consequently, DOE did not know how large the LAW immobilization capacity would be during Phase II.

A second reason was uncertainty regarding whether LAW vitrification would prove to be the best immobilization solution for all of the LAW that would be generated. DOE and international entities in the United Kingdom and France had experience with the vitrification of HLW. Vitrification of LAW, however, was unique to Hanford. The Tank Waste Remediation System (TWRS) Environmental Impact Statement (EIS) Record of Decision (ROD) (62 FR 8693, Record of Decision for the Tank Waste Remediation System) left open the possibility other remediation approaches could result as information emerged during the conduct of the mission.

"The Phased Implementation alternative was selected because it provides a balance among short-and long-term environmental impacts, meets all regulatory requirements, addresses the technical uncertainties associated with remediation, and provides the flexibility necessary to accommodate future changes in the remediation plans in response to new information and technology development." [TWRS EIS ROD, DOE 1997]

\subsection{HOW WERE THE CANDIDATE LAW TECHNOLOGIES SELECTED?}

In 2002 and 2003 DOE initiated a series of meetings with Ecology and the U.S. Environmental Protection Agency (EPA) that were focused on determining whether an approach other than building a Second WTP LAW Vitrification Plant would best fill out the RPP flowsheet and, if so, what technologies should be considered ${ }^{5}$. Over the course of a year, a joint work group with representatives from each of those agencies and the Hanford Tank Farm Contractor reviewed several dozen potential technical approaches; four of which were evaluated in detail as the primary contenders for completing the LAW immobilization mission. Those four are the same as were listed earlier in the Introduction of this report, Second LAW Vitrification Plant, Bulk Vitrification, Cast Stone, and FBSR.

A procurement process was initiated to obtain design, cost, and waste form data for the latter three technologies. This was not considered necessary for the Second LAW Vitrification Plant

\footnotetext{
${ }^{5}$ The meetings were held as a subgroup of the Cleanup, Constraints, and Challenges Team (C3T), an informal forum where ideas and concepts could be discussed openly between DOE, EPA, and Ecology. Ideas were developed and evaluated to determine whether they could accelerate cleanup; reduce costs; or protect workers, the public, and the environment.
} 
RPP-48935, Rev.0

given the significant DOE investment in that technology and information available from the WTP Project.

On the basis of its meetings with the Washington Department of Ecology (Ecology) and EPA, DOE decided to further evaluate Bulk Vitrification at Hanford based primarily on a substantial cost advantage it appeared to have over a Second LAW Vitrification Plant and FBSR. DOE further decided that Idaho National Laboratory (INL) would conduct FBSR studies considering both INL sodium-bearing waste (SBW) and Hanford LAW. The SRS was already substantially invested in Saltstone, the SRS equivalent to cast stone, which SRS planned to use to immobilize its counterpart to Hanford LAW.

\subsection{REGULATORY REQUIREMENTS FOR ON-SITE DISPOSAL OF LAW}

There are six sets of regulatory requirements that must be met to dispose of immobilized LAW on-site at Hanford.

- RCRA Requirements, ( Resource Conservation and Recovery Act of 1976)

- TPA Requirements (DOE, 1989, Hanford Federal Facility Agreement and Consent Order - Tri-Party Agreement, (TPA),

- DOE Manual 435.1-1 Waste Incidental to Reprocessing (WIR) Requirements,

- DOE Manual 435.1-1 Disposal Authorization Requirements,

- Integrated Disposal Facility (IDF) IDF 2004, Integrated Disposal Facility Waste Acceptance Criteria, and

- IDF Permit Requirements. (IDF 2004 CEES-0134, Rev. B, Integrated Disposal Facility Waste Acceptance Criteria.)

Each is briefly discussed below.

\subsubsection{RCRA Requirements}

All Hanford tank waste is regulated under RCRA because of the hazardous constituents in the tank wastes. The hazardous (dangerous waste) constituents are also regulated under the Washington State Hazardous Waste Management Act and respective implementing regulations. The tank wastes carry RCRA codes D002 (corrosive), D004 (toxicity arsenic (As)), D005 (toxicity barium (Ba)), D006 (toxicity cadmium (Cd)), D007 (toxicity chromium (Cr)), D008 (toxicity Pb), D009 (toxicity mercury (Hg)), D010 (toxicity selenium (Se)), and D011 (toxicity silver (Ag)) for which the RCRA best demonstrated available technology (BDAT) is High Level Vitrification (HLVIT). In order to deploy a non HLW vitrification technology to treat the tank wastes DOE would need to submit a request for a Determination of Equivalent Treatment (DET) to the EPA for the alternative technology. The EPA would need to approve the DET before DOE could deploy the technology. The DET formally establishes the adequacy of the nonvitrification technology to treat the LAW and establish that the final waste product will meet RCRA LDR.

In addition, since DOE plans to base the contents of the immobilized waste on its analysis of what is in the waste feed rather than sample the contents of every immobilized waste package, DOE must also request Ecology to approve a Treatability Variance (TV) to enable that approach. This would be required regardless of the immobilization technology deployed. 


$$
\text { RPP-48935, Rev.0 }
$$

DOE must also obtain a RCRA permit to build and operate any facility to treat and immobilize the LAW regardless of the technology deployed.

\subsubsection{Tri-Party Requirements (TPA)}

The TPA (http://www.hanford.gov/?page=82) was signed in 1989 by Ecology, EPA and DOE with the purpose of coordinating the Comprehensive Environmental Response, Compensation, and Liability Act (CERCLA) and RCRA cleanup authorities at Hanford. The TPA also identifies specific cleanup milestones to be met; the process for changing, removing, or adding milestones; the conditions under which penalties may be issued; and the requirements for public involvement relating to Hanford cleanup actions. Major changes to the TPA require approval of all three agencies and are only made after a public participation process has been followed.

Appendix D to the TPA, Work Schedule and Designation of Lead Regulatory Authority, establishes key milestones for the processing and immobilization of the HLW and LAW from the Hanford tanks (M-062 milestone series). These include (paraphrased):

M-062-00 Complete all treatment and immobilization of tank wastes by December 31, 2047.

M-062-30 Complete negotiations establishing milestones for implementing near-term (2011 2016) actions related to LAW treatment and immobilization (October 2011).

M-062-40 Multipart milestone that includes requirement for DOE to submit a one-time Hanford Tank Waste Supplemental Treatment Technologies Report if a technology other than a $2^{\text {nd }}$ LAW vitrification facility is proposed.

M-062-45 Multipart milestone that includes requirement for a one-time supplemental LAW treatment selection consistent with M-062-00 including implementing supplemental treatment milestones (April 30, 2015).

M-062-49 Submit a report to Ecology with data certified to be accurate that demonstrates that the WTP is designed to accomplish at least the pretreatment of $100 \%$ of retrievable waste, vitrify $100 \%$ of HLW, and WTP LAW with supplemental treatment can immobilize $100 \%$ of LAW (October 31, 2011).

\subsubsection{DOE Manual 435.1-1 Waste Incidental to Reprocessing (WIR)}

Most of the waste in the Hanford tanks either originated during spent nuclear fuel reprocessing or has been subsequently comingled with reprocessing wastes. In order to manage and dispose of tank waste as other than HLW, DOE must determine the waste to not be HLW using either the citation or evaluation WIR process set forth in DOE Manual 435.1-1. The citation process is primarily applied to wastes that can be readily determined to not be HLW based on inspection, e.g., contaminated tools and clothing. The responsible DOE field element manager makes the process determinations.

Evaluation process WIR determinations are more complex. With evaluation process WIRs, treatment and analyses are required to render the waste not highly radioactive and then demonstrate that it is suitable for disposal in a LLW disposal site. Treatment (e.g., ultra or 


$$
\text { RPP-48935, Rev.0 }
$$

micro filtration and $\mathrm{Cs}$ ion exchange) is required to remove key radionuclides (typically

actinides, ${ }^{90} \mathrm{Sr}$, and ${ }^{137} \mathrm{Cs}$ ) to the maximum extent technically and economically practical. An engineering trade study is required to demonstrate that the degree of radionuclide removal will meet that objective. A performance assessment and other analyses are required to demonstrate that performance objectives comparable to those in 10 CFR Part 61, Subpart C will be met if the waste is disposed of by land disposal, e.g., in the Hanford IDF. Additional analyses are required to demonstrate that the immobilized waste will have radionuclide concentrations within those set forth in 10 CFR 61.55, Class C concentration limits.

Once the WIR analyses and supporting documentation are approved by DOE HQ, the draft WIR is published in the Federal Register and public comments are elicited. DOE also requests NRC staff consultation on the draft WIR and supporting documentation. This typically takes nine months or longer and involves NRC requests for additional information, DOE responses to those requests, and a NRC Technical Evaluation Report. Once the NRC and public input are integrated into the WIR as appropriate, the formal evaluation process WIR determination is made by the responsible DOE secretarial officer or designee.

\subsubsection{DOE Manual 435.1-1 Disposal Authorization}

In order for a waste to be disposed of in a DOE disposal facility such as the IDF, a formal disposal authorization must be in place that authorizes disposal. The disposal authorization is issued by an EM Deputy Assistant Secretary and is largely based on a recommendation from the Low-Level Waste Federal Review Group (LFRG) that the disposal facility is adequately protective of human health and the environment based on a Performance Assessment (PA) developed for that facility and contributing impacts from near-by facilities.

\subsubsection{IDF Waste Acceptance Criteria Requirement}

Waste acceptance criteria will be established for the IDF that places restrictions or requirements on wastes received at that facility for disposal in order to ensure that those wastes are properly characterized and documented by the waste generator relative to their origin, constituents, inventory, and characteristics or properties of the waste forms. The waste acceptance criteria is in part derived to be consistent with the waste types/inventories evaluated in the PA for the facility and in part based on engineering considerations such as compressive strength to protect against post-disposal surface subsidence.

At present, the IDF waste acceptance criteria exists in draft form (IDF 2004, CEES-0134, Rev. $\mathrm{B}$, Integrated Disposal Facility Waste Acceptance Criteria). The waste acceptance criteria will need to be finalized prior to waste acceptance for disposal in the IDF.

\subsubsection{IDF Permit Requirement}

Because the ILAW and related secondary waste to be disposed of in the IDF are derived from the Hanford tank waste, those wastes are regulated under RCRA and must meet RCRA LDR. Moreover, the IDF disposal cells that receive those wastes are subject to a RCRA permit issued by Ecology. The current IDF RCRA permit only covers ILAW glass from the WTP and up to 50 boxes of vitrified waste from Bulk Vitrification. The permit will need to be updated in order to receive secondary wastes from the tank farms and WTP as well as ILAW from other than a 
RPP-48935, Rev.0

Second WTP LAW Vitrification Facility. The permit update will in part be based on the results set forth in the IDF PA.

\subsection{DETERMINING WASTE FORM PERFORMANCE}

\subsubsection{Tests Used to Predict Long-Term Waste Form Performance}

A variety of tests are used to determine the long-term performance properties of candidate waste forms (waste form durability). Information derived from those tests is used to provide waste form performance input to the IDF PA analyses. The types of tests used depend, in part, upon the type of waste form. While ideally a waste form would hold radioactive and hazardous constituents permanently, that just is not practical to achieve. Rather, the purpose of a waste form is to retard the release of radioactive and hazardous constituents such that releases are at very low rates and extend over very long periods, such that impacts to human health and the environment are within levels allowed by environmental laws and regulations. Because the times over which releases can occur are typically measured in thousands, tens of thousands, or even millions of years for $100 \%$ release, the tests and analytical techniques used to measure waste form performance must rely on relatively short-term periods of measurements (days, months, or years) to make very long-term predictions.

Accordingly, scientists have devised ways to approximate the long-term corrosion of waste forms over the shorter time frames during which tests can be reasonably conducted using tests at higher temperatures and higher $\mathrm{pH}$ conditions, both of which accelerate the rate of attack well beyond what would occur in the Hanford vadose zone environment. Some waste forms, such as cast stone, release contaminants when water or contaminants move through the waste form by diffusion through the small pores within the waste form. Other waste forms such as glass and minerals suffer surface corrosion, are protected for some period of time by the corrosion product buildup on their surfaces, and then suffer corrosion again when the corrosion products are ultimately flushed or dissolved away. Determining the rates of releases for such waste forms requires batteries of complex tests and complex kinetic rate equations.

For glass and for mineral waste forms such as produced by the FBSR process, the tests are essentially the same due to similarities in the means by which those two waste forms eventually release contaminants to the vadose zone groundwater. In both cases kinetic rate equations are used to calculate the projected release rates, which can span millions of years. Cast stone uses some different test protocols that are focused on diffusion through the waste form over periods of thousands or tens of thousands of years. The applicability of the tests to various waste forms is shown in Table 1-1. A brief discussion of each test protocol ${ }^{6}$ is provided below.

\footnotetext{
${ }^{6}$ The Vapor Hydration Test (VHT), is not discussed because it was specifically developed for glass, has not yet been adequately demonstrated to the scientific community to provide information that correlates well to long-term performance (WSRC-STI-2008-00268), and is not well suited for surrogate testing.
} 
RPP-48935, Rev.0

Table 1-1. Principal Waste Form Test Protocols

\begin{tabular}{|l|c|c|c|c|}
\hline \multicolumn{1}{|c|}{ Test Protocol } & $\begin{array}{c}\text { WTPLAW } \\
\text { Glass }\end{array}$ & $\begin{array}{c}\text { Bulk } \\
\text { Vitrification }\end{array}$ & $\begin{array}{c}\text { FBSR } \\
\text { Mineral }\end{array}$ & $\begin{array}{c}\text { Cast } \\
\text { Stone }\end{array}$ \\
\hline $\begin{array}{l}\text { Toxicity Characteristic Leaching Procedure } \\
\text { (TCLP) }\end{array}$ & $\checkmark$ & $\checkmark$ & $\checkmark$ & $\checkmark$ \\
\hline Product Consistency Test (PCT or ASTM C1285) & $\checkmark$ & $\checkmark$ & $\checkmark$ & \\
\hline $\begin{array}{l}\text { Single Pass Flowthrough Test (SPFT or ASTM } \\
\text { C1662) }\end{array}$ & $\checkmark$ & $\checkmark$ & $\checkmark$ & \\
\hline $\begin{array}{l}\text { Pressurized Unsaturated Flow (PUF) test } \\
\text { ASTM D6527, Hydraulic Conductivity in Porous } \\
\text { Media }\end{array}$ & $\checkmark$ & $\checkmark$ & $\checkmark$ & \\
\hline ASTM/ANS 16.1, Leachability of Solidified LLW & & & & $\checkmark$ \\
\hline $\begin{array}{l}\text { ASTM C39/C 39M, Compressive Strength of } \\
\text { Cylindrical Concrete Specimens }\end{array}$ & & & & $\checkmark$ \\
\hline
\end{tabular}

TCLP-The EPA Test Method 1311, Toxicity Characteristic Leaching Procedure (TCLP) is designed to determine the mobility of both organic and inorganic analytes present in liquid, solid, and multiphasic wastes. This usually determines if a waste may meet the definition of EPA toxicity, that is, carrying a hazardous waste code under RCRA (40 CFR Part 261) of D004 through D052. The TCLP analysis simulates landfill conditions and determines which of the contaminants identified by the EPA are present in the leachate and the concentrations of such contaminants. For Hanford tank wastes, TCLP analysis will be used to determine whether the treated immobilized waste will meet RCRA LDR (42 USC 6901, Resource Conservation and Recovery Act, 40 CFR 268, and WAC 173-303, Washington State Dangerous Waste Regulations to be suitable for on-site disposal.

$P C T$ - The Product Consistency Test (PCT) was developed between 1987 and 1994 when it became an ASTM standard for HLW borosilicate glass (Jantzen 1994). In 1997 and 2002 the scope was broadened to include hazardous waste glasses, mixed waste glasses, and glass ceramics. Based on extensive testing of glasses and glass-ceramics, including a sevenlaboratory round robin, and confirmatory testing with radioactive samples, the PCT has been shown to be reproducible to distinguish between waste forms of different durability and homogeneity, to yield reliable results, and to be suitable for radioactive samples testing. Additional PCT testing of ceramic waste forms has occurred since 2002 and application of this test to ceramic waste forms is currently being considered by ASTM (WSRC-STI-2008-00268, "Mineralization of Radioactive Wastes by Fluidized Bed Steam Reforming (FBSR); Comparisons to Vitreous Waste Forms and Pertinent Durability Testing").

The PCT uses a granular waste form product typically between $>74 \mu \mathrm{m}$ and $<149 \mu \mathrm{m}$ at elevated temperature $\left(90^{\circ} \mathrm{C}\right)$ in de-ionized water at a solid-to-water ratio of $10 \mathrm{~g} / \mathrm{mL}$. The PCT 
testing will be conducted using water solutions developed to represent burial conditions in the IDF, including natural vadose zone water chemistry and vadose zone water chemistry altered by groundwater attack on waste disposed of in the IDF. Ideally, PCT tests should be conducted over extended times (months to years) to better represent in situ weathering processes and to enable modeling of the weathered state of the waste form. The long-term PCT tests will be conducted consistent with ASTM C1285 - 02, 2008, "Standard Test Methods for Determining Chemical Durability of Nuclear, Hazardous, and Mixed Waste Glasses and Multiphase Glass Ceramics: The Product Consistency Test (PCT)".

SPFT - The SPFT test (ASTM C1662-10, Standard Practice for Measurement of the Glass Dissolution Rate Using the Single-Pass Flow-Through Test Method) is designed to measure reaction rates under tightly controlled, dilute solution conditions. Dissolution of silicate glasses or minerals in an aqueous solution is a dissociation-association process in which two or more soluble species are released into or removed from solution. It is subject to the common ion effect, which occurs when a solution already contains the same ions that would be released when a solid dissolves (or precipitates). The presence of common ions released from the glass or from other sources reduces the net rate of release relative to the rate in pure water. Hence, the idea of the SPFT test is to remove the elements released into solution from waste form dissolution by continuously introducing fresh water into the system. Run properly, the SPFT test provides a direct measure of the so-called "forward reaction rate." The forward reaction rate is the maximum rate at which a silicate glass or mineral can dissolve at a given temperature and $\mathrm{pH}$. Once the forward rate is known, it is straight forward to calculate the absolute upper bound on the release rate of any glass component, including a radionuclide such technetium $99\left({ }^{99} \mathrm{Tc}\right)$.

The SPFT test as a LAW product acceptance test is attractive for several reasons. First, the test provides a direct measure of the maximum possible corrosion rate of a glass or mineral that can be used in performance assessment analyses. Second, the test eliminates ambiguity that is unavoidable in interpreting the results from a closed-system test such as the PCT, where the solution $\mathrm{pH}$ and concentration of waste form components change as a function of time. The changing $\mathrm{pH}$ is particularly problematic because SPFT tests show that the forward reaction rate increases by approximately a factor of 3 for every unit increase in $\mathrm{pH}$ over the $\mathrm{pH}$ range from 7 to 12. Also, secondary phases can form in the PCT, which means that the solution concentration of some components may not give an accurate measure of the waste form corrosion rate.

Finally, because the PCT is a closed-system test, the results, particularly at early times and temperatures $<40^{\circ} \mathrm{C}$, are subject to phenomena such as ion-exchange, dissolution of fines, and reaction of highly strained fracture surfaces that are not true measures of the long-term, waste form dissolution rate.

$P U F$ - PUF tests (McGrail, Accelerated Testing of Waste Forms Using a Novel Pressurized Unsaturated Flow (PUF) Method) are important because they are conducted under hydraulically unsaturated conditions, which are the hydraulic conditions that exist in the vadose zone where the wastes will be ultimately disposed. PUF tests allow the corroding waste form to achieve its final reaction state in the most representative geochemical environment. Accordingly, PUF tests can provide insights into:

- Alteration phases that will form over time when the wastes are contacted by unsaturated groundwater, 


$$
\text { RPP-48935, Rev.0 }
$$

- Time-phased changes in leachate (groundwater) chemistry resulting from waste form-groundwater interactions, and

- Waste form water reactions that occur under hydraulically unsaturated conditions similar to those expected in the Hanford disposal-system environment.

The PUF tests are conducted at elevated temperatures that accelerate the rate of attack on the waste form to enable predictions of long-term releases using tests conducted over months or years. Correlations will be developed between PUF test results and those obtained from the simpler (and less expensive) PCT tests and SPFT tests. PUF tests require the use of expensive equipment and protocols that limit the number of tests that can be performed with available equipment.

\section{American Society for Testing Materials (ASTM)}

ASTM D6527 - ASTM test method D6527, Test Method for Determining Unsaturated and Saturated Hydraulic Conductivity in Porous Media by Steady-State Centrifugation, is useful for measuring the hydraulic conductivity of grout-based waste forms. It is useful in measuring hydraulic conductivity in unsaturated disposal sites such as exists in the Hanford vadose zone.

ASTM C39/C39M - ASTM C39/C39M, Standard Test Method for Compressive Strength of Cylindrical Concrete Specimens, is a test used to determine the compressive strength of cylindrical concrete specimens such as molded cylinders and drilled cores with densities in excess of $50 \mathrm{lb} / \mathrm{ft}^{3}\left[800 \mathrm{~kg} / \mathrm{m}^{3}\right]$. The test protocols are also used for the FBSR monolithic waste form.

American National Standards Institute (ANSI) /American National Standards (ANS)

ANSI/ANS 16.1 - ANSI/ANS 16.1, Measurement of the Leachability of Solidified Low-Level Radioactive Waste, leaching procedure is used to determine the concentration and to calculate the leach rate for $\mathrm{Tc}, \mathrm{U}, \mathrm{I}$, nitrate, nitrite, $\mathrm{Cr}$, and $\mathrm{Cs}$. This standard provides a uniform procedure to measure and index the release of radionuclides from waste forms as a result of leaching in demineralized water for five days (seven data points). The results can be interpreted to apply to specific environmental situations through correlative studies of actual disposal site conditions.

\subsubsection{Performance Objectives Used to Evaluate Performance Assessment Results}

The ILAW waste form selected for use must be evaluated in the IDF PA and be shown to be protective of human health and the environment. The PA will evaluate the first 10,000 years following IDF closure and will also identify the time and magnitude of maximum doses if those peaks occur after 10,000 years. From a practical point of view, however, predictions of waste form performance and the fate and transport of long-lived radionuclides (such as ${ }^{99} \mathrm{Tc},{ }^{129} \mathrm{I}$, and ${ }^{238} \mathrm{U}$ ) over tens of thousands of years are subject to a number of uncertainties. These include those associated with using accelerated testing techniques to predict long-term waste form performance, as well as those associated with uncertainties regarding the chain of events assumed to occur in performance assessments. The latter are illustrated in Figure 1-4, which is adapted from RPP-15834, Revision 0, Integrated Disposal Facility Risk Assessment. As such, the performance assessment does not make a prediction of what will occur, but rather, tests the durability and robustness of the waste form and waste disposal system to perform acceptably 
given the variety of conditions (uncertainties) that could exist over the long time frames considered.

\section{Figure 1-4. Eight Steps Assumed in Performance Assessment Groundwater Pathway Models}

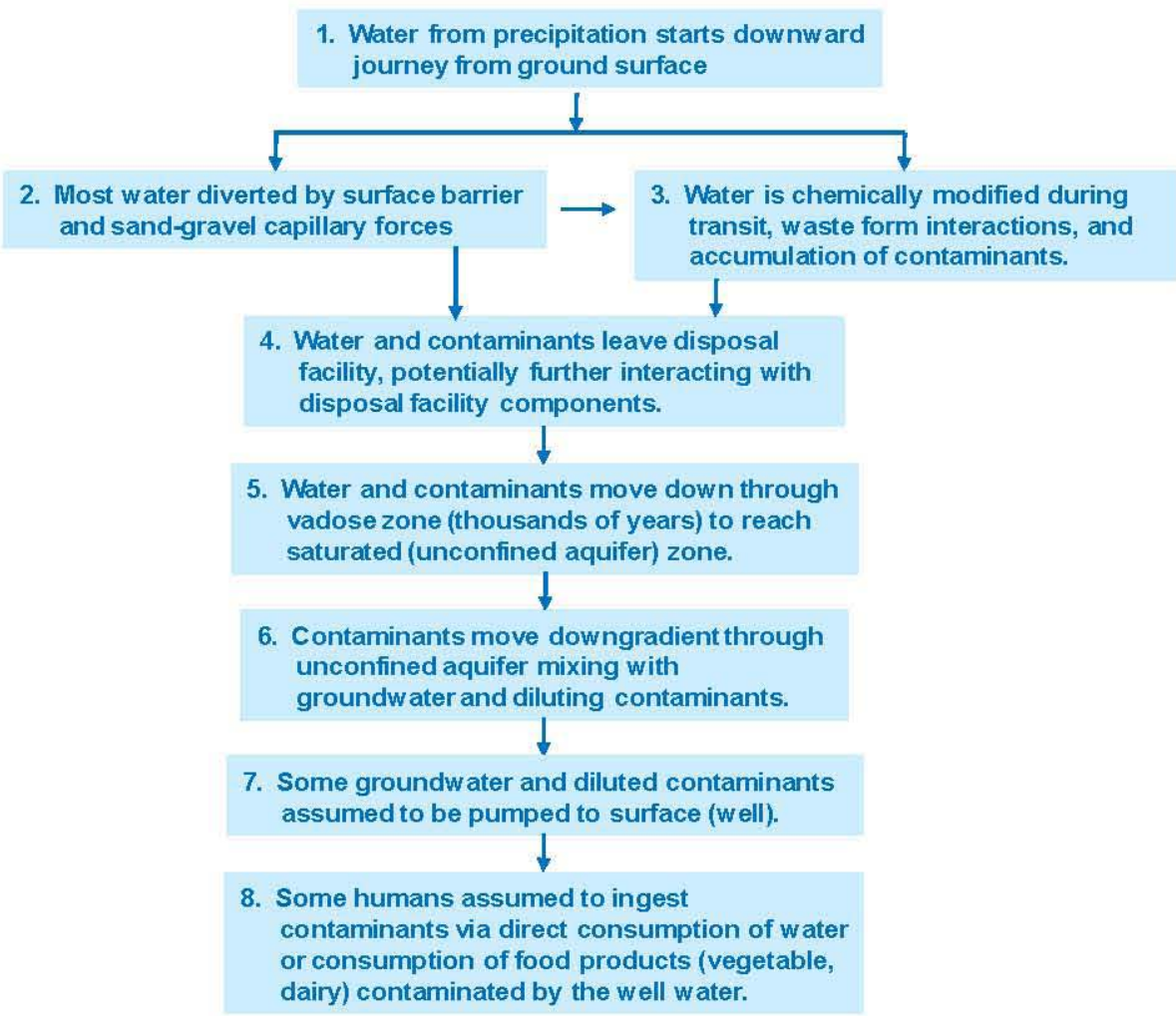

Such uncertainties include long-term climate changes that affect rainfall; long-term effectiveness of surface barriers that promote evaporation of precipitation over penetration into native soils; chemical reactions between the groundwater and soils and waste forms disposed of in the facility; influence of human-caused changes involving land use, technology, and current food chain-based predictive model applicability; and other currently unforeseen factors.

The PA analyses ultimately result in projections of doses to members of the public in close proximity to the disposal facility (e.g., drinking water or eating vegetables using water from a well adjacent to the disposal facility), lifetime cancer risks, and radionuclide concentrations; all of which are measured against established regulatory standards. The regulatory performance objectives or standards typically used are listed in Table 1-2 which was derived from RPP14283, Performance Objectives for Tank Farm Closure Performance Assessments. 
RPP-48935, Rev.0

Table 1-2. Key Performance Objectives for Performance Assessment

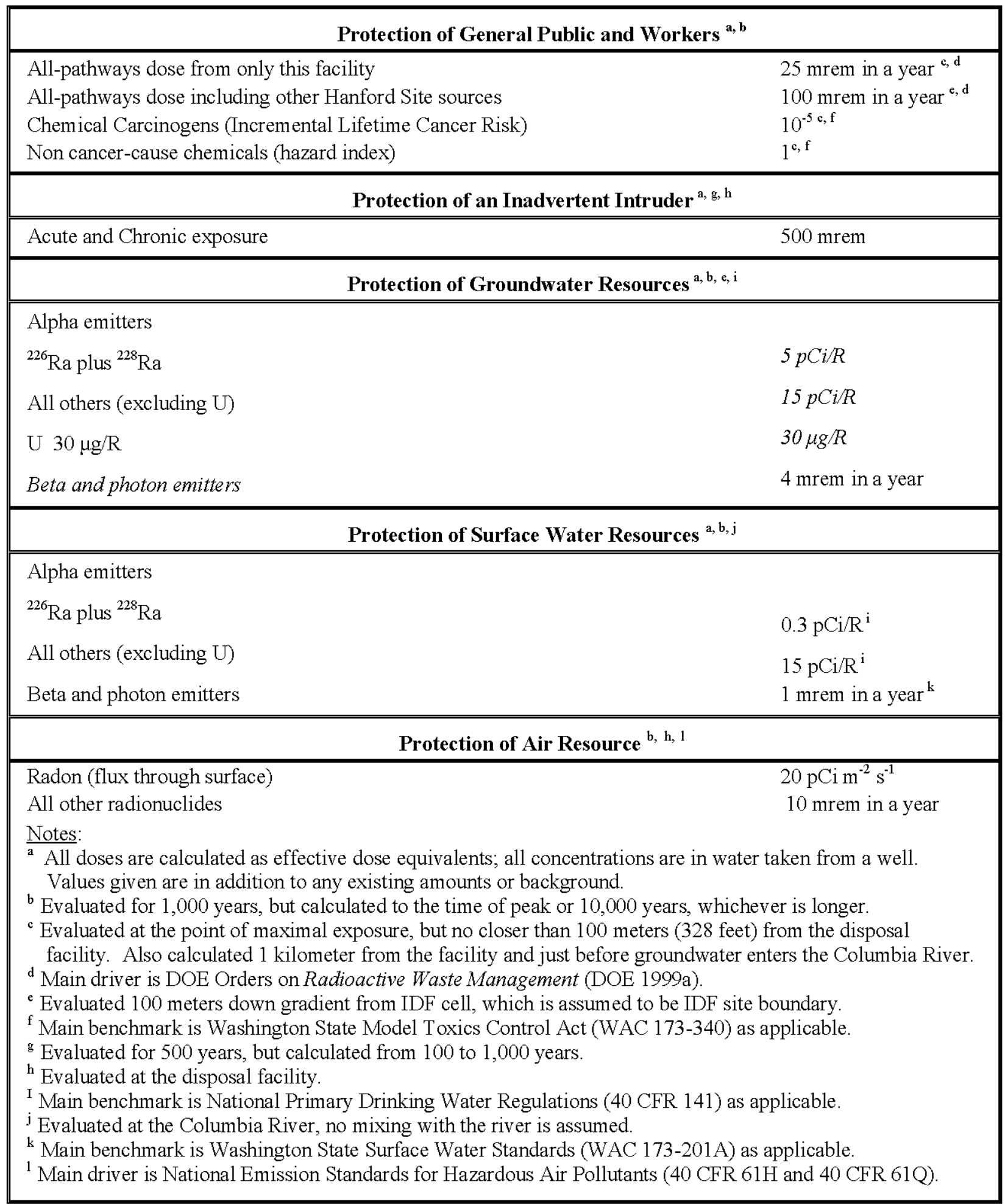




\subsection{DESIRED ATTRIBUTES OF SELECTED TECHNOLOGIES}

Any technology selected to immobilize Hanford LAW should have the following attributes:

- RCRA Compliant: Can be demonstrated to perform on an equivalent level to HLVIT standards under RCRA such that EPA DET approval is likely.

- Robust treatment: Ability to treat and immobilize the spectrum of LAW chemical and radioactive constituents anticipated to be in LAW feed.

- Operationally Stable: Minimal need for operator adjustments to system during operations for any given batch of feed.

- Predictable: Waste form performance characteristics can be adequately correlated to feed chemistry to support a Treatability Variance.

- Safe: Operationally reliable, stable, and predictable such that risks to operators, the public, and the environment are minimized.

- Durable waste form: Waste form controls release of radioactive and hazardous constituents to sufficiently low levels over sufficiently long time frames that projected impacts to human health and the environment are within applicable environmental regulatory standards.

- Cost Effective: Offers best value (capital and lifecycle costs) to the government considering whether the levels of performance, assurance, benefits, and risks inherent in the other parameters are listed above.

The remainder of this report is focused on the Second LAW technology and why it is being considered for use at Hanford for the treatment and immobilization of LAW. 
RPP-48935, Rev.0

\subsection{INTRODUCTION TO SECOND LAW VITRIFICATION}

The vitrification process is well defined and under full-scale implementation at the Hanford Site. This section will describe the vitrification process as it applies to Hanford's LAW immobilization project. The 2nd LAW Vitrification Facility is assumed to perform the same functions using the same processes as the Waste and Immobilization Treatment Plant (WTP) LAW Facility. More specific detail on specific unit operations can be found in 24590-WTPRPT-PT-02-005 Rev 5, "Flowsheet Bases, Assumptions, and Requirements".

\subsection{WHAT IS SECOND LAW VITRIFICATION?}

Vitrification is the process of converting a material into an amorphous solid glass material, usually achieved by cooling a liquid through the glass transition.

As a typical vitrified solution cools, its viscosity increases. However the increase in viscosity does not inhibit molecules from reaching a formation of lowest energy, typically a crystalline form. The crystalline form and solidification occur at the same time. In the case of glass, as the temperature (energy level) drops and viscosity increases, the network of compounds is essentially locked into place before a crystalline form is reached.

The vitrification process uses heat to decompose waste into elemental oxides that dissolve into a glass pool. As the glass cools, it passes through its glass transition temperature (Tg) where the physical characteristics of the material change from rubbery (able to have some amount of physical change imparted on it without fracture) to a glass (hard, brittle substance where largescale molecular motion is not possible due to the high viscosity of the oxide matrix). As an amorphous solid, glass is neither a solid nor a liquid. Liquids and glasses do not have molecular order, while crystalline structures such as salt, sugar, or quartz do have order. The molecular structure of glass is more organized than that found in liquids. Glass structures are organized over short ranges and disorganized over longer ranges. Like liquids, the disorganized solids in glass can flow, but unlike liquids the flow is very slow. With time, the molecules making up glass will shift themselves into a more stable, crystal-like formation. The closer the glass is to its glass transition temperature, the quicker glass will move towards a crystal-like formation. As the glass is cooled farther and farther from its glass transition temperature, the more it behaves as a solid.

In Figure 2-1 the example of glass shows the incorporation of non-bridging oxygen into the matrix as negative $(-)$ anions and metals shown as $(+)$ or $(++)$ cations. Network formers are shown in blue. Silicon and boron are examples of network formers. They form the backbone of the glass and become located in the center of oxygen polyhedral in the configuration to tetrahedra, or tetrahedra and triangles. These tetrahedral are then tied together by sharing corners, which make up the framework of the random network structure of the solid waste glass form. Intermediates such as alumina and iron ( $\mathrm{Fe}$ ) can replace network formers and still maintain the framework structure of the glass. Intermediates typically create singly bonded oxygen ions (non-bridging oxygen atoms) that attract cations for charge neutrality. Network modifiers are generally part of the alkali and alkali earth constituents. Modifiers are located within the holes of the random network structure. Modifiers can associate with nearby singly bonded oxygen ions. 
Figure 2-1. Examples of Crystalline and Glass Matric es.

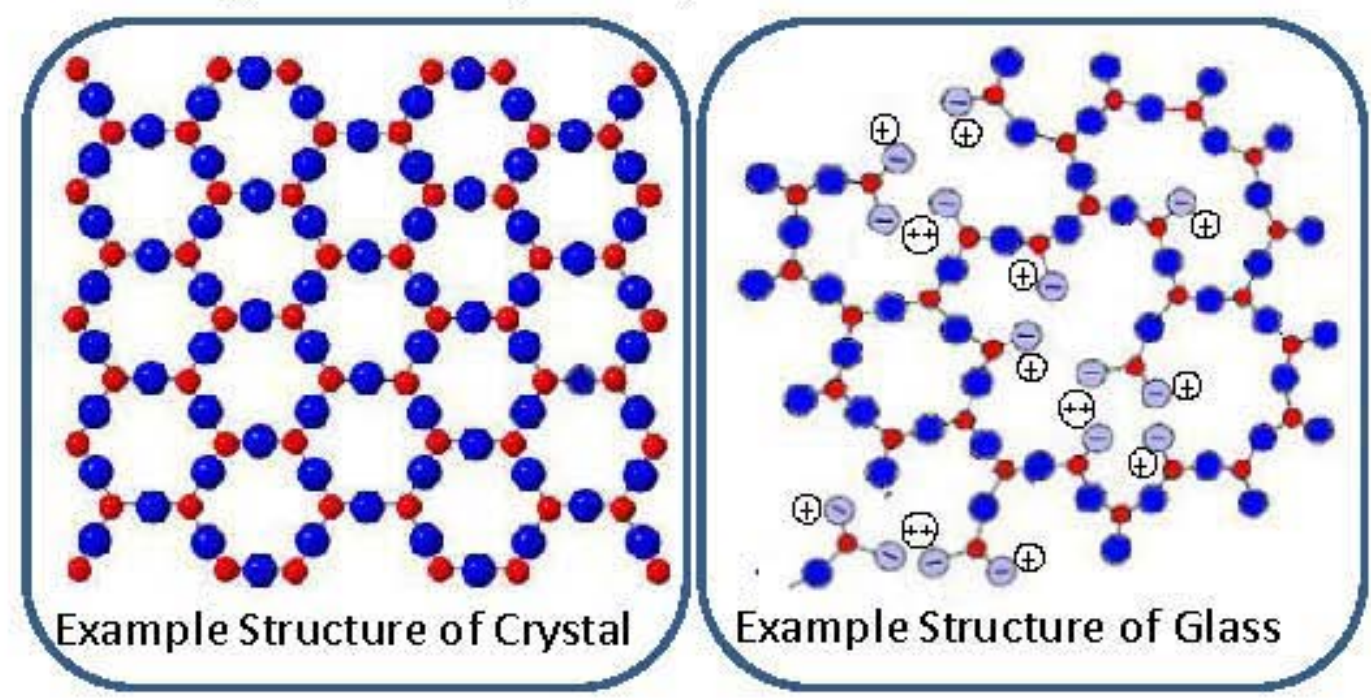

Both glass and waste glass components become an integral part of the random network structure of the glass. Components are incorporated by primary and/or secondary bonding, which helps explain why the glass is resistant to leaching.

\subsection{WHY IS SECOND LAW BEING EVALUATED FOR POSSIBLE USE AT HANFORD?}

All production-scale vitrification efforts within DOE have been implemented with joule-heated melters. Joule-heated melting technology is mature and has been successfully applied in both the commercial glass-making industry and the DOE complex. At the Defense Waste Processing Facility (DWPF) alone, more than 3,000 canisters of immobilized, vitrified waste have been produced.

The joule-heated ceramic melter (JHCM) technology has already been chosen as the immobilization technology for approximately $40 \%$ of Hanford's LAW. Construction of the WTP LAW Vitrification facility is nearly complete. The glass waste form offers excellent immobilization effectiveness.

\subsection{HOW DOES THE SECOND LAW VITRIFICATION PROCESS WORK?}

There are many different vitrification technologies available. The main difference between the technologies is the method of heating the glass formers. As the primary technology employed by $\mathrm{DOE}$ for radioactive waste treatment, the JHCM vitrification process is very well developed. Therefore, a good system overview with unit operations is possible. This section outlines the proposed $2^{\text {nd }}$ LAW Vitrification facility based on WPT LAW design and process flow. The process flow starts with single-shell tank (SST) and double-shell tank (DST) waste treated to meet LAW specifications, and proceeds through the unit operations required to support the melter operation; that is, feed preparation, melter operation, vitrified product, off-gas, and secondary liquid effluent.

The process has been divided into three sections. The first section is waste feed preparation, the second is the melter and product form ation, and the third is secondary waste streams treatment. 
The WTP LAW melters are configured in parallel lines with most unit operations supporting just one melter. Many of the unit operations are arranged in parallel to have redundancy. Most of the information provided is from WTP-RPT-PT-02-005 Rev 5; and 24590-LAW-RPT-RT-04003 Rev 0, "Preliminary ILAW Formulation Algorithm Description".

\subsubsection{Waste Feed Preparation}

Simply adding the waste into a joule-heated melter would result in the creation of what glass scientists call goop or a glob. The formation of globs would be the result of having waste elements in the wrong molecular form and the lack of enough network formers in the melt to form glass. Waste feed preparation steps ensure that product coming out of the melter meets the waste form characteristics required by the repository.

The LAW concentrate receipt and feed preparation processes store, sample, blend with glass formers, and then feed the LAW to the melter. The LAW melter feed system ensures feed is available to all LAW melters at all times. Feed preparation tanks are not capable of heating or cooling LAW or the feed. See Figure 2-2 for a simple flow schematic of the melter feed preparation system.

Figure 2-2. Melter Feed Preparation.

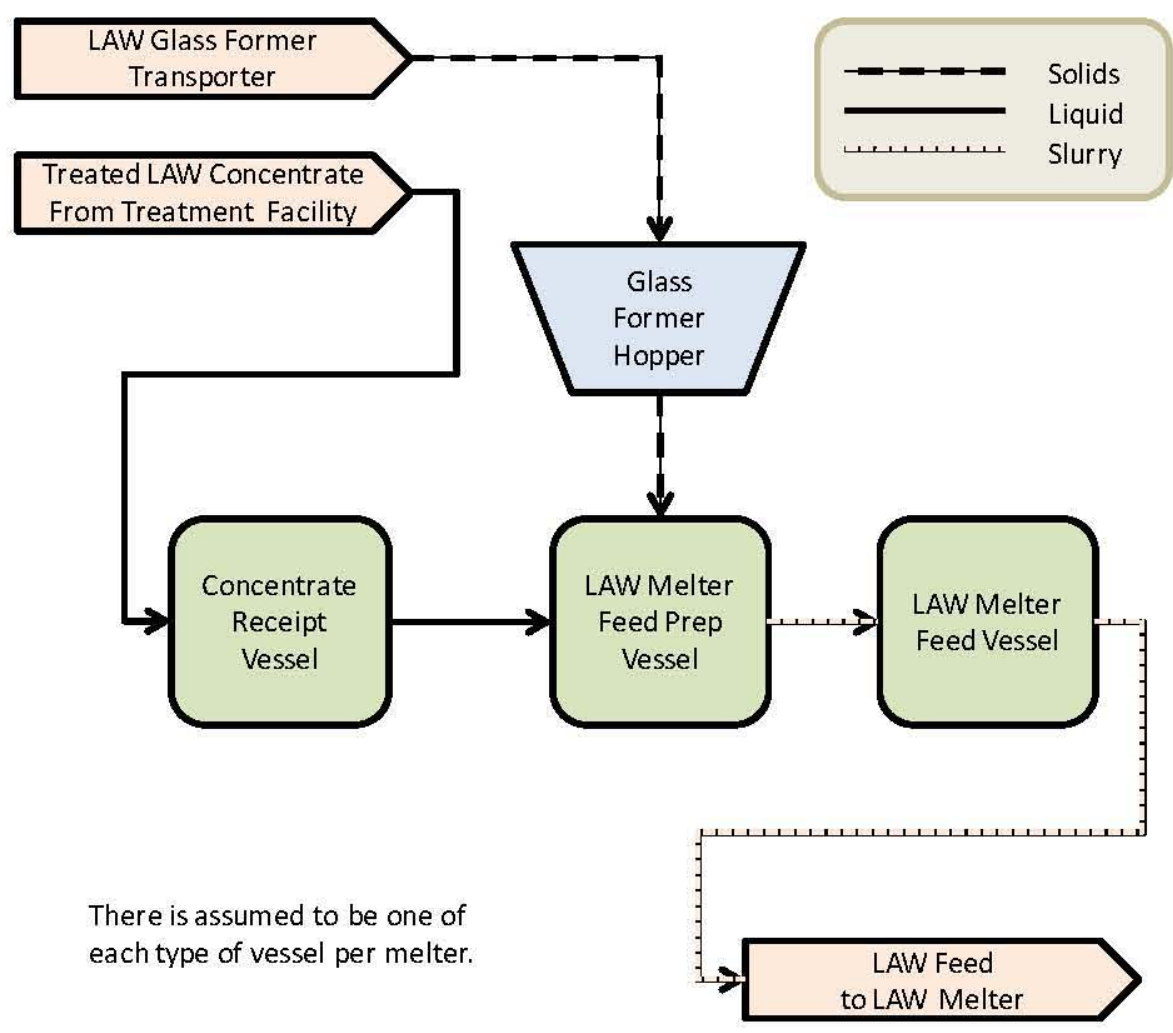

\subsubsection{Receipt Vessel and Glass Formulation}

The waste is transferred from the pretreatment facilities concentrate storage vessel to the melter's concentrate receipt vessel (CRV). Ideally feed from treatment is as concentrated as possible upon delivery to the vessel to reduce the number of waste sampling and waste feed 
formulations. The glass formulation takes into account the LAW feed in the CRV, the heel in the melter feed preparation vessel (MFPV), and the makeup of the glass formers and reagents added.

\subsubsection{Glass Formulation}

The glass product is dependent upon the composition of the feed into the melter and conditions within the melter (e.g., temperature and cold cap thickness). This section will focus on the composition of the feed. The types and methods for formulating glass for the $2^{\text {nd }}$ LAW facility are assumed very similar to those used by the WTP LAW Vitrification facility. The WTP LAW facility uses 24590-LAW-RPT-RT-04-0003, Rev 0, Preliminary ILAW Formulation Algorithm Description to document the algorithm to be used by batching LAW and glass-forming chemicals (GFCs) in the MFPV.

The algorithm was developed by interpolation of 15 successful glass compositions, which meet all WTP contractual requirements. Vitreous State Laboratory (VSL) formulated the compositions for the immobilization of a full range of Hanford LAW streams. Each glass met all quality requirements and process constraints in Table $2-1$, and was successfully produced at increasing scales up to pilot scale.

Table 2-1. Summary of WTP LAW Feed, Melt, and Glass Constraints

\begin{tabular}{|c|c|c|}
\hline Constraint Description & Value/Range & Reference \\
\hline $\begin{array}{l}\text { Product consistency test }\left(\mathrm{P}^{\prime} \mathrm{C}^{\prime} \mathrm{l}\right) \text { normalized } \\
\text { releases of } \mathrm{Na}, \mathrm{B} \text {, and } \mathrm{Si}\end{array}$ & $r_{i}<2\left(\mathrm{~g} / \mathrm{m}^{2}\right)($ for $i=\mathrm{Na}, \mathrm{B}$, and $\mathrm{Si})$ & DOE 2000 \\
\hline Vapor hydration test (VHT) $200^{\circ} \mathrm{C}$ alteration rate & $r_{V}<50\left(\mathrm{~g} / \mathrm{m}^{2} / \mathrm{d}\right)$ & DOE 2000 \\
\hline Waste classification & $<$ Class C limits & DOE 2000 \\
\hline${ }^{90} \mathrm{Sr}$ concentration & $R_{i,{ }^{90} \mathrm{Sr} r}^{\text {Volume }}<20\left(\mathrm{Ci} / \mathrm{m}^{3}\right)$ & DOE 2000 \\
\hline${ }^{137} \mathrm{Cs}$ concentration (waste form compliance) & $R_{i,{ }^{137} \mathrm{Cs}}^{\text {Volmue }}<3\left(\mathrm{Ci} / \mathrm{m}^{3}\right)$ & DOE 2000 \\
\hline${ }^{137} \mathrm{Cs}$ concentration (system maintenance) & $R_{i, 1,37}^{\text {Volume }} \mathrm{Cs}<0.3\left(\mathrm{Ci} / \mathrm{m}^{3}\right)$ & DOE 2000 \\
\hline Waste loading (wt $\%$ waste $\mathrm{Na}_{2} \mathrm{O}$ in glass) & $\begin{array}{l}W_{N a} \geq 14(\mathrm{wt} \%), 3,10 \text { for envelopes } \\
\mathrm{A}, \mathrm{B}, \text { and C I AW, respectively }\end{array}$ & DOE 2000 \\
\hline Viscosity at $1150^{\circ} \mathrm{C}$ & $20 \leq \eta_{115 n}(\mathrm{P}) \leq 80$ & Muller (2005) \\
\hline Viscosity at $1100^{\circ} \mathrm{C}$ & $10 \leq \eta_{\ln n}(\mathrm{P}) \leq 150$ & Wilson (2004) \\
\hline Electrical conductivity at 1100 to $1200^{\circ} \mathrm{C}$ & $0.1 \leq \varepsilon_{1100}(\mathrm{~S} / \mathrm{cm}), \varepsilon_{1200}(\mathrm{~S} / \mathrm{cm}) \leq 0.7$ & Wilson (2004) \\
\hline$\Lambda$ gitated melter feed yield stress & $\mathrm{Y}_{\mathrm{S}} \leq 15(\mathrm{~Pa})$ & Poloski et al. (2004) \\
\hline$\Lambda$ gitated melter feed consistency & $\eta_{f} \leq 90(\mathrm{mPa} \cdot \mathrm{s})$ & Poloski et al. (2004) \\
\hline Refractory corrosion rate & $<6$ (inches $/ 5 \mathrm{y}$ ) & Wilson (2004) \\
\hline Refractory corrosion mechanism & no spallation $-\mathrm{Li}_{2} \mathrm{O}<4.5(\mathrm{wl} . \%)$ & Muller et al. (2002) \\
\hline Specific melting rate & $\geq 1.5\left(\mathrm{MTg} / \mathrm{m}^{2} / \mathrm{d}\right)$ & Wilson (2004) \\
\hline
\end{tabular}

Table 2. Summary of LAW Melter Feed, Melt, and Glass Constraints

24590-LAW-RPT-RT-04-0003, Rev 0, Preliminary ILAW Formulation Algorithm Description

The key parameters for the glass formulation method include the mass fractions of sodium oxide $\left(\mathrm{Na}_{2} \mathrm{O}\right)$, sulfur trioxide $\left(\mathrm{SO}_{3}\right)$, and potassium oxide $\left(\mathrm{K}_{2} \mathrm{O}\right)$ in the CRV (represented as $\mathrm{g}_{\mathrm{ij}}{ }^{C R V}$ for $j$ $=\mathrm{Na}_{2} \mathrm{O}, \mathrm{SO}_{3}$, and $\mathrm{K}_{2} \mathrm{O}$ in Figure 2-3). The first step in this process is determining the 
acceptable concentration of $\mathrm{Na}_{2} \mathrm{O}$ in the final glass by the following rules (which are depicted graphically in Figure 2-3):

1. $\mathrm{Na}_{2} \mathrm{O}$ must be at or below $21 \%$ in glass;

2. $\mathrm{Na}_{2} \mathrm{O}$ plus 0.66 times $\mathrm{K}_{2} \mathrm{O}$ must be at or below $21.5 \%$ in glass. (The application of the 0.66 scale factor for potassium is to adjust for differences in molecular masses of $\mathrm{Na}_{2} \mathrm{O}$ and $\mathrm{K}_{2} \mathrm{O}$.);

3. $\mathrm{Na}_{2} \mathrm{O}$ must be at or below the value of $35.875 \%$ minus $42.5 \% \mathrm{SO}_{3}$ in glass;

4. $\mathrm{SO}_{3}$ must be at or below $0.77 \%$ in glass.

Figure 2-3. Graph of Rules for Waste Loading as a Function of SO3 and Na2O

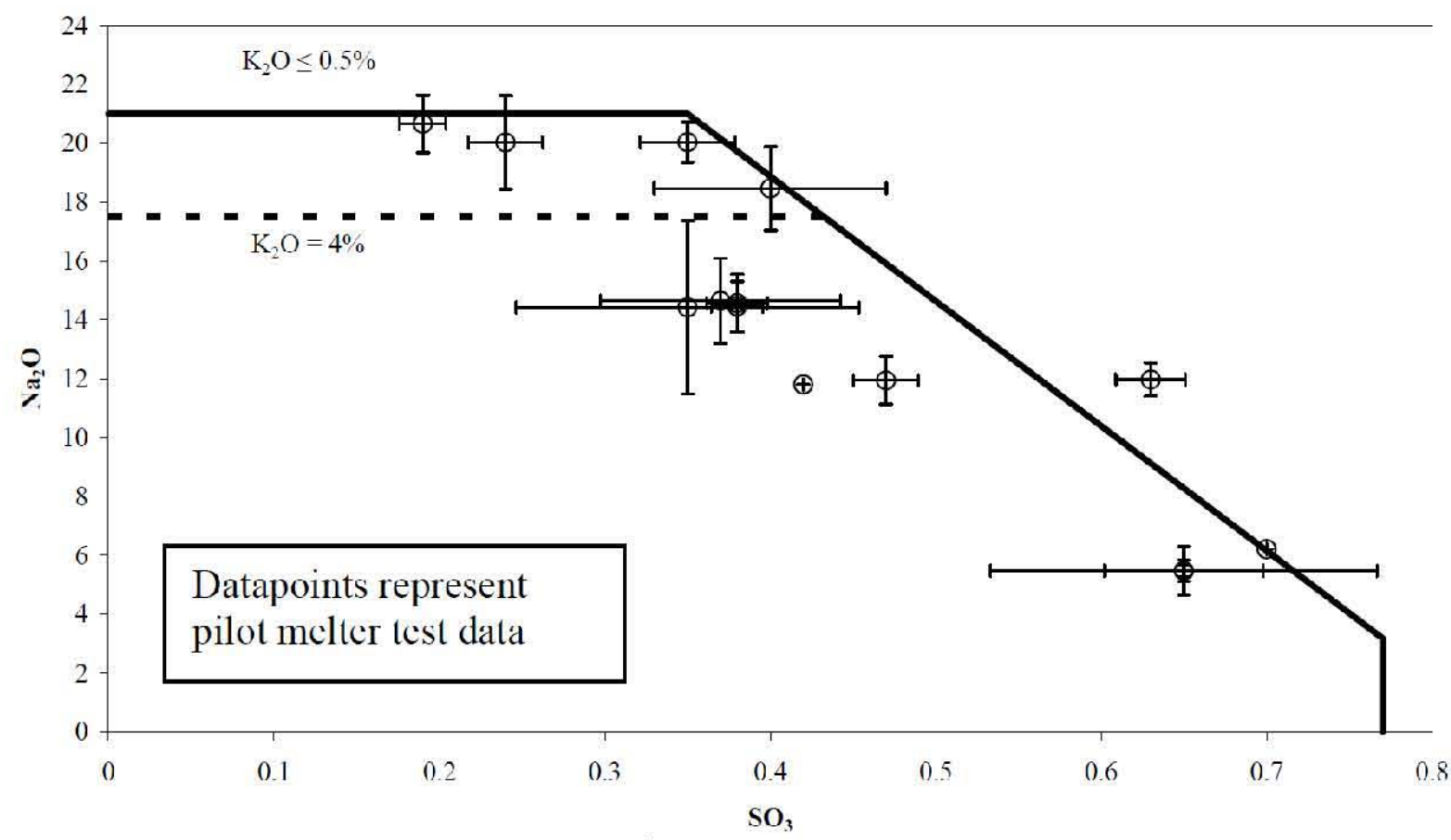

Figure 3. Schematic of Rules for $\mathrm{g}_{i, \text { Initial }}$ as a Function of $\mathrm{SO}_{3}$ (in $\mathrm{w} \mathrm{t} \%$ ) from:

24590-LAW-RPT-RT-04-0003, Rev 0, Preliminary ILAW Formulation Algorithm Description

The $\mathrm{Na}$ loading equation assumes that no other component (besides $\mathrm{Na}_{2} \mathrm{O}, \mathrm{K}_{2} \mathrm{O}$, and $/$ or $\mathrm{SO}_{3}$ ) will limit the loading of LAW in glass. If additional compositional constraints (e.g., radionuclides, phosphate, or fluorine (F) are found to limit the loading of a particular LAW batch, additional rules will be added. The target waste loading is defined as the mass fraction glass that originated from the material in the CRV.

The algorithm uses the sample results of the LAW feed as mixed with the previous heel in the CRV, the volume of the heel and composition of the MFPV) (previous batch), and the compositions of individual GFCs.

Using the inputs stated above, the algorithm determines the process component additions of the LAW from the CRV, dilution water, and mass of each GFC to be mixed in the melter feed hopper (MFH) and then added to the MFPV. The algorithm also estimates the ILAW composition and glass properties for batches to be produced from the resulting feed. 
The goal of the algorithm is not to maximize waste loading, but rather target a high waste loading while ensuring process stability. Many important glass modifiers are held at a constant concentration for all glass formulations (the targeted weight percent is shown in brackets):

- Aluminum oxide, $\mathrm{Al}_{2} \mathrm{O}_{3}[6.1]$

- Boron trioxide, $\mathrm{B}_{2} \mathrm{O}_{3}[10]$

- Iron III oxide, $\mathrm{Fe}_{2} \mathrm{O}_{3}$ [5.5]

- Titanium oxide, $\mathrm{TiO}_{2}[1.4]$

- Zinc oxide, $\mathrm{ZnO}[3.5]$; and

- Zirconium oxide, $\mathrm{ZrO}_{2}[3]$;

Holding these components constant allows the facility to maintain waste loading at or above contract requirements, while ensuring the composition of the glass exiting the melter will meet ILAW disposal requirements.

\subsubsection{LAW Feed by Component}

The behavior of LAW feed components in the melter are outlined in this section. Table 2-2 is a quick reference for understanding the impact of a feed component on vitrified LAW.

Table 2-2. Glass Component Properties

\begin{tabular}{|c|c|c|c|}
\hline COMPONENT & ADDED AS & PROCESSING EFFECTS & $\begin{array}{l}\text { PRODUCT } \\
\text { PERFORMANCE }\end{array}$ \\
\hline $\mathrm{SiO}_{2}$ & $\begin{array}{l}\text { Silica } \\
\left(\mathrm{SiO}_{2}\right)\end{array}$ & $\begin{array}{l}\text { Increases viscosity greatly, reduces waste } \\
\text { solubility }\end{array}$ & Increases durability \\
\hline $\mathrm{B}_{2} \mathrm{O}_{3}$ & $\begin{array}{l}\text { Boric acid } \\
\left(\mathrm{H}_{3} \mathrm{BO}_{3}\right)\end{array}$ & $\begin{array}{l}\text { Reduces viscosity; increases waste } \\
\text { solubility; form chosen over borax } \\
\left(\mathrm{Na}_{2} \mathrm{~B}_{4} \mathrm{O}_{7}\right) \text { to limit the addition of } \mathrm{Na}\end{array}$ & $\begin{array}{l}\text { Increases durability in low } \\
\text { amounts, reduces } \\
\text { durability in large } \\
\text { amounts }\end{array}$ \\
\hline $\mathrm{Na}_{2} \mathrm{O}$ & $\begin{array}{l}\text { Sodium Carbonate } \\
\mathrm{Na}_{2} \mathrm{CO}_{3}\end{array}$ & $\begin{array}{l}\text { Reduces viscosity and resistivity; increases } \\
\text { waste solubility }\end{array}$ & Reduces durability \\
\hline $\mathrm{Li}_{2} \mathrm{O}$ & $\begin{array}{l}\text { Lithium carbonate } \\
\left(\mathrm{Li}_{2} \mathrm{CO}_{3}\right)\end{array}$ & $\begin{array}{l}\mathrm{Same} \text { as } \mathrm{Na}_{2} \mathrm{O} \text { but to a greater affect; } \\
\text { increases tendency to devitrify; increases } \\
\text { sulfate incorporation; accelerates corrosion } \\
\text { of melter refractory }\end{array}$ & $\begin{array}{l}\text { Reduces durability, but to } \\
\text { a lesser extent than } \mathrm{Na}_{2} \mathrm{O}\end{array}$ \\
\hline $\mathrm{K}_{2} \mathrm{O}$ & N/A & $\begin{array}{l}\text { Same as } \mathrm{Na}_{2} \mathrm{O} \text { but to a greater affect; } \\
\text { decreases tendency to devitrify }\end{array}$ & $\begin{array}{l}\text { Reduces durability more } \\
\text { than } \mathrm{Na}_{2} \mathrm{O}\end{array}$ \\
\hline $\mathrm{CaO}$ & $\begin{array}{l}\text { Wollastonite } \\
\left(\mathrm{CaSiO}_{3}\right)\end{array}$ & $\begin{array}{l}\text { Increases then reduces viscosity and waste } \\
\text { solubility }\end{array}$ & $\begin{array}{l}\text { Increases, then reduces } \\
\text { durability }\end{array}$ \\
\hline $\mathrm{MgO}$ & $\begin{array}{l}\text { Forsterite olivine } \\
\left(\mathrm{Mg}_{2} \mathrm{SiO}_{4}-\mathrm{Fe}_{2} \mathrm{SiO}_{4}\right)\end{array}$ & $\begin{array}{l}\text { Same as } \mathrm{CaO} \text {; reduces tendency to vitrify; } \\
\text { increases sulfate incorporation into glass }\end{array}$ & $\begin{array}{l}\text { Increases, then reduces } \\
\text { durability; more likely to } \\
\text { decrease durability than } \\
\mathrm{CaO}\end{array}$ \\
\hline $\mathrm{TiO}_{2}$ & Rutile $\left(\mathrm{TiO}_{2}\right)$ & $\begin{array}{l}\text { Reduces viscosity slightly; increases then } \\
\text { reduces waste solubility; increases tendency }\end{array}$ & $\begin{array}{l}\text { Increases durability, } \\
\text { especially relative to acids }\end{array}$ \\
\hline
\end{tabular}


RPP-48935, Rev.0

\begin{tabular}{|c|c|c|c|}
\hline COMPONENT & ADDED AS & PROCESSING EFFECTS & $\begin{array}{l}\text { PRODUCT } \\
\text { PERFORMANCE }\end{array}$ \\
\hline & & to devitrify & \\
\hline $\mathrm{ZnO}$ & $\begin{array}{l}\text { Zinc oxide } \\
(\mathrm{ZnO})\end{array}$ & Reduces corrosion of the melter refractory & Increases durability \\
\hline $\mathrm{ZrO}_{2}$ & $\begin{array}{l}\text { Zircon } \\
\left(\mathrm{ZrSiO}_{4}\right)\end{array}$ & Reduces waste solubility & $\begin{array}{l}\text { Increases durability } \\
\text { greatly }\end{array}$ \\
\hline $\mathrm{Al}_{2} \mathrm{O}_{3}$ & $\begin{array}{l}\text { Kyanite } \\
\left(\mathrm{Al}_{2} \mathrm{SiO}_{5}\right)\end{array}$ & $\begin{array}{l}\text { Increases viscosity and has the tendency to } \\
\text { devitrify }\end{array}$ & Increases durability \\
\hline $\mathrm{Fe}_{2} \mathrm{O}_{3}$ & $\begin{array}{l}\text { Hematite } \\
\left(\mathrm{Fe}_{2} \mathrm{O}_{3}\right)\end{array}$ & $\begin{array}{l}\text { Does not increase viscosity; difficult to } \\
\text { dissolve; increases likelihood of foam } \\
\text { formation; increases likelihood of crystal } \\
\text { formations }\end{array}$ & Increases durability \\
\hline $\mathrm{NiO}$ & N/A & $\begin{array}{l}\text { Is hard to dissolve; increases tendency to } \\
\text { devitrify }\end{array}$ & Reduces durability \\
\hline $\mathrm{MnO}$ & N/A & Is hard to dissolve & Increases durability \\
\hline Zeolite & $\begin{array}{l}\text { N/A (Al silicates of } \\
\mathrm{Ca}, \mathrm{Na} \text {, or } \mathrm{K})\end{array}$ & Is slow to dissolve; produces foam & Increases durability \\
\hline Sugar & $\begin{array}{l}\text { Sucrose } \\
\left(\mathrm{C}_{12} \mathrm{H}_{22} \mathrm{O}_{11}\right)\end{array}$ & Inexpensive reducer; adds heat to cold cap & Not applicable. \\
\hline Sulfate & N/A & $\begin{array}{l}\text { Increases corrosion of processing } \\
\text { equipment; solubility into glass increases as } \\
\text { alkali and alkali-earth concentrations } \\
\text { increase }\end{array}$ & $\begin{array}{l}\text { Too much causes foam or } \\
\text { a formation of a soluble } \\
\text { second phase }\end{array}$ \\
\hline
\end{tabular}

Note: Components having "N/A" in the ADDED AS column are not added to LAW feed, but are part of the LAW portion of the waste feed and important glass considerations.

\section{Metal Oxides}

Most of the metals in LAW feed are in the form of hydroxides (the result of using $\mathrm{NaOH}$ as a corrosion inhibitor for the carbon steel SSTs and DTSs). As metal hydroxides and complexed metals make their way through the cold-cap to the melt, most are destroyed, forming metal oxides. Almost all of the metal oxide enters the molten glass pool and leaves as glass product. A very small amount is lost to the melter off-gas stream as particulates. These metal oxides are partitioned in accordance with an empirically determined, unit less, decontamination factor (DF).

If the melter is operated in an over-reducing environment the result can lead to foaming and molten metal accumulation in the bottom of the melter, refractory damage, and shorting of the melter current. A good indication of the oxidation state of the melt is to track the $\mathrm{Fe}^{++} / \mathrm{Fe}_{\text {total }}$ ratio. Since the desired oxide for iron is $\mathrm{Fe}_{2} \mathrm{O}_{3}$ (with $\mathrm{Fe}$ in the $3+$ oxidation state) the goal is to keep the $\mathrm{Fe}^{++} / \mathrm{Fe}_{\text {total }}$ low.

\section{Sulfates and Sulfites}

Sulfates are either destroyed in the cold-cap to produce metal oxides that are absorbed by the glass pool or released as gaseous $\mathrm{SOx}$ (mainly sulfur dioxide, $\mathrm{SO}_{2}$ ) into the plenum (PNNL- 


$$
\text { RPP-48935, Rev.0 }
$$

14649, Preliminary Investigation of Sulfur Loading in Hanford LAW Glass, 2004). The redox conditions of the borosilicate waste glass melt affect the final distribution of sulfur.

Sulfur exists as sulfate in glass and is surrounded by alkali and alkaline earth cations. Sulfate decreases the interaction of $\mathrm{Na}$ with the silica in the glass, which in turn increases the polymerization of the glass (24590-WTP-RPT-PT-02-005, Rev 5).

If the sulfate limit of a borosilicate glass is exceeded, the sulfate can form water-soluble secondary phases and/or a molten salt layer on the melt pool surface. These sulfate salts, which are soluble, can impact radionuclide release from the cooled glass, if they are present as inclusions or a frozen gall layer. The alkali and alkaline earth sulfate salts, in conjunction with alkali chlorides, can collect on the melt surface as a low melting $\left(600-800^{\circ} \mathrm{C}\right)$, low density, and low viscosity melt phase. At moderate concentrations, the salts have a beneficial effect on melting rates. At excessively high feed concentrations, molten alkali sulfates float on the surface of the melt pool or become trapped as inclusions in the glass (WSRC-MS-2004-00290, Rev. 0, Dependency of Sulfate Solubility on Melt Composition and Melt Polymerization (U))

\section{Halides}

The acid gases behave like the sulfate. Some are expected to form acid gases and salt particulates. iodine (I), is also expected to form elemental I gas.

Most of the chlorine ( $\mathrm{Cl}$ ) and fluorine $\mathrm{F}$ are emitted from the melter as gaseous species (e.g., $\mathrm{HCl}, \mathrm{HF}$ ). The gaseous species of these two elements is primarily hydrofluoric acid (HF) and Hydrochloric acid $(\mathrm{HCl})$, though some chlorine is frequently detected. Essentially $100 \%$ of the I emitted from the melter is as a gas.

\section{Nitrates, Nitrites, and Ammonia}

Many of the metals and compounds in the LAW are in the form of nitrates and nitrites. Nitrogen oxide gases are generated during vitrification from the decomposition of nitrates and nitrites in the feed as they react with a reducing agent (carbon-based molecule such as sucrose). Test data has shown that an average of $63 \%(39 \%$ to $100 \%)$ of the feed nitrogen oxides are released as NOx. The majority of the NOx leaving the melter gases is NO. The use of sugar as a reducing agent leads to the conversion of some nitrates and nitrites to $\mathrm{NH}_{3}$ and $\mathrm{HCN}$ in the offgas. Although the relative amounts of the production of these compounds are small, $\mathrm{NH}_{3}$ is important for Submerged Bed Scrubber (SBS) neutralization.

\section{Carbonates}

Carbonates react with the reducing agent, sugar, to form oxides, carbon monoxide (CO), and carbon dioxide $\mathrm{CO}_{2}$.

\section{Reducers}

Sugar is used as a reductant in the melter. Sugar has been added during the Research \& Testing development efforts at the $\mathrm{VSL}^{7}$ and Duratek ${ }^{8}$.

\footnotetext{
${ }^{7}$ The Vitreous State Laboratory is part of Catholic University in Washington, DC

${ }^{8}$ Duratek, Inc. of Columbia, Maryland is a wholly owned business unit of Energy Solutions of Salt Lake City, Utah.
} 
Organics present in the feed are mainly in the form of complexants that were used in the Hanford process for separation of species or decomposition products of these complexants. These compounds include ethylenediamine tetra-acetic acid (EDTA), N-(2-hydroxyethyl) ethylenediamine tri-acetic acid (HEDTA), acetate, formate, oxalate, and other organics. These organics were evaluated to determine the effectiveness of each as a reductant (24590-101-TSAW000-0009-98-00008, Rev 00A, Compositional Variation Tests on DuraMelter 100 with LAW SubEnvelope C2 Feed in Support of LAW Pilot Melter). Results showed that sugar was the most effective reductant. Sugar was the only organic compound that was effective in increasing the partitioning of sulfur from the glass to the exhaust stream. Sugar was also the only organic compound that increased the amount of reduced iron in the glass and the only organic compound to reduce iodine emissions.

\section{Radionuclides}

Radionuclides follow their non-radionuclide components, if present. For example, all Carbon$14\left({ }^{14} \mathrm{C}\right)$ forms carbon dioxide $\left({ }^{14} \mathrm{CO}_{2}\right)$ in the melter, so ${ }^{14} \mathrm{C}$ follows $\mathrm{CO}_{2}$ in the off-gas system and cesium-134 $\left({ }^{134} \mathrm{Cs}\right)$ and cesium-137 $\left({ }^{137} \mathrm{Cs}\right)$ exhibit the same DF factors in the meter as cesium (Cs).

\section{Technetium}

The capture of technetium (Tc) is critical to the success of any waste form chosen for ILAW. The concentration of Tc in LAW ranges on the order of one to five parts per million (ppm). Melter tests show Tc retention in Hanford's LAW ranging from $<20 \%$ to $>50 \%$, with the nominal range from $30 \%$ to $40 \%$. Work is ongoing to improve first pass retention of Tc in LAW glasses (VSL-10R1920-1, Improving Technetium Retention in Hanford LAW Glass - Phase 1, January 14, 2010).

Technetium can exist in valence states from $2+$ through +7 , but prefers valence states +4 and +7 . Technetium in Hanford's LAW is predominately in the +7 oxidation state. The oxides of these two states have very different boiling points. The +7 valence state oxide, ditechnetium heptoxide $\left(\mathrm{Tc}_{2} \mathrm{O}_{7}\right)$, boils at $311^{\circ} \mathrm{C}\left(592^{\circ} \mathrm{F}\right)$, while the +4 valence state oxide, technetium oxide $\left(\mathrm{TcO}_{2}\right)$, sublimes at $900^{\circ} \mathrm{C}\left(1,650^{\circ} \mathrm{F}\right)$ (VSL-10R1920-1).

The differences in the properties of these oxides, along with test results of Tc concentrations in off-gas, help explain the reactions in the cold-cap. As LAW feed enters the melter and is distributed onto the cold-cap, compounds containing Tc are first reduced and then oxidized. If the cold-cap is thin, the temperature gradient across it is small (i.e., the surface temperature of the cold-cap is higher and closer to the melt temperature) and there is little time for $\mathrm{Tc}^{7+}$ to be reduced to $\mathrm{Tc}^{4+}$. As a result, the $\mathrm{Tc}_{2} \mathrm{O}_{7}$ oxide forms and volatilizes to the off-gas system. If the cold-cap is thick, its surface temperature is lower, allowing reducing reactions to occur and formation of $\mathrm{TcO}_{2}$, which is incorporated into the melt.

Another cold-cap reaction of $\mathrm{Tc}$ is the formation of cesium pertechnetate, $\mathrm{CsTcO}_{4}$, which increases the volatility of $\mathrm{Cs}$, and therefore of ${ }^{134} \mathrm{Cs}$ and ${ }^{137} \mathrm{Cs}$. The reaction is rate-limited by the concentrations of both species in the cold-cap. Due to the very low concentration of Cs (LAW is treated for Cs removal), the availability of Tc controls its formation. For a given concentration of $\mathrm{Cs}$, a high ratio of $\mathrm{Tc}$ is required for appreciable amounts of $\mathrm{CsTcO}_{4}$ to be observed. For LAW, the base model predicts that, because of very low Cs concentration, very 
high Tc concentrations are required to form appreciable amounts of $\mathrm{CsTcO} 4$. Therefore, the Cs volatility enhancement from the presence of Tc is insignificant for typical LAW feed batches.

Although operating the $2^{\text {nd }}$ LAW melters with thick cold-caps may be beneficial for incorporation of Tc into the melt, the cost is lower melter throughput. As stated, melter throughput is based on the dissolution rate of the cold-cap. Also, as the reducing environment of the cold cap in increased (increasing Tc retention), so is the likelihood of creating forming a secondary sulfate phases on the surface of the melt pool.

\subsubsection{Creation of LAW Feed}

Once a waste feed formulation is developed, glass formers and sucrose (reducing agent) are transferred from the Glass Former Facility (GFF) (Figure 2-4) to the glass former feed hopper, and Figure 2-5, which is part of the glass formers reagent system (GFR). The chemicals are mixed.

The MFPF receives batches of concentrated LAW from the CRV. The volume transferred is based on volume of water and glass formers to be added to the tank to complete the feed batch. Then the glass formers and reducers are metered into the MFPV from the GFR. Water is added as the glass formers are metered into the MFPV to control dust and ensure the feed is mixable.

Figure 2-4. Glass Former Facility (WTP December 2009)

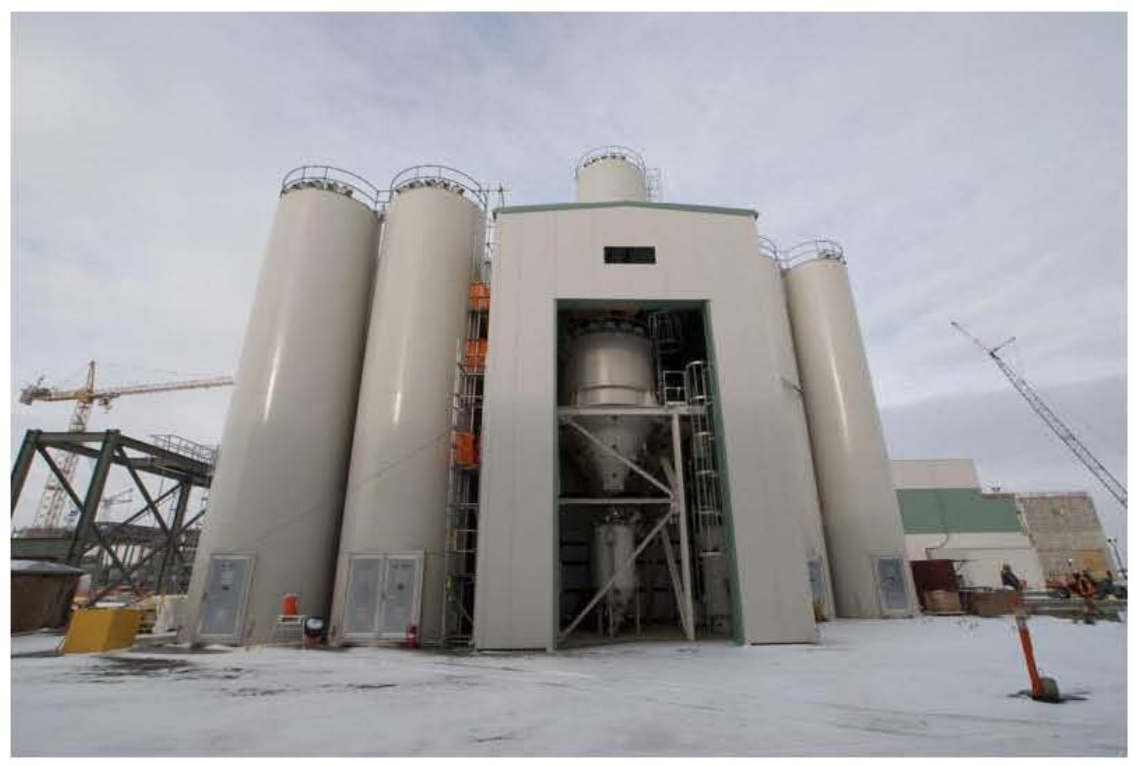


Figure 2-5. Glass Former Feed Hopper (WTP LAW facility March 2010)

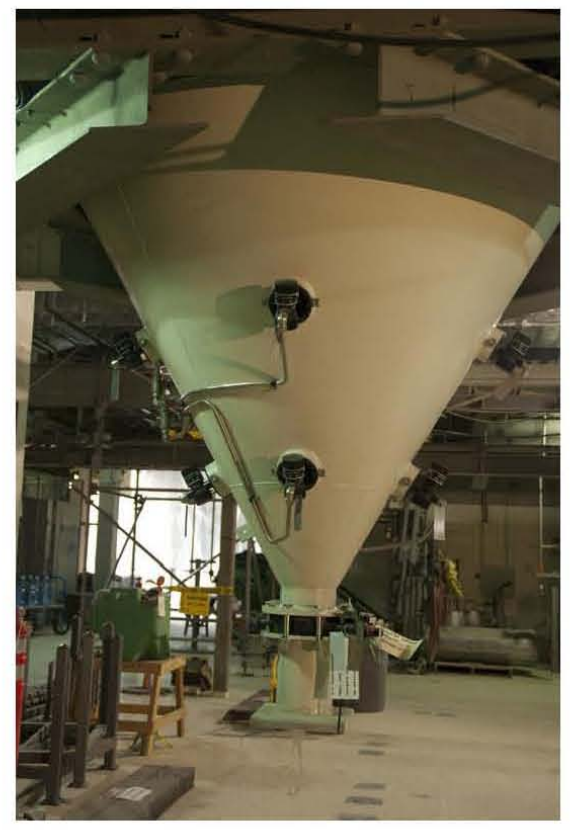

After the waste concentrate and glass formers are mixed, the MFPV is sampled and analyzed to verify the feed. If the water concentration is below $36 \%$, water will be added to bring the concentration to at least $36 \%$ to meet rheological requirements.

At this point the feed is prepared and changes will not be made before delivery to the melter. The prepared feed is pumped from the MFPV to the melter feed vessel (MFV), which keeps the feed mixed and provides continuous feeds to the melter.

\subsubsection{Melter and Product Handling}

The function of the $2^{\text {nd }}$ LAW Melter Process System will be to convert LAW into glass using JHCM technology. The heat created using joule-heating technique decomposes the waste into elemental oxides (and other minor compounds) that dissolve into the glass pool, with a moist gaseous secondary waste stream that exits the melter's plenum. The product -- glass -discharges from the melter through one of two discharge chambers into large cylindrical steel containers.

\subsubsection{The Melter}

The surface area of WTP's LAW melter is $10 \mathrm{~m}^{2}$, and has a design throughput rating of 1.5 $\mathrm{MTGD} / \mathrm{m}^{2}$. The volume of the melt (glass pool) is $269 \mathrm{ft}^{3}\left(7.62 \mathrm{~m}^{3}\right)(24590$-WTP-RPT-PT-02005), see Figure 2-6. 
Figure 2-6. LAW Melter under Construction (prior to installation of ceramic lining)

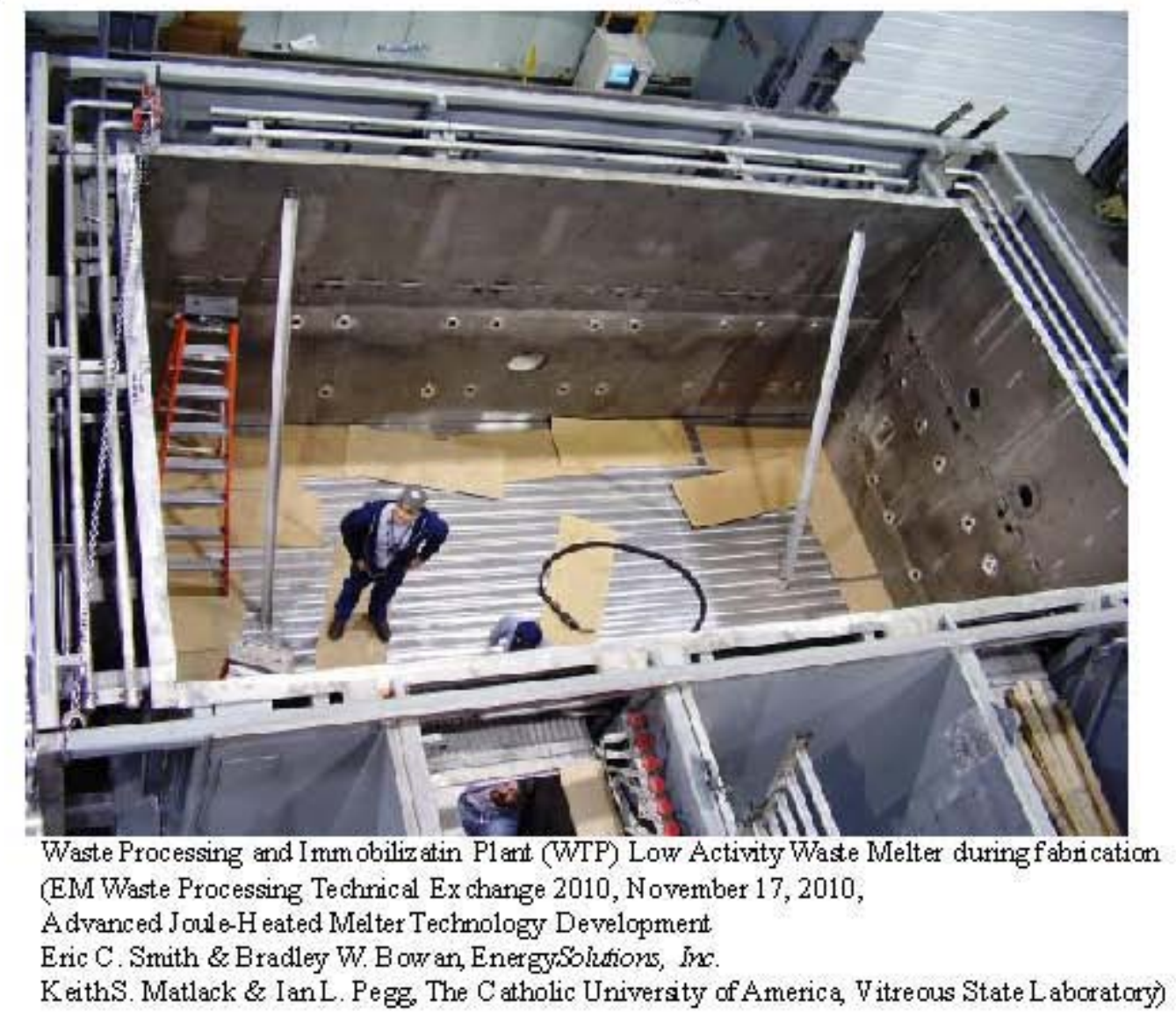

Processing rates for dissolution processes are typically controlled by three parameters -temperature, contact area, and circulation. The large surface area of the melter provides a good contact region for cold-cap dissolution into the glass. Bubblers increase the processing rate through better heat transfer to the cold-cap. See Figure 2-7 for an illustration of the melter during processing.

The LAW feed is pumped from the MFV into the melter through six feed nozzles. Multiple nozzles are used to spread the feed as evenly as possible across the surface of the melt, creating a cold cap of uniform thickness.

Several processes take place within the cold-cap and the top upper region of the molten glass as the melter feed of LAW, glass formers, reducers, and water increase in temperature from ambient to melt pool temperature:

- Volatile compounds evaporate;

- Sucrose reacts to reduce nitrates and nitrites in the waste;

- Feed is dried;

- Compounds that decompose at higher temperatures are converted into oxides and/or gases; and

- Oxides melt or dissolve into and become part of the glass pool. 
The melter maintains a large pool of molten glass at approximately $1150^{\circ} \mathrm{C}$ during steady-state operating conditions, and has an operating range of $950^{\circ}$ to $1250^{\circ} \mathrm{C}$. The melt temperature is maintained by joule-heating (electrical resistance heating); energy consumed pushing the alternating current directly through the melt is absorbed as heat. Current is delivered to three sets of opposing Inconel $\mathbb{R}^{9}$ electrodes in the glass pool. Current to the electrodes is singlephase. The glass pool temperature is used to adjust electrode power via a temperature feedback loop.

Figure 2-7. LAW Melter During Operation

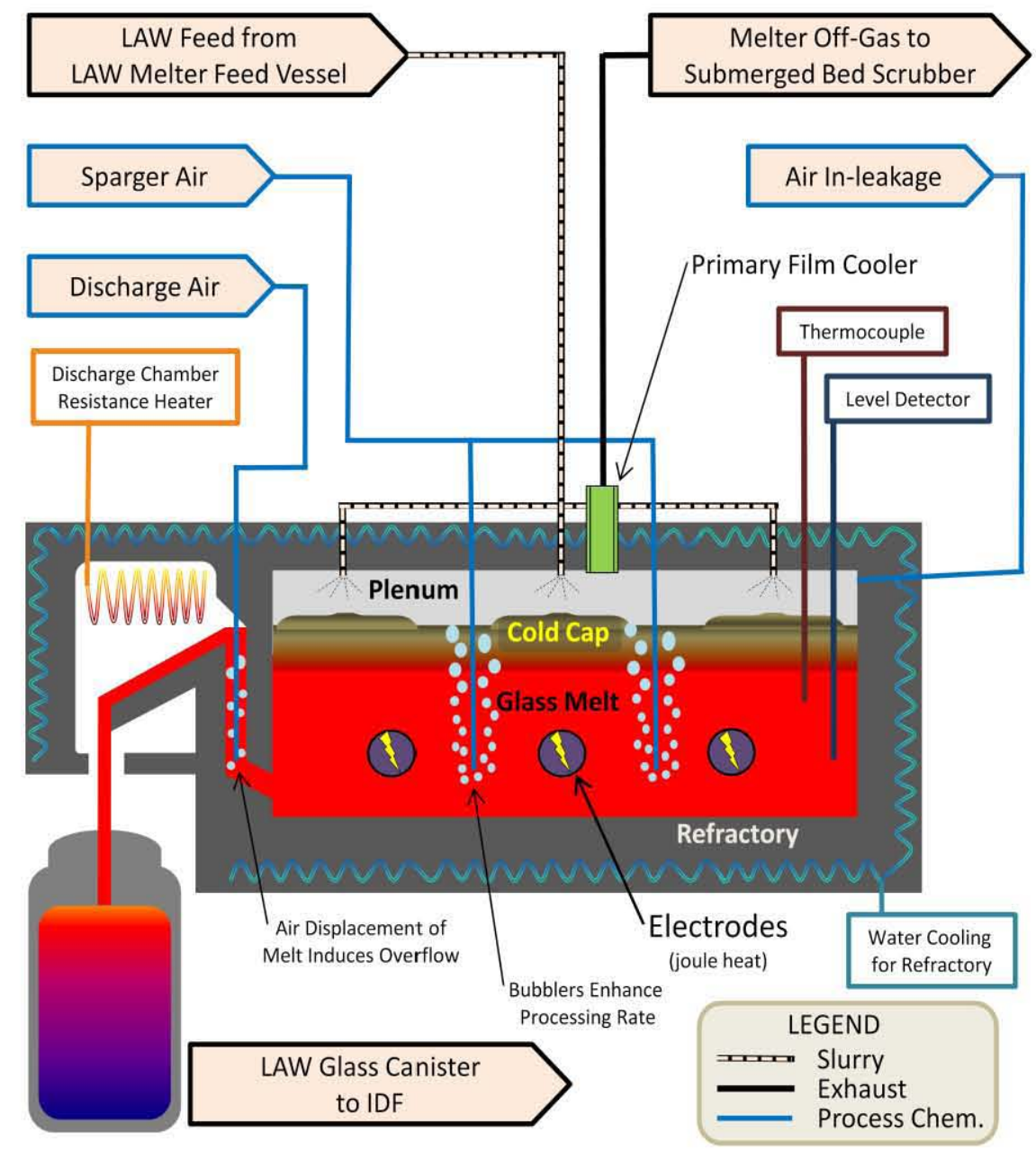

The melters convert treated LAW concentrate with glass formers into molten glass through dissolution. In this process, the molten glass is the solvent. The waste oxides entering the solvent have a higher melting temperature than that of the molten glass. Glass can only be made at the rate at which the oxides in the cold-cap can dissolve into the glass pool.

Glass discharges from the melter from one of two discharge chambers, both located on the same wall of the melter. The glass exits the main melter into one of the chambers through a port, riser, near the bottom of the glass pool. Air is bubbled into the bottom of the riser displacing

\footnotetext{
${ }^{9}$ Inconel is a registered trademark of Inco Alloys International, Inc., of Huntington, West Virginia.
} 
and lifting molten glass, creating a weir where the molten glass flows down a trough into a disposal container, see Figure 2-7 and Figure 2-8.

The melter is primarily constructed of refractory (ceramic) bricks. These bricks have a high melting temperature and are as chemically inert to the glass melt as possible; they will dissolve into the melt over time. To increase the life of the refractory and keep molten glass from creeping between the refractory bricks, cooling panels are located along the walls and bottom of the melter.

Waste feed components that do not make their way into the glass melt become secondary waste and leave the meter via the plenum and off-gas system. These components are volatile organics, compounds with high vapor pressures at cold-cap temperatures, chemicals that decompose into gases (such as the nitrates and nitrites that are reduced by the consumption of sucrose), and particulates that get entrained in the off-gas and carried out. These components first enter the melter plenum, typically at $350^{\circ}$ to $600^{\circ} \mathrm{C}$. They exit the melter through the primary film cooler, which is designed to aid in entraining compounds that can fall out or condense on process walls and foul off-gas piping, see Figure 2-7. The film cooler creates a layer of gas along pipe walls where semi-volatile materials typically condense and is considered the first step of the primary off-gas system. The melter plenum is maintained at a slightly negative pressure to aid in the capture of the off-gas and to maintain radiological control.

Figure 2-8. Canister Turntables beneath LAW Melter Discharge Chambers

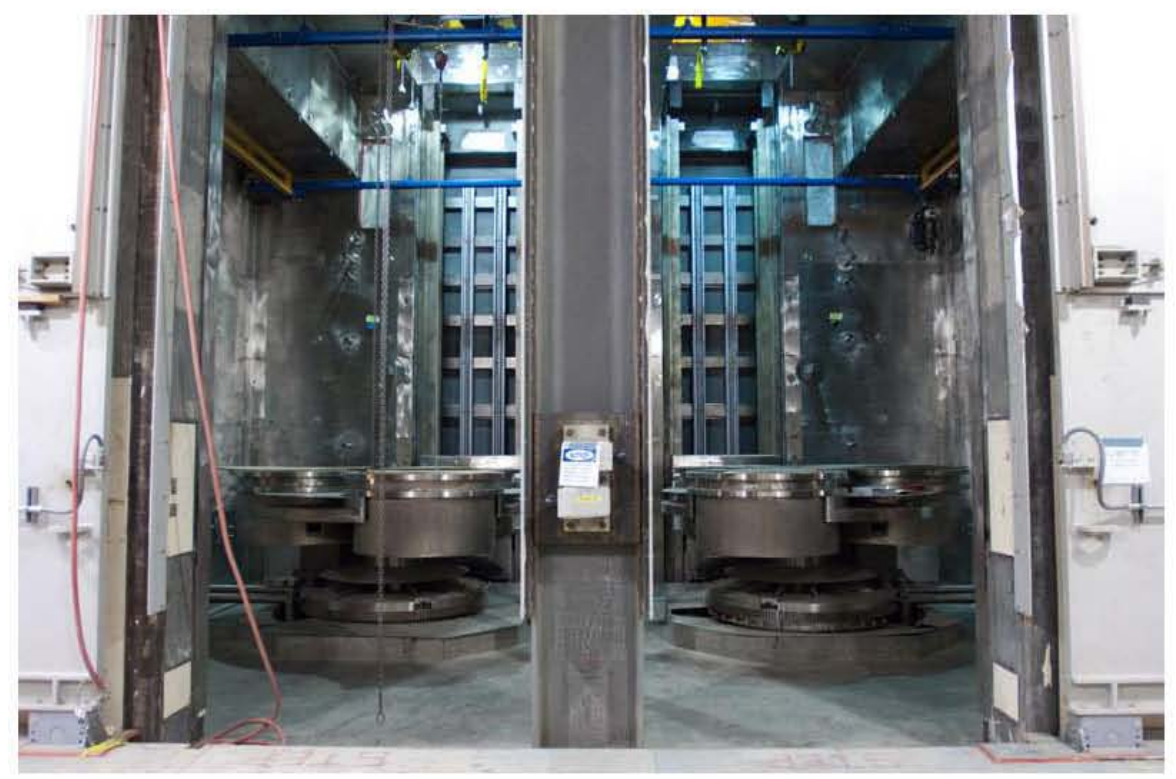

\subsubsection{The Product}

Glass is poured into canisters to maintain the proper operating level in the melter. Filling of a canister continues until its fill volume reaches $\sim 90 \%$. The WTP LAW steel canisters are 2.3 meters ( 7.5 feet) in height, 1.22 meters ( 4 feet) in diameter, and roughly six MT in weight when full (24590-WTP-RPT-PT-02-005). 


$$
\text { RPP-48935, Rev.0 }
$$

The system used to transport canisters from operation to operation is referred to as the mechanical handling system. The mechanical handling system is subdivided into four subsystems:

1. Container Receipt Handling;

2. Container Pour Handling;

3. Container Finishing Handling; and

4. Container Export Handling.

The containers are transferred throughout the facility with the use of hoists and transport bogies (small railway truck/cart).

After partial cooling, the filled container is ready to enter a lidding station. Each lidding station performs three operations:

1. If needed, a glass sample can be taken;

2. Void volume is calculated, the canister void is filled with inert material, and the final fill height of the canister is taken; and

3. The container is lidded.

The lidding bogie then transports the container into the container finishing and handling system decontamination station.

Both fixed and smearable contamination is expected to be present on the container surfaces after pouring. Two likely paths for contamination are condensation of volatile radiochemical constituents and contact with radioactive material from the surrounding environment (Washington Savannah River Company (WSRC-TR-2003-00084, Rev0, "LAW Radioactive Coupon $\mathrm{CO}_{2}$ Decontamination Test").

The method used for cleaning the canister is called $\mathrm{CO}_{2}$ pellet blasting; using solid $\mathrm{CO}_{2}$ pellets as working material. The method creates, and then propels, high quantities of small $\mathrm{CO}_{2}$ pellets using a $\mathrm{CO}_{2}$ source and compressed air. The pellets remove contaminants from surface material via two mechanisms:

- Mechanically removes contaminants by impacting the surface at high velocities.

- Upon impact, the solid $\mathrm{CO}_{2}$ pellet deforms around and under particulates on the steel surface of the canister, as soon as deformation takes place, the solid $\mathrm{CO}_{2}$ very rapidly sublimates, carrying contaminates away from the surface. 
Figure 2-9. Typical CO2 Blasting Pellets

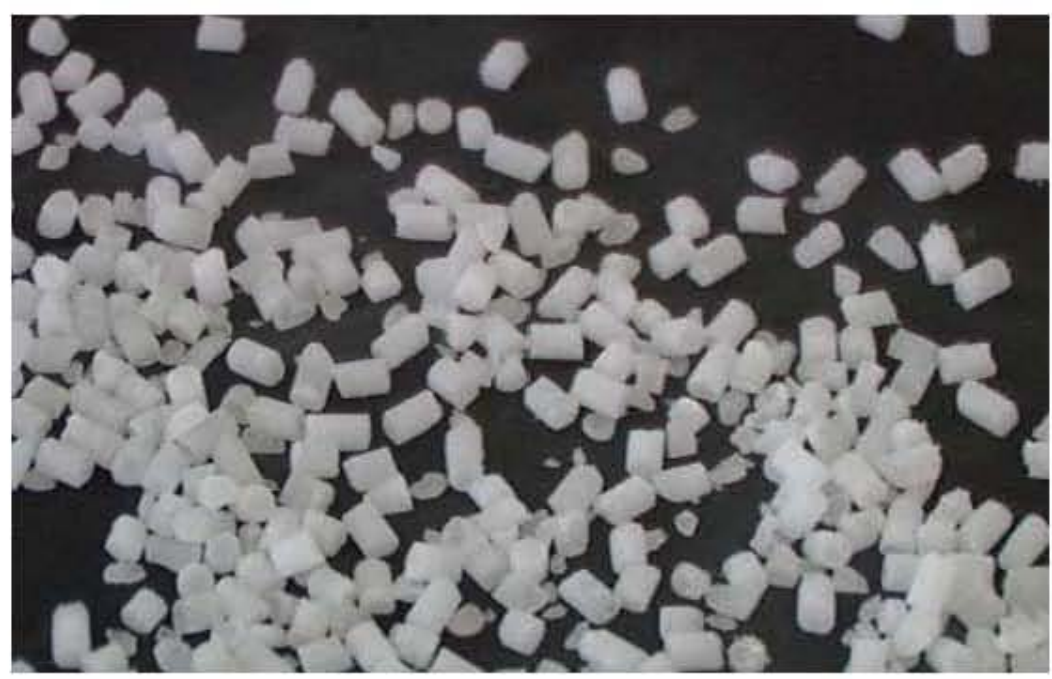

The bogie transports the container into the swabbing station, where swabbing is used to verify that the surface of the canister is free of radioactive contamination. If the container meets acceptable criteria, the canister is moved into the monitoring/export station and gamma monitoring equipment measures the surface dose rate of the decontaminated container and records it in the container's records. The canister is then transported to the IDF using a cask mounted onto a flatbed trailer.

\subsubsection{LAW Primary and Secondary Off-gas Treatment Systems}

Low Activity Waste Primary and Secondary Off-Gas Treatment Systems are a critical part of the melter system. The processes that treat the LAW off-gas maximize waste loading of key elements in the melt by recycling those components back into LAW pretreatment facility, prevent pressurization and release of radioactive contamination and hazardous gas release to potentially occupied areas, and meet air discharge permit limits. The discharge limits require:

- Cooling;

- removing particulates and aerosols $>1 \mu \mathrm{m}$;

- HEPA filtering to remove submicron particulates and aerosols including radionuclides;

- Treating to remove mercury $(\mathrm{Hg})$;

- controlling nitrogen oxides (NOx) emissions;

- controlling CO emissions;

- destroying organics;

- removing acid gases;

The off-gas from the melter consists of:

- Gases resulting from decomposition, oxidation, and vaporization of feed material;

- NOx from decomposition of nitrates and nitrites in the melter feed;

- $\mathrm{Cl}, \mathrm{F}$, and $\mathrm{S}$ as acid gases, elements, and volatile salts;

- Semi-volatile radionuclides such as $\mathrm{Cs}, \mathrm{Tc}$, and I;

- Air in-leakage to the melter due to operating the melter under vacuum; 


$$
\text { RPP-48935, Rev.0 }
$$

- Air from the operation of the bubblers and air purges of equipment;

- Particles entrained in the off-gas as it flows into the primary off-gas treatment system.

\subsubsection{LAW Primary Off-gas Treatment Systems}

After leaving the melter plenum and film cooler, the off-gas enters the primary off-gas treatment system, which is comprised of three types of process vessels -- a SBS, a wet electrostatic precipitator (WESP), and condensate vessels (SBS condensate vessels). Each melter will have its own set of primary off-gas treatment vessels.

The SBS is the first vessel in which off-gas treatment is performed. The SBS uses water for scrubbing the off-gas of ammonia $\left(\mathrm{NH}_{3}\right)$ and entrained radioactive and nonradioactive particulates, cooling the gasses, and condensing the liquids. The condensed liquids flow to the SBS condensate vessels. As the off-gas cools, water and other condensable compounds increase the liquid inventory in the SBS. The additional volume is sent to the SBS condensate vessel (shown in 
Figure 2-10 as SBS Condensate Vessel (A)). The optimum operating level is maintained in the SBS, while the volume in the SBS condensate vessel is allowed to fill over time. To help suspend solids captured by the SBS, both the SBS and SBS condensate vessels are recirculated. As the SBS condensate vessels reach their operating capacity, condensate is sampled, analyzed, and then, based on the sample analysis, purged back to either the pretreatment facility, plant wash vessel, or a balance of facilities storage tank.

Sulfur is a key component in waste loading of the glass. Much of it volatilizes, is captured by the primary off-gas system and recirculated to the LAW feed system. After larger particulates and aerosols are removed in the SBS, the cooled off-gas is routed to the WESP for high efficiency removal of sub-micron particulates and aerosols.

When off-gas enters a WESP, entrained particulate is negatively charged by bombardment of ions created by a corona-generating electrode. As the charged off-gas flows past wetted collection tubes that are grounded and maintain a neutral charge, the charged particles adhere to the water. The collection tubes are kept wet by a continuous mist of water droplets. Particulate entrained by the continually added water drain off by gravity. To prevent fouling, the tubes are cleaned by a periodic high volume wash-down spray. 
Figure 2-10. Primary Off-Gas Treatment System

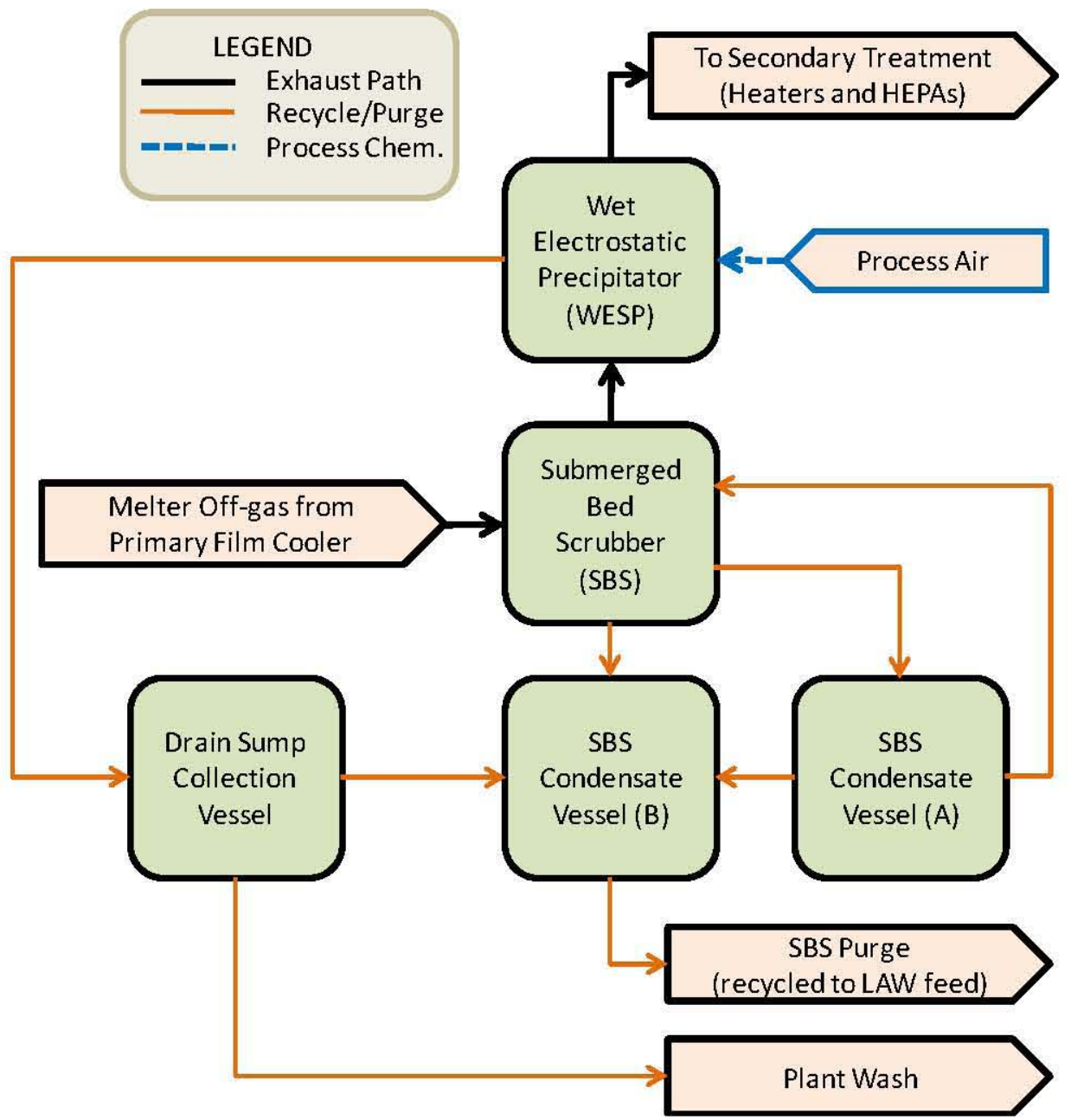

\subsubsection{Secondary Off-gas Treatment Systems}

After processing through the WESP, the melter exhaust is joined with the vessel vent header (process vessel exhaust) and enters the secondary off-gas treatment system. The system is comprised of HEPA and activated carbon filters, a thermal catalytic oxidizer and reducer, and a final off-gas scrubber unit, see. The secondary off-gas treatment system targets the removal or destruction of almost all remaining particulates. $(\mathrm{Hg}, \mathrm{NOx}, \mathrm{CO}$, volatile organic carbons (VOCs), and miscellaneous acid gases.)

The tie-in with the vessel vent header allows the secondary off-gas treatment system to maintain LAW melter feed system, plant wash, condensate, and the effluent vessels under vacuum. This vacuum controls emissions from vessels during operation and maintenance. 
Figure 2-11. Secondary Off-gas Treatment System

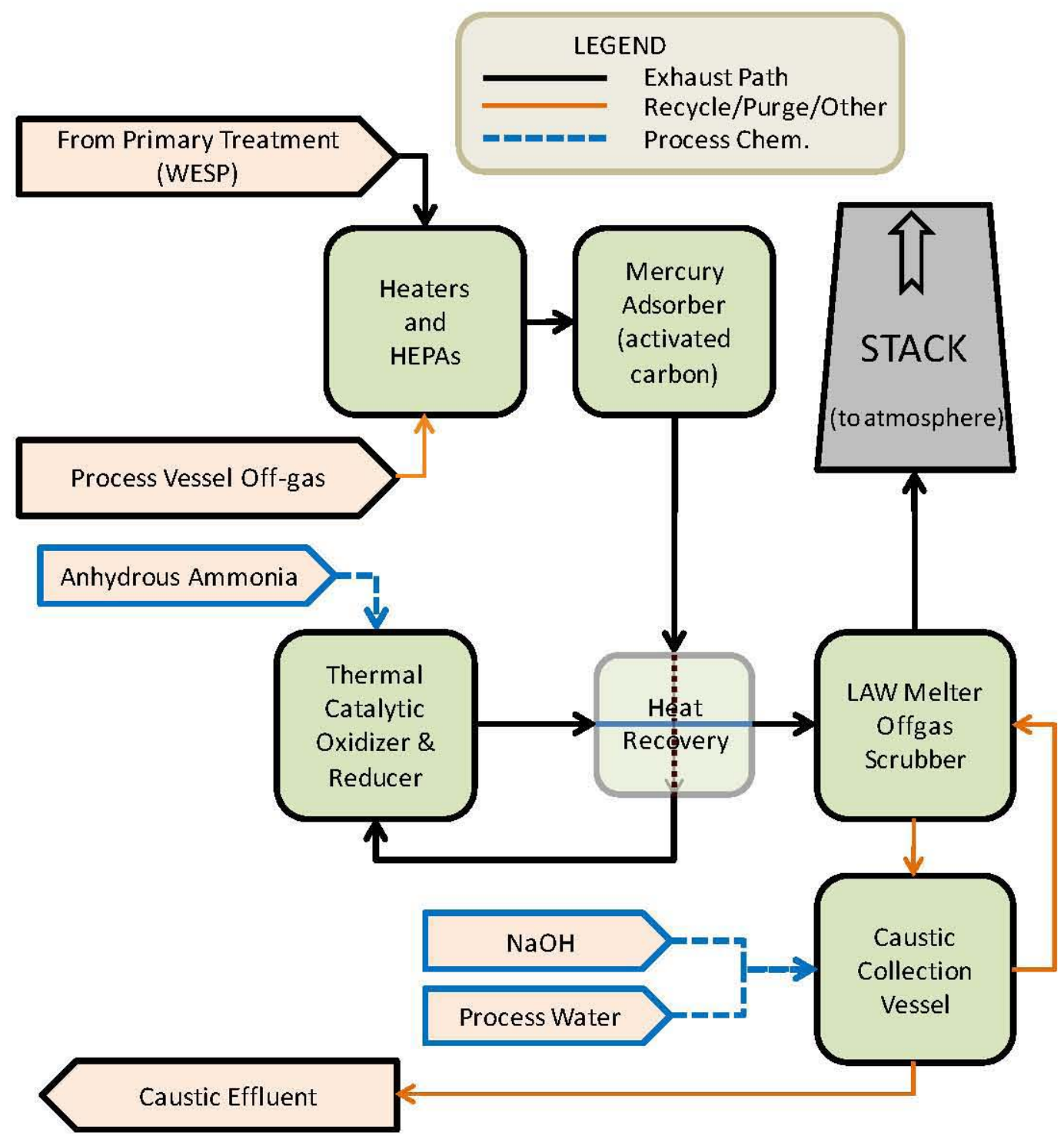

After the off-gas exits the WESP and is combined with the vessel vents, it is heated to lower its relative humidity. A relative humidity in the range of $70 \%$ or less prevents condensate from forming in the HEPA filters. The HEPA filters remove particulate contamination to comply with environmental release limits and to allow downstream equipment to be contact-maintained.

There are two stages of HEPAs; the first stage has a DF of 3,333 or $99.97 \%$ removal of particulate. The efficiency of the second stage is not as high since the majority of the particulates that are best captured by the filters have been caught by the first stage. The second stage DF is 500 or $99.8 \%$ removal of remaining particles. Pressure drop across the filters is used to determine the status of the system and alerts the operator as to when the filter banks need to be changed.

After the off-gas exits the HEPA filters, it enters sulfur impregnated activated carbon adsorbers. In $2^{\text {nd }} \mathrm{LAW}$ Vitrification, the activated carbon will remove $\mathrm{Hg}$, gaseous acids, and halides 
(including iodine as ${ }^{129} \mathrm{I}$ ). Removal of $\mathrm{Hg}$ and acid compounds is required to prevent their poisoning of the catalyst used by the thermal catalytic oxidizer. Two activated carbon adsorbers are used in series during normal operation with the following targeted results:

- Maximum Hg concentration leaving the stack is $45 \mu \mathrm{g} / \mathrm{dscm}$;

- DF for iodine (including ${ }^{129} \mathrm{I}$ ) is 100 (>99\% removal);

- DF for gaseous acids is 33.3 (97\% removal);

Although the activated carbon bed is not required for removal of organics, heavy organics, such as polychlorinated biphenyls (PCBs), are also captured with activated carbon and compete with other contaminants for active sites on the carbon. Active site loading with organics may reduce the planned two-year operating life of each bed.

The off-gas exits the activated carbon bed at temperatures ranging from $180^{\circ}$ to $200^{\circ} \mathrm{F}$. The minimum required inlet temperature for the Thermal Catalytic Oxidizers (TCOs) is $650^{\circ} \mathrm{F}$ $\left(343^{\circ} \mathrm{C}\right)$. To recover some of the energy in the off-gas as it exits the Selective Catalytic Reducer (SCR), the off-gas leaving the activated carbon bed is passed through a heat exchanger that heats it using the off-gas leaving the SCR.

As the off-gas enters the $\mathrm{TCO}$, it is heated to an operating temperature of $750^{\circ} \mathrm{F}\left(400^{\circ} \mathrm{C}\right)$. The first step in the process is oxidation of VOCs and CO. The oxidation of carbon is exothermic. The organic removal DF is 20 or $95 \%$ conversion to $\mathrm{CO}_{2}$.

Following organic destruction in the TCO the off-gas enters the SCR at a minimum temperature of $585^{\circ} \mathrm{F}\left(307^{\circ} \mathrm{C}\right)$. Ammonia is injected into the SCR above the stoichiometric ratio to ensure optimal conversion of NOx to nitrogen $\left(\mathrm{N}_{2}\right)$ and water $\left(\mathrm{H}_{2} \mathrm{O}\right)$. The SCR has a NOx DF of 50 (98\% removal).

As stated earlier, after leaving the SCR the off-gas then goes through a recovery heat exchanger, then to a caustic scrubber. The caustic scrubber is the final operation performed on the off-gas before it exits the stack. The caustic scrubber removes the remaining acid gases such as $\mathrm{HCl}$ and sulfur oxides (SOx). The scrubbing solution is maintained at $\mathrm{pH}$ of 9 to 9.5 using a caustic solution of 5 Molar (M) NaOH.

\subsubsection{Balance of Facilities}

The unit processes and process vessels discussed in Sections 3.1, 3.2 and 3.3 make up most of the operational units needed for a $2^{\text {nd }}$ LAW facility. Other facilities will be required to support those facilities. Examples are:

- The Glass Formers Reagent (GFR) System;

- Reagents $(\mathrm{NaOH}$, nitric acid, defoamers, etc.);

- Chilled Water;

- Steam Plant;

- Plant Air;

- Demineralized Water. 
RPP-48935, Rev.0

\subsection{PREVIOUS RELEVANT TESTS AND DEVELOPMENT HISTORY}

The $2^{\text {nd }}$ LAW facility is fundamentally a copy of the WTP LAW Vitrification Facility. However, it is expected to have certain enhancements including a significant increase in the total treatment capacity. JHCM-type vitrification has been deployed for use to treat radioactive waste in the U.S. and abroad. Some domestic applications for tank waste vitrification operations include the SRS Defense Waste Processing Facility and WVDP, both started operations in the mid-1990s. The JHCM melters are the selected treatment method in other radioactive waste disposal projects overseas such as in Germany and at the Tokai Vitrification Facility in Japan, which have been operated since 1995 .

The Hanford Tank Waste Remediation System was initiated in 1991 and selected JHCM technology as the method to immobilize high-level tank waste. JHCM and LAW waste processing for Hanford tank waste has gone through several design and testing iterations (WHC-SD-WM-SE-023, The Tank Waste Remediation System Privatization).

The JHCM technology selected for use in the WTP was a result of a down-selection process. Other competing vitrification technologies included combustion, plasma, and carbon arc melters (WHC-SA-2857-FP, Melter Technology Evaluation for Vitrification of Hanford Site Low-Level Waste).

The JHCM systems used at the Defense Waste Processing Facility and WVDP were GTS Duratek-developed melters. EnergySolutions acquired GTS Duratek and its JHCM proprietary design. Both the WTP LAW and HLW vitrification systems are JHCM designed by Duratek/EnergySolutions. Several pilot scale units, including the JHCM DM-1200, have been developed by EnergySolutions.

JHCM has been under development for more than 20 years with the intent to process Hanford tank waste through the WTP and its predecessor designs. Initial testing demonstrated the ability to vitrify simulated wastes to a glass product that captures constituents of concern. Later tests have refined the process and focused on demonstrating the durability of the product and composition of the offgas stream.

\subsection{OVERVIEW OF PREVIOUS RELEVANT TESTS AND DEVELOPMENT HISTORY}

All production-scale vitrification efforts within DOE have been implemented with joule-heated melters. Joule-heated melting technology is mature and has been successfully applied in both the commercial glass-making industry and the DOE complex; at the DWPF alone more than 3,000 canisters of immobilized waste have been produced. At the West Valley Demonstration Project in New York, a JHCM was used to treat over 600,000 gallons of reprocessing wastes to produce 275 canisters of glass.

Facilities under development are the WTP High Level Waste vitrification facility and WTP LAW vitrification facility at Hanford.

In addition to these several small scale melters have been used for development of the technology, including EnergySolutions DM10 small-scale JHCM located at VSL. 
RPP-48935, Rev.0

\subsubsection{PROCESS ISSUES AND LESSONS LEARNED}

The Department of Energy compiled a list of issues and lessons learned from DOE's Fernald Vitrification Pilot Plant, SRS Vendor Treatment Facility, Oak Ridge Transportable Vitrification System, SRS DWPF, and WVDP. Most of the issues occurred during start up, prior to hot operations. All issues are related to joule-heated melters, but not all issues are inherent in all melter designs (Waste Vitrification Systems Lessons Learned, US Department of Energy, March 1999).

\section{Issues}

Most issues with JHCM are due to the operating temperature and corrosiveness of the glass melt. The result of these two items typically lead to glass melt breaching the melter walls, degradation of the pour spout, and corrosion to other components internal to the melter such as electrodes and instrumentation.

The lack of correlation between instrumentation indications and actual conditions can also be a process issue. As the size of the melter increases, so does the importance of knowing the temperature profile of the melt. Localized hot spots have lead to the breaching of melter refractory.

Issues with operations that support the melter, such as the primary exhaust system components, are typically mitigated by having a redundant system.

\section{Lessons Learned}

A few of the key lessons learned that have been incorporated into melter design and operations are:

- Minimize or eliminate refractory penetrations;

- Evaluate materials of construction for form, fit, reaction to each other, and life expectancy;

- Improve reliability of temperature monitoring and level indicators;

- Incorporate ground current monitoring into the melter design;

- Incorporate redundant back-up and support systems, such as airflow indicators, bubblers, and sensors;

- Reduce the voltage potentials and improve current control by converting the melter from a two-phase to a single-phase unit;

- Plan operations to minimize thermal cycling;

- Develop a "pre-fire plan" and additional emergency procedures;

- Evaluation of operational safety of full-scale systems should start during pilot-scale testing;

\subsection{PREVIOUS USES INSIDE AND OUTSIDE THE DOE COMPLEX}

The JHCM was developed in the United States in 1973. Since that time, JHCMs have been used at facilities around the world for waste cleanup. Non-DOE Facilities include (Nuclear Waste Vitrification in the United States: Recent Developments and Future Options, Vienna, 2010):

- Tokai Plant in Tokai, Japan (1994-present); 
- Mayak Chemical Combine in the Russian Federation (1994-present);

- Bhabha Atomic Research Centre in Tarapur and Trombay, India (1990-present);

- German Waste Vitrification Plant (known as VEK) in Karlsruhe (2009-present);

Designs for melters vary based on processing requirements and the drive to maximize waste loading. For example, the German VEK uses a steeply sloped bottom leading to a bottom drain to allow higher crystal content in the melt. The concentrations of light transition metals (e.g., iron $(\mathrm{Fe})$, nickel $(\mathrm{Ni})$, chromium $(\mathrm{Cr})$, manganese $(\mathrm{Mn})$ are limited in the glass melt due to the formation and potential accumulation of transition metal spinels (nominally $\left.[\mathrm{Fe}, \mathrm{Ni}, \mathrm{Zn}, \mathrm{Mn}][\mathrm{Fe}, \mathrm{Cr}]_{2} \mathrm{O}_{4}\right)$. Likewise, noble metals and their oxides (Pd, $\mathrm{Rh}, \mathrm{Ru}$, etc.) are sparsely soluble in silicate liquids and tend to agglomerate and accumulate at the melter bottom. These conductive solids can disrupt power deposition in the melter. Combining a steeply sloped bottom and a bottom drain allows these solid particles to be flushed from the melter, allowing for higher waste loadings. (Vienna, 2010). 
RPP-48935, Rev.0

\subsection{CURRENT STATE OF THE KNOWLEDGE FOR USING VITRIFICATION TECHNOLOGY FOR HANFORD LAW}

\subsection{HOW SECOND LAW MIGHT FIT INTO THE HANFORD TANK WASTE TREATMENT FLOW SHEET}

The immobilization facility must produce an ILAW product that meets the waste acceptance criteria for disposal at the IDF.

- Manage Tank Waste (tank waste is defined as any waste that originated in the Hanford tanks that has been treated to the specifications of the Immobilization Facility);

- Process Tank Waste;

- Dispose Tank Waste;

- Manage System Generated Waste and Excess Facilities;

The facility(s) will need to be capable of processing 2,600 MT sodium (Na) per year (RPPSPEC-48094, Rev 4, Immobilization Project Facility System Specification). The instantaneous throughput capacity shall be at least 3,700 MT Na per year, assuming a 70\% total operating efficiency (TOE).

Interface requirements for the Immobilization Facility include interfaces with the Treatment Facility, IDF, Hanford Site utilities and infrastructure, and liquid and solid waste disposal facilities. Figure 4-1 illustrates these interfaces, which will be controlled formally with Interface Control Documents (ICDs) or memoranda of understanding, as appropriate.

Figure 4-1. LAW Immobilization Facility Interface Diagram

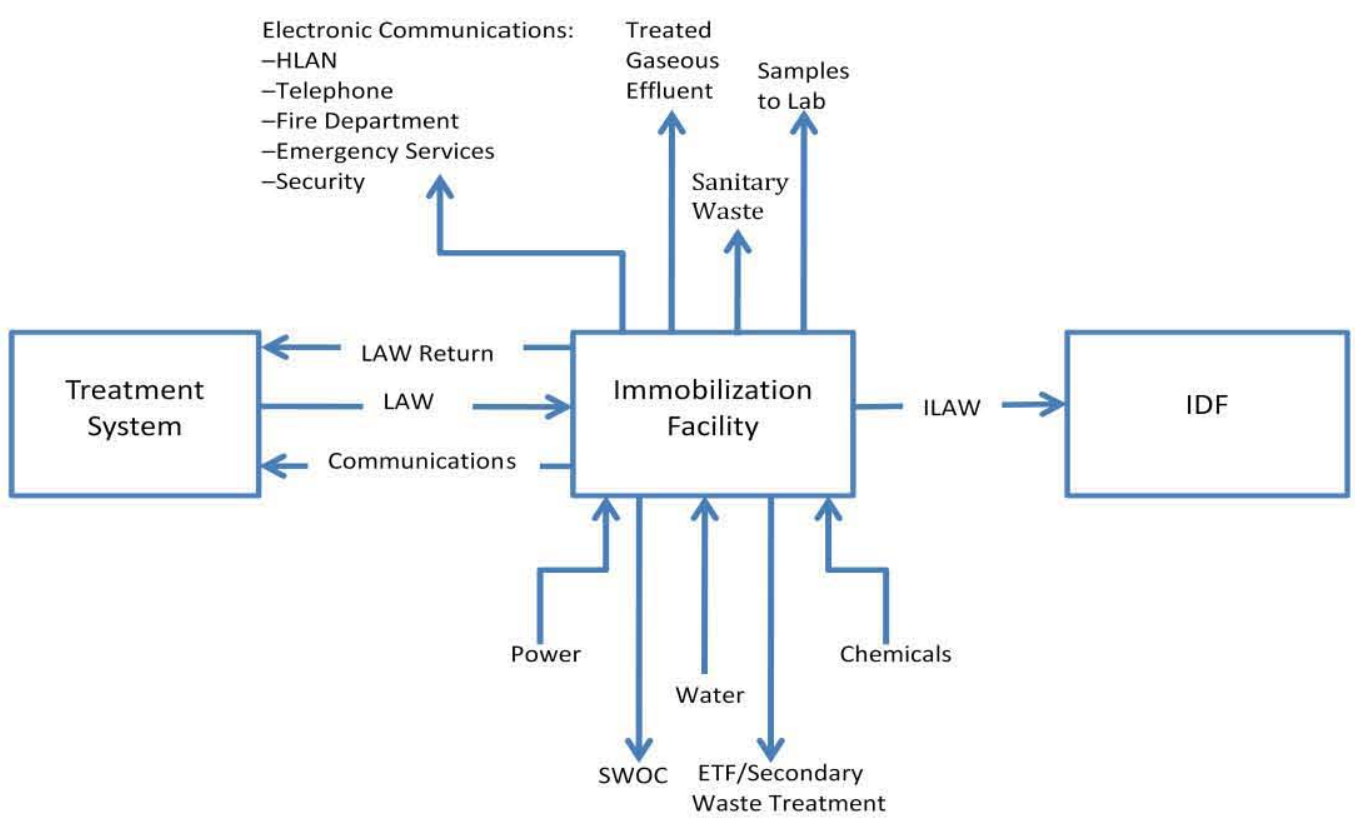




\subsection{TECHNOLOGY MATURITY}

A technology readiness assessment (TRA) has been performed on all of the technologies under consideration for supplemental immobilization of Hanford's LAW (RPP-RPT-48092, Rev 0, Supplemental Treatment Program Technology Readiness Assessment). The DOE uses a TRA methodology implemented by the U.S. Department of Defense. In March 2008, EM is sued its Technology Readiness Assessment (TRA)/Technology Maturation Plan (TMP) Process Guide (DOE 2008), which established the TRA process as an integral part of EM project management's critical decision process. The integration of the TRA process and critical decision (CD) process is shown in Figure 4-2.

\section{Figure 4-2. DOE Integration of TRL with the Critical Decision Process}

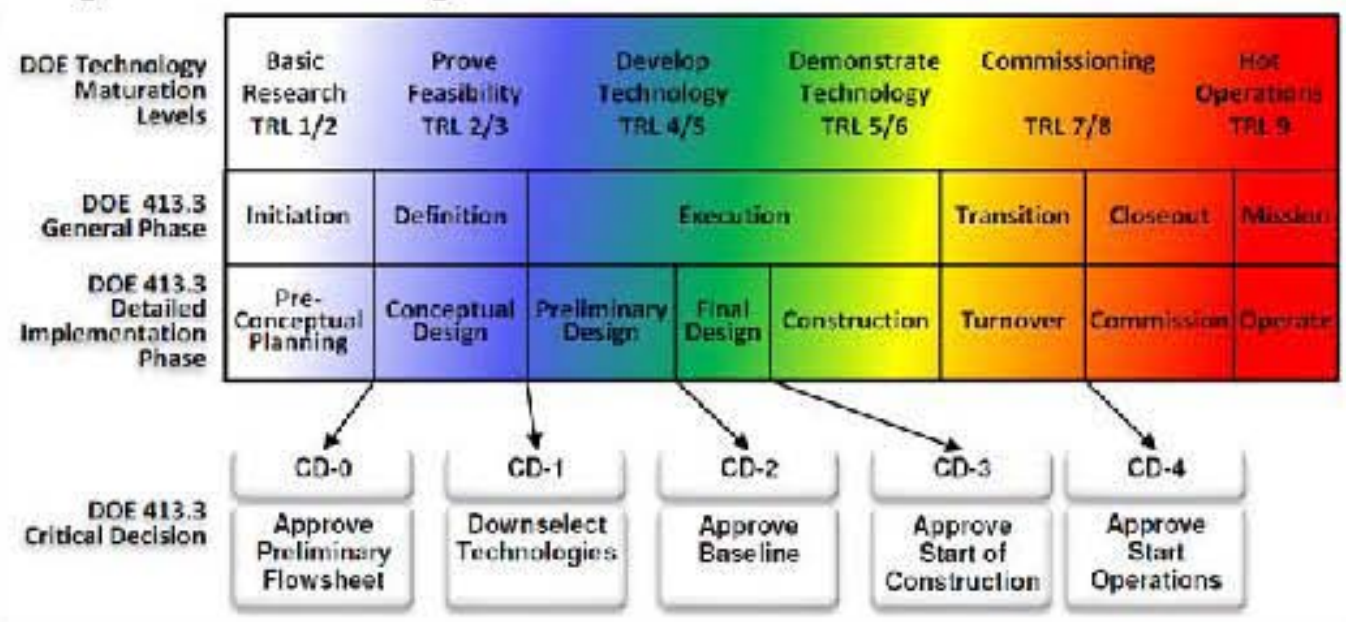

A TRA can (1) identify the gaps in testing, demonstration and knowledge of a technology's current readiness level, and the information and steps needed to reach the readiness level required for successful inclusion in the project; (2) identify at-risk technologies that need increased management attention or additional resources; and (3) increase the transparency of management decisions by identifying key technologies that have been demonstrated to work or by highlighting immature or unproven technologies that might result in increased project risk. Additional TRAs will be reevaluated during future project phases to reflect future design and technology development activities.

The TRA process consists of three parts:

1. Identifying critical technology elements (CTE);

2. Assessing the TRL of each CTE using an established readiness scale;

3. Preparing the TRA report; 


$$
\text { RPP-48935, Rev.0 }
$$

The analysis resulted in a TRL of 6 for JHCM (Table 4-1). A full-scale first generation $2^{\text {nd }}$ LAW JHCM has a melt surface are of $10 \mathrm{~m} 2$. Justifications for the TRA level where sited as:

- VSL's DM 3300, a $3.3 \mathrm{~m} 2$ (a 1/3 cross-section of a full-scale) melter, has been operated over the past five years with a variety of Hanford-specific simulant waste recipes;

- SRNL has tested actual tank waste on a laboratory scale;

- VLS is performing additional tests in crucibles at laboratory scale with a range of simulants.

- WTP LAW JHCM development, testing, and operations program will be applicable to the implementation of a $2^{\text {nd }}$ LAW facility.

Table 4-1. Technology Readiness Level Determination and Associated Rationale (RPPRPT-48092)

\begin{tabular}{|l|c|l|l|l|}
\hline \multicolumn{1}{|c|}{ CTE } & TRL & \multicolumn{1}{|c|}{ Scale } & \multicolumn{1}{c|}{ Fidelity } & \multicolumn{1}{c|}{ Environment } \\
\hline JHCM system & 6 & $\begin{array}{l}\text { Engineering: testing } \\
\text { completed on several } \\
\text { systems }\end{array}$ & $\begin{array}{l}\text { Similar: Components } \\
\text { closely match the final } \\
\text { configuration. }\end{array}$ & $\begin{array}{l}\text { Relevant: Range of simulants on } \\
\text { engineering scale and limited range of } \\
\text { actual waste on laboratory scale }\end{array}$ \\
\hline Melter subsystem & 6 & $\begin{array}{l}\text { Engineering: 1/3-scale } \\
\text { tested over past 5 years }\end{array}$ & $\begin{array}{l}\text { Similar: The DM-3300 } \\
\text { system closely matches } \\
\text { the current design. }\end{array}$ & $\begin{array}{l}\text { Relevant: Range of simulants on } \\
\text { engineering scale and limited range of } \\
\text { actual waste on laboratory scale }\end{array}$ \\
\hline $\begin{array}{l}\text { Offgas treatment } \\
\text { subsystem }\end{array}$ & 6 & $\begin{array}{l}\text { Engineering: 1/10-scale } \\
\text { system }\end{array}$ & $\begin{array}{l}\text { Similar: The DM-1200 } \\
\text { system closely matches } \\
\text { the current design. }\end{array}$ & $\begin{array}{l}\text { Relevant: Range of simulants on } \\
\text { engineering scale and limited range of } \\
\text { actual waste on laboratory scale }\end{array}$ \\
\hline $\begin{array}{l}\text { JHCM = joule-heated ceramic melter. } \\
\text { TRL = technology readiness level. }\end{array}$
\end{tabular}

\subsubsection{Process scale up requirements}

As stated in section 4.2, process scale up is necessary for implementation of joule-heated melters for $2^{\text {nd }}$ LAW and bringing the TRA level from 6 to a 9 . Current testing has been performed on a melter roughly $1 / 3$ full scale. Since the WTP LAW facility uses the same technology, full-scale operations should be in progress prior to start up operations for a $2^{\text {nd }}$ LAW facility. 


$$
\text { RPP-48935, Rev.0 }
$$

\subsubsection{Technology Developments}

The implementation of processing enhancements may result in the need to re-evaluate the TRL for a $2^{\text {nd }}$ LAW facility. EnergySolutions and VSL are working to increase meter throughput without increasing melter's footprint. Proposed improvements include:

- Increasing melt surface area;

- Less conservatism on refractory requirements;

- Increasing waste loading;

- High sodium glasses;

- Increase concentration of $\mathrm{ZrO}_{2}, \mathrm{SnO}_{2}, \mathrm{SiO}_{2}$, and/or $\mathrm{Al}_{2} \mathrm{O}_{3}$;

- Increase $\mathrm{Cr}_{2} \mathrm{O}_{3}$ to reduce corrosion of refractory;

- High sulfur glasses;

- Increase $\mathrm{Li}_{2} \mathrm{O}, \mathrm{CaO}$, and $\mathrm{V}_{2} \mathrm{O}_{5}$;

- Increasing melt temperature;

- Less conservatism on refractory requirements;

- Use of bulk containers for glass and new container handling systems

- Alternative off-gas treatment configurations.

\subsection{PROCESS SAFETY CONSIDERATIONS AND CONCERNS}

Recent preliminary hazards category analysis, based on radionuclide inventory, indicate that implementation of $2^{\text {nd }}$ LAW is Hazard Category 3 . A Hazard Category 3 facility is considered a low-hazard facility in that the analysis shows the potential for localized consequences of less than 10 rem at 30 meters. Primary toxicological risks related to the $2^{\text {nd }}$ LAW vitrification process include are outlined in Table 4-2.

Table 4-2. Process Safety Considerations for $2^{\text {nd }} \mathrm{LAW}$

\begin{tabular}{|l|l|}
\hline \multicolumn{1}{|c|}{ Hazard } & \multicolumn{1}{c|}{ Control Strategy } \\
\hline $\begin{array}{l}\text { Leaks and Spills - Leaks and spills during waste } \\
\text { transfers within the facility in normally occupied areas. } \\
\text { The caustic waste can cause chemical burns if a worker } \\
\text { is wetted by the leak or spill. }\end{array}$ & $\begin{array}{l}\text { Engineering or administrative control will be in place } \\
\text { for these process areas. }\end{array}$ \\
\hline $\begin{array}{l}\text { Flammable Gas Deflagrations - The primary flammable } \\
\text { gas hazard is steady-state accumulation in process } \\
\text { equipment. Flammable gases (primarily hydrogen) are } \\
\text { generated by the waste due to radiolysis and } \\
\text { thermolysis. }\end{array}$ & $\begin{array}{l}\text { Process areas are not normally occupied. Blast and } \\
\text { fragment missiles not expected or mitigated by process } \\
\text { cell walls. }\end{array}$ \\
\hline $\begin{array}{l}\text { Melter Off-gas Release - The primary hazardous } \\
\text { components of the LAW melter off-gas are the oxides of } \\
\text { nitrogen. Two of these, nitrogen dioxide }\left(\mathrm{NO}_{2}\right) \text { and } \\
\text { nitric oxide (NO), are toxic at relatively low } \\
\text { concentrations. }\end{array}$ & $\begin{array}{l}\text { Safety-significant LAW melter off-gas system (active) } \\
\text { to ensure confinement and a stack release of NOx. } \\
\text { Includes exhausters (active), uninterruptable power } \\
\text { supply, normal off-gas system by-pass including valves } \\
\text { and interlocks, primary confinement barrier including } \\
\text { melter shell, off-gas system piping, certain off-gas } \\
\text { system components and the exhaust stack for elevating } \\
\text { the release. The off-gas system components must } \\
\text { maintain confinement of the gases and maintain an open }\end{array}$ \\
\hline
\end{tabular}




\begin{tabular}{|c|c|}
\hline Hazard & Control Strategy \\
\hline & $\begin{array}{l}\text { flow path for the exhaust of the off-gas to the stack. } \\
\text { Note that removal of the toxic gases from the off-gas } \\
\text { before release to the environment is not a required safety } \\
\text { function (e.g., SCR function) } \\
\text { Includes a number of safety-significant instruments and } \\
\text { interlocks, as well as support systems (e.g., LAW } \\
\text { structure) to implement the safety -significant LAW } \\
\text { melter off-gas system controls. }\end{array}$ \\
\hline $\begin{array}{l}\text { Off-gas System Carbon Bed Fire - Activated carbon } \\
\text { adsorbers are contained in the melter off-gas system to } \\
\text { remove } \mathrm{Hg} \text { and halides from the melter off-gas before } \\
\text { discharge through the LAW stack. A fire can release } \\
\text { adsorbed Hg and entrain it in the fire products from the } \\
\text { burning media. } \\
\text { Primary controls for off-gas system carbon bed fires are } \\
\text { likely to be safety-significant (public, onsite worker, and } \\
\text { facility worker hazards) }\end{array}$ & $\begin{array}{l}\text { Safety-significant } \mathrm{Hg} \text { abatement skid } \mathrm{CO} / \mathrm{CO}_{2} \text { monitors, } \\
\mathrm{Hg} \text { abatement skid inlet off-gas temperature monitor, } \\
\text { carbon adsorber isolation valves and interlocks, carbon } \\
\text { adsorber exhaust path, } \mathrm{Hg} \text { abatement skid bypass vale } \\
\text { and interlocks, melter off-gas treatment system } \\
\text { confinement boundary. }\end{array}$ \\
\hline $\begin{array}{l}\text { Ammonia Release - The LAW melter secondary off-gas } \\
\text { system uses ammonia }\left(\mathrm{NH}_{3}\right) \text { in its } \mathrm{SCR} \text { unit to abate } \\
\text { oxides of nitrogen from the melter off-gas before release } \\
\text { of the gas to the environment. The ammonia is supplied } \\
\text { to the LAW facility from two } 6,000 \text {-gallon ammonia } \\
\text { storage vessels containing liquid anhydrous ammonia. } \\
\text { The hazard is the release of ammonia to the environment } \\
\text { (e.g., failed ammonia delivery line). } \\
\text { The primary controls for an ammonia release are likely } \\
\text { to be safety-significant (public, onsite worker, and } \\
\text { facility worker hazards) }\end{array}$ & $\begin{array}{l}\text { Safety-significant ammonia transfer lines, all } \\
\text { connections, and in-line valves to confine ammonia. } \\
\text { Safety-significant off-gas system and components } \\
\text { downstream of the exhauster designed to prevent release } \\
\text { of unreacted NOx or ammonia from entering the facility. } \\
\text { Safety-significant interlocks and associated isolation } \\
\text { valves on the ammonia/air supply to terminate ammonia } \\
\text { flow to the SCR on low dilution-airflow, loss of power } \\
\text { or control signal, high SCR skid differential pressure, } \\
\text { and high melter plenum pressure. The ammonia supply } \\
\text { is also isolated by interlock on detection of high } \\
\text { ammonia supply flow. }\end{array}$ \\
\hline $\begin{array}{l}\text { Fires- The worst-case fire is one that results in an off- } \\
\text { gas release (see above). } \\
\text { The controls for an off-gas system fire are expected to } \\
\text { be safety-significant. }\end{array}$ & $\begin{array}{l}\text { Safety-significant 2-hour fire barriers with electrical } \\
\text { separation between redundant melter off-gas exhausters } \\
\text { and the associated power, instrumentation, controls, } \\
\text { ductwork, and piping needed for their operation. }\end{array}$ \\
\hline
\end{tabular}


RPP-48935, Rev.0

\subsection{COST CONSIDERATIONS AND CONCERNS}

Technology considerations and concerns are outlined in Table 4-3.

Table 4-3. Cost Considerations/Concerns

\begin{tabular}{|l|}
\hline \multicolumn{1}{|c|}{ Unfavorable Attributes } \\
\hline Facility construction costs are assumed to be high when compared to alternatives \\
\hline Facility operational costs are assumed to be high when compared to alternatives \\
\hline $\begin{array}{l}\text { Does not incorporate all waste components into the product (e.g., some Tc will be present in the secondary waste } \\
\text { stream) }\end{array}$ \\
\hline High temperature operating conditions cause equipment failure \\
\hline $\begin{array}{l}\text { Number of melters required will be greatly dependent on melter specifications (operating temperature and surface } \\
\text { area per footprint) and waste loading assumptions. }\end{array}$ \\
\hline
\end{tabular}

\subsection{WASTE FORM CHARACTERISTICS INCLUDING STRENGHS, WEAKNESSES, OR UNCERTANTIES}

Extensive testing has been performed on the waste form characteristics of glass produced by JHCM with the results of relatively broad operating windows for producing a waste form that exceeds disposal requirements.

Several tests have been done to develop LAW glass formulation with subsequent waste qualification (24590-WTP-RTP-PT-02-005). Due to the cost and complexity of working with actual radioactive wastes, the majority of LAW glass formulation tests have used simulants. A comparison of the properties of glasses made from samples of actual and simulated waste was conducted in 24590-101-TSA-W000-0009-157-00002, Rev A. Over 55 different samples of glasses representing each of the LAW sub-envelopes were reviewed. Product quality properties were compared for samples of glasses that were prepared from a variety of tests, performed at four different institutions over a period of about 5 years. The comparison reviewed samples that were prepared from crucible melts as well as melter tests (DM100, DM1200, DM3300); simulants as well as real waste; and dry chemicals as well as wet slurries. The product consistency test (PCT) response was used as the primary basis for product quality comparison, but vapor hydration test (VHT) and TCLP responses were also compared. The sample treatment included quenching and heat treatment according to the centerline cooling curve (CCC), as well as REDOX adjustment.

The study indicated that there is not a significant difference in the PCT response of samples of similar composition that were prepared from simulants in crucibles, actual waste samples in crucibles, in melters of various scales, or from wet or dry chemicals. The results also indicated that heat treatment according to LAW CCC profiles has no significant effect on the glass PCT response. The adjusted REDOX states of the glass samples $(\sim 20 \%)$ also had no effect on the PCT test. 
RPP-48935, Rev.0

\subsection{OFF-GAS TREATMENT AND CONSTITUENTS OF OFF-GAS RELEASED TO THE ATMOSPHERE}

Please see sections 2.3.3.1 LAW Primary Off-gas Treatment Systems and 2.3.3.1 Secondary Off-gas Treatment Systems.

\subsection{SECONDARY WASTE STREAMS AND THEIR MANAGEMENT}

Implementation of JHCM technology for the processing of LAW solutions results in a secondary liquid waste stream. The volume of the stream is dependent on the ability of the system to recycle process fluids, the level of purging (blow-down) of scrubbers to keep the SBS (primary off-gas treatment vessel) and LAW melter off-gas scrubber (secondary off-gas treatment vessel) within optimum operating limits.

The waste stream will make its way to a process condensate tank in the Radioactive Liquid Disposal system via a treated LAW evaporator (in the LAW Treatment facility). From there it will be transferred to Liquid Effluent Retention Facility (LERF), Effluent Treatment Facility (ETF), or a new facility. Due to the amount of dilute solution expected to be produced by $2^{\text {nd }}$ LAW, either a new secondary waste facility will need to be constructed, or ETF will need to be upgraded.

The waste streams will be managed by ETF interface during design and construction of the facility.

The secondary wastes will also include failed melters and other process equipment as well as solid wastes such as personal protective equipment from maintenance and decontamination activities. 
RPP-48935, Rev.0

\subsection{INFORMATION NEEDS}

The JHCM technology is very mature in terms of information needs. Most requirements at this stage can only be gathered by full-scale implementation of the technology.

\subsection{WHAT ARE THE DATA GAPS?}

The principal open issue relates to the retention of ${ }^{99} \mathrm{Tc}$ in the glass. As noted previously, the retention of ${ }^{99} \mathrm{Tc}$ in the first pass through a melter is nominally expected to be $30-40 \%$. The fraction that is not captured will evolve to the off-gas treatment system where it will be captured there and will be available for recycle back to the melter. The recycle approach has not been demonstrated. Testing of the recycle strategy is planned for FY-11 and FY-12. As a TRL 6, full scale testing is required to reach the next technology development level. If there are changes or enhancements made to the design, the TRL may need to be re-evaluated. 
RPP-48935, Rev.0

\subsection{RISKS AND BENEFITS}

\subsection{KEY TECHNICAL AND PROGRAMMATIC RISKS}

Programmatic risk is a combination of budget and schedule. Assuming the implementation of existing designs, the schedule and budget risk is minimized. Enhancements offer the potential for programmatic risk particularly if development is required.

Technical risks for the implementation of $2^{\text {nd }} \mathrm{LAW}$ with the existing design are very low. The technology has a Technology Readiness Level of 6 and only needs to be demonstrated full-scale to reach 9. This level should be attained with the start up of the WTP LAW facility.

Joule-Heated Ceramic Melter technology has been implemented at DOE sites with success, so the potential for failure of the system is low. However, the WTP including the pre-treatment facility is very complex. The main technical uncertainty with $2^{\text {nd }} \mathrm{LAW}$ is associated with the incorporation of $\mathrm{Tc}$ into the melt and the recycle discussed above. Due to the size of the melter, the ability to maintain a uniform cold-cap will be critical to the retention of $\mathrm{Tc}$ in the melt. Testing has shown that melters with thick cold-caps (low melter turnover rate) incorporate Tc at a higher rate. Implementation of a $2^{\text {nd }} \mathrm{LAW}$ facility may enable one melter to be operated with a thick cold-cap and low melt rate -- conditions optimal for Te retention. Operational experience gained during the operation of the WTP LAW facility will provide a valuable resource for implementing solutions into the design of $2^{\text {nd }} \mathrm{LAW}$.

\subsection{BENEFITS AND PRINCIPAL ADVANTAGES}

Key benefits for implementation of JHCM in the form of a $2^{\text {nd }}$ LAW facility are:

- Product is well studied and meets disposal requirements;

- Waste form is very compact (high waste loading per $\mathrm{ft}^{3}$ of product);

- Product performance tests are developed, understood, and accepted; and

- Although the waste processing method is mature, there are still advances being made to the technology that offer the potential for substantial process improvements;

\subsection{HOW WILL THE RISKS BE MITIGATED?}

Risks will be mitigated by creating a risk mitigation plan during implementation (design, construction, and start up) of the facility. 


$$
\text { RPP-48935, Rev.0 }
$$

\subsection{REFERENCES}

10 CFR 61, "Licensing Requirements for Land Disposal Requirement of Radioactive Waste," Code of Federal Regulations, as amended.

10 CFR 61.55, "Waste Classification," Code of Federal Regulations, as amended.

40 CFR 261, "Identification and Listing of Hazardous Waste," Code of Federal Regulations, as amended.

40 CFR 268, "Land Disposal Restrictions, "Code of Federal Regulations, as amended.

49 CFR 173.465(d), "Type A Packaging Tests," Code of Federal Regulations, as amended.

62 FR 8693, 1997, Record of Decision for the Tank Waste Remediation System, Federal Register, February 1997.

1993, Letter from R. M. Bernero, Director, Office of Nuclear Materials Safety and Safeguards, U.S. Nuclear Regulatory Commission, Washington, D.C., to J. Lytle, Deputy Assistant Secretary for Waste Operations, Office of Environmental Restoration and Waste Management, U.S. Department of Energy, Washington, D.C., March 2, 1993.

24590-101-TSA-W000-0009-98-00008, Rev 00A, "Final Report- Compositional Variation Tests on DuraMelter 100 with LAW Sub-Envelope C2 Feed in Support of the LAW Pilot Melter", Bechtel, Richland, Washington

24590-101-TSA-W000-0009-155-00003, Rev 00A, Final Report - DuraMelter 100 Tests with LAW AP-101/AY-102 Blended Feed from the Semi-Integrated Pilot Plant, Bechtel, Richland, Washington

24590-101-TSA-W000-0009-157-00002, Rev A, Final Report - Comparison of LAW Simulant, Actual Waste, and Melter Glasses, Bechtel, Richland, Washington

24590-LAW-RPT-RT-04-003 Rev 0, "Preliminary ILAW Formulation Algorithm Description", Bechtel, Richland, Washington, 2005

24590-WTP-RPT-PT-02-005 Rev 5, "Flowsheet Bases, Assumptions, and Requirements", Bechtel, Richland, Washington, 2009

AMEC 2006, Demonstration Bulk Vitrification System (DBVS) Series 38 Full Scale Testing, 34005-RT-0003, AMEC Earth and Environmental, Richland, Washington.

ANSI/ANS 16.1, 2003, Measurement of the Leachability of Solidified Low-Level Radioactive Waste, American Nuclear Society

ASTM B553-79, Test Method for Thermal Cycling of Electroplated Plastics, ASTM International.

ASTM WK84, Test Method for Measuring Waste Glass Durability by Vapor Hydration Test. ASTM International.

ASTM C1662-10, Standard Practice for Measurement of the Glass Dissolution Rate Using the Single-Pass Flow-Through Test Method, ASTM International, ASTM International.

ASTM G21-96, Standard Practice for Determining Resistance of Synthetic Polymeric Materials to Fungi, ASTM International. 
ASTM G22-76, Standard Practice for Determining Resistance of Plastics to Bacteria. ASTM International.

ASTM C39/C39M, Standard Test Method for Compressive Strength of Cylindrical Concrete Specimens, ASTM International.

ASTM C1285-02, 2008, Standard Test Methods for Determining Chemical Durability of Nuclear, Hazardous, and Mixed Waste Glasses and Multiphase Glass Ceramics: The Product Consistency Test (PCT), ASTM International.

ASTM D6527-00, 2008, Test Method for Determining Unsaturated and Saturated Hydraulic Conductivity in Porous Media by Steady-State Centrifugation, ASTM International.

CCN 160525, "Reconciliation of LAW and HLW Melters Decontamination Factors for BARD" Rev. 4, Update, April 2008.

C. Jantzen, N. Bibler, D. Beam, and W. Ramsey, 1994, "Development of an ASTM Standard Glass Durability Test, the Product Consistency Test (PCT), for High Level Radioactive Waste Glass," Proceedings of Spectrum 94 Nuclear and Hazardous Waste Management International Topical Meeting, Am. Nuclear Soc., 164-169.

DOE M 435.1-1, 1999, Radioactive Waste Management Manual, United States Department of Energy, Washington, D.C.

Ecology, EPA, and DOE, 1989, Hanford Federal Facility Agreement and Consent Order-TriParty Agreement, 2 vols., as amended, State of Washington Department of Ecology, U.S. Environmental Protection Agency, and U.S. Department of Energy, Olympia, Washington.

Eggenberger, A. J., et al., 2008, Defense Nuclear Facilities Safety Board-Issues Resolved During the Period, Defense Nuclear Facilities Safety Board, Washington, D.C. 200042901.

IDF 2004 CEES-0134, Rev. B, Integrated Disposal Facility Waste Acceptance Criteria, prepared by Columbia Energy and Environmental Services, Inc. for CH2M Hill Hanford Group, Inc., Richland, WA, August 18, 2004.

NWPA 1983, Nuclear Waste Policy Act of 1983, Public Law 97-425; Stat. 2201.

Nuclear Waste Vitrification in the United States: Recent Developments and Future Options, Vienna, PNNL, Richland, Washington, 2010

PNNL-14649, Preliminary Investigation of Sulfur Loading in Hanford LAW Glass, Pacific Northwest National Laboratory, Richland Washington, April 2004,

Resource Conservation and Recovery Act of 1976, 42 USC 6901, et seq. 42 USC 6901, et seq.

RPP-48703, 2011, Bulk Vitrification Technology for the Treatment and Immobilization of LowActivity Waste, Rev. 0, Washington River Protection Solutions, LLC, Richland, Washington.

RPP-49062, 2011, Cast Stone Technology for the Treatment and Immobilization of Low-Activity Waste, Rev. 0, Washington River Protection Solutions, LLC, Richland, Washington.

RPP-48903, 2011, Fluidized Bed Steam Reforming for Treating and Immobilizing Low-Activity Waste, Rev. 0, Washington River Protection Solutions, LLC, Richland, Washington. 
RPP-RPT-48092, Rev 0, Supplemental Treatment Program Technology Readiness Assessment, December 2010, Washington River Protection Solutions, LLC, Richland, Washington.

RPP-SPEC-48094, Rev 4, Immobilization Project Facility System Specification, Washington River Protection Solutions, LLC, Richland, Washington, 2011

Vendel 2009, NEA/CSNI/R 200

VSL-10R1920-1, Improving Technetium Retention in Hanford LAW Glass - Phase 1, The Catholic University of America, Washington DC, 2010

Waste Vitrification Systems Lessons Learned, US Department of Energy, March 1999

WHC-SD-WM-SE-023, Rev 0-A, "The Tank Waste Remediation System Privatization", Westinghouse Hanford Company, Richland, WA, 1996

WSRC-MS-2004-00290, Rev. 0, "Dependency of Sulfate Solubility on Melt Composition and Melt Polymerization (U)", Savannah River National Laboratory, Aiken, South Carolina, 2004

WHC-SA-2857-FP, "Melter Technology Evaluation for Vitrification of Hanford Site Low-Level Waste", Westinghouse Hanford Company, Richland, Washington, 1995

WSRC-TR-2003-00084, Rev0, "LAW Radioactive Coupon CO2 Decontamination Test", Washington Savannah River Company, 2003 
RPP-48935, Rev.0

\subsection{GLOSSARY OF TERMS}

Amorphous Solid is a non-crystalline solid with no well-defined ordered structure.

Bogie is a rail truck or cart of low height used for transporting heavy items.

Borosilicate Glass a material used to vitrify radioactive waste in which boron is used to take the place of lime in ordinary glass mixtures. The main glass forming (network former) constituents are silica and boron oxide.

Crystalline solids have regular (repeating on a predictable basis) geometric arrangement of atoms; ordered arrangement of particles.

Daily Production Capacity (or instantaneous rate) is the daily production rate the system is designed to produce. It can be derived by dividing the design production capacity by 365 days $/ y r$, or dividing the nominal production capacity by $70 \%$ of 365 days $/ y r$. For example: $3,700 \mathrm{MT} \mathrm{Na} / \mathrm{yr} \div 365$ days/yr, or $2,600 \mathrm{MT} \mathrm{Na} / \mathrm{yr} \div(365$ days $/ \mathrm{yr})(0.7) \quad 10.2 \mathrm{MT} \mathrm{Na} /$ day.

Decontamination Factor $(D F)$ represents the ability of a process to remove a contaminant from a product; ratio of a compounds capture to its release through a process. For example, given a thermal catalytic oxidation process has a decontamination factor of 20 for $\mathrm{CO}$; the process will convert $95 \%$ of $\mathrm{CO}$ to $\mathrm{CO} 2$.

Design Production Capacity (or installed capacity) is derived from the nominal production capacity by assuming a total operating efficiency (TOE) for the system. For example: if the nominal production capacity is $2,600 \mathrm{MT} \mathrm{Na}$ /year and the TOE is assumed to be $70 \%$, then the design production capacity is $2,600 \mathrm{MT} \mathrm{Na} /$ year $\div 0.7 \quad 3,700 \mathrm{MT} \mathrm{Na}$ /year.

Glass Network Formers form the backbone of the glass and become located in the center of oxygen polyhedral in the configuration to tetrahedra, or tetrahedra and triangles. These tetrahedral are then tied together by sharing corners, which make up the framework of the random network structure of the solid waste glass form.

Glass Network Intermediates replace network formers and still maintain the framework structure of the glass. Intermediates typically create singly bonded oxygen ions (non-bridging oxygen atoms) that attract cations for charge neutrality.

Glass Network Modifiers are generally part of the alkali and alkali earth constituents. Modifiers are located within the holes of the random network structure. Modifiers can associate with nearby singly bonded oxygen ions.

Glass Transition Temperature is the temperature at which an amorphous solid (glass) becomes soft when during heating or brittle during cooling.

Hanford Integrated Disposal Facility (IDF) is a low-level waste and mixed low-level waste disposal facility on the Hanford site that will be used to dispose of immobilized LAW as well as secondary wastes produced by tank farm and treatment operations.

HLVIT Standards (not an acronym) is a RCRA Universal Treatment Standard (UTS) that requires the vitrification of high-level radioactive waste generated during the reprocessing of fuel rods mixed with characteristic metal wastes. It was promulgated in the Third Rule at 55 FR 
22626 (June 1, 1990). The Third Rule stated that all the promulgated treatment standards in that rule for RCRA listed and characteristic wastes apply to the RCRA hazardous portion of mixed radioactive (high-level, TRU, and low-level) wastes, unless EPA has specifically established a separate treatability group for a specific category of mixed waste. Thus, that rule required that radioactive waste mixed with metal characteristic waste would have to comply with the LDR treatment standard for the metal characteristic waste, as well as any requirements set forth by the $\mathrm{NRC}$ for the radioactive component of the mixed waste.

Immobilized Low-Activity Waste $(I L A W)$ refers to Hanford tank waste that has been treated to remove key radionuclides to the maximum extent technically and economically practical, converted to a solid form that meets 10 CFR Part 61.55 Class $\mathrm{C}$ concentration limits, and demonstrated through a formal performance assessment to meet performance objectives comparable to those set forth in 10 CFR Part 61, Subpart C.

Joule-Heat is the process of creating heat by passing electric current through a conductor; also known as ohmic heating.

Liquidus Temperature is the maximum temperature at which crystals can co-exist with the melt. Above the liquidus temperature, the material is homogeneous.

Nominal Production Capacity is the production rate that the facility must achieve to meet production goals in support of the mission completion date. For example, the Immobilization Project has recently calculated a nominal production rate in RPP-CALC-48104 of 2,600 MT $\mathrm{Na} /$ year to support mission completion.

Resource Conservation and Recovery Act (RCRA), enacted by Congress in 1976, is the principal federal law in the U. S. governing the disposal of solid and hazardous waste. The Hanford tank wastes and systems used for the treatment of those wastes are regulated by Ecology under RCRA.

Single-Phase electricity has one hot wire and one ground wire. All current passing through the melter follows the same sine wave.

Tetrahedral Crystal is a central atom with four atoms located at the corners, each having a bond angle of approximately 109.5 degrees.

Unit less Value is a value containing no units (e.g., foot, gram, second, etc.) implemented as a ratio when performing a calculation. For example percents are unit less.

Vitrification is the process of converting a waste material into an amorphous solid material glass. 